\title{
Dominica: Poverty Reduction Strategy Paper
}

Poverty Reduction Strategy Papers (PRSPs) are prepared by member countries in broad consultation with stakeholders and development partners, including the staffs of the World Bank and the IMF. Updated every three years with annual progress reports, they describe the country's macroeconomic, structural, and social policies in support of growth and poverty reduction, as well as associated external financing needs and major sources of financing. This country document for Dominica, dated April 2006, is being made available on the IMF website by agreement with the member country as a service to users of the IMF website.

To assist the IMF in evaluating the publication policy, reader comments are invited and may be sent by e-mail to publicationpolicy@imf.org.

\author{
Copies of this report are available to the public from \\ International Monetary Fund • Publication Services \\ $70019^{\text {th }}$ Street, N.W. • Washington, D.C. 20431 \\ Telephone: (202) 623-7430 • Telefax: (202) 623-7201 \\ E-mail: publications@imf.org•Internet: http://www.imf.org
}

Price: $\$ 15.00$ a copy

\section{International Monetary Fund \\ Washington, D.C.}





\section{COMMONWEALTH OF DOMINICA}

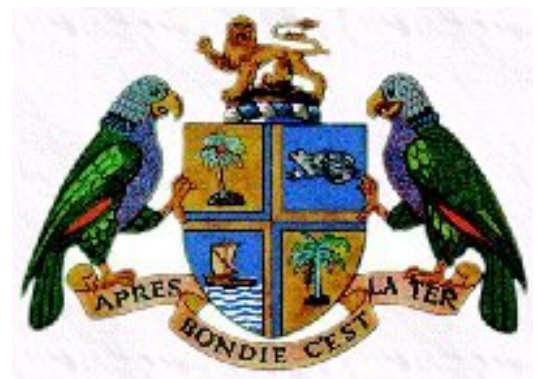

\section{MEDIUM-TERM \\ GROWTH AND \\ SOCIAL PROTECTION STRATEGY}

(GSPS)

Roseau, Dominica

April 2006 


\section{TABLE OF CONTENTS}

PAGE

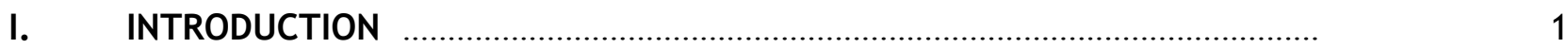

A. Scope and Purpose of the GSPS ……………………………………........

B. $\quad$ The Public Consultation Process ……………………………………........

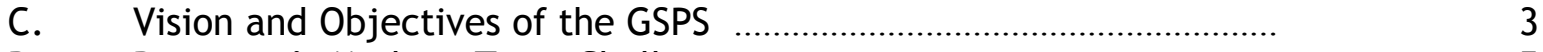

D. Dominica's Medium Term Challenges ………………………………........

II. DIMENSIONS AND DETERMINANTS OF POVERTY _...........................................

A. Poverty and Social Conditions in the Context of the Millennium Development Goals ..............................................................................

B. Characteristics of Poverty in Dominica …………………………........

C. The Incidence of Poverty in Dominica ……………………………….........

1. Geographical Distribution ...........................................................

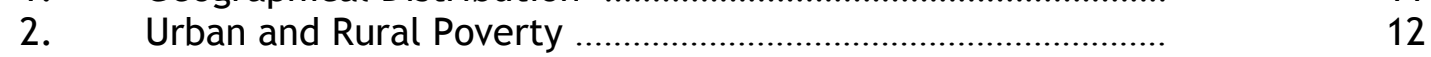

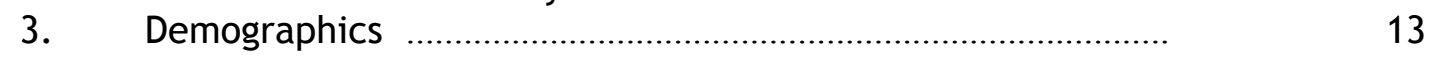

4. Ethnicity .............................................................................

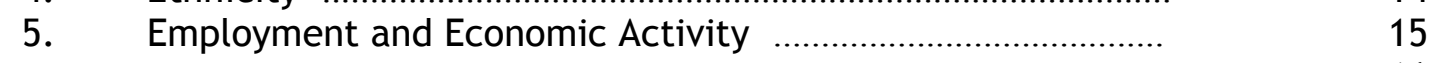

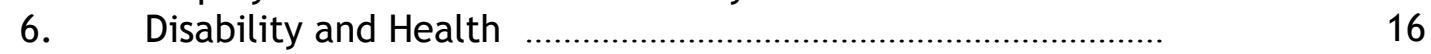

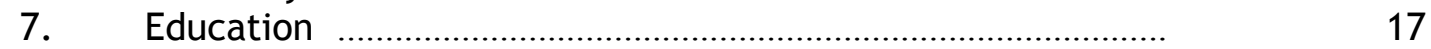

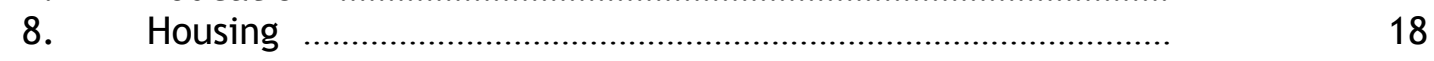

9. Ownership of Assets and Durables ........................................... 19

10. Children/Single Parenthood ........................................................

11. The Elderly and the Disabled .................................................. 20

12. The Indigent ....................................................................... 20

D. Coping Mechanisms and Survival Strategies ……………………….... 21

E. The Challenge of Poverty Reduction ……………………………….... 22

III. REDUCING POVERTY AND IMPROVING SOCIAL PROTECTION ......................

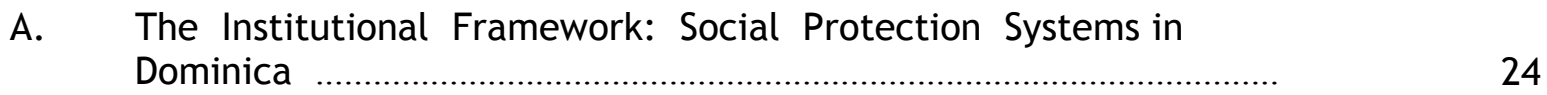

B. The Medium-Term Poverty Reduction Strategy for Dominica .............. 25

C. Poverty Reduction Policies and Programmes ……………………….... 26

D. Economic Development and Job Creation ............................................... 27

E. The Maintenance of Existing Social and Physical Infrastructure

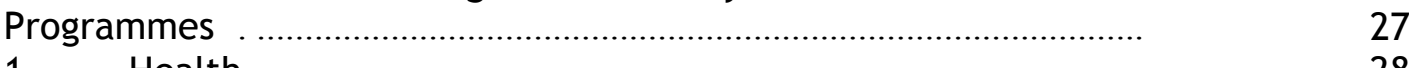

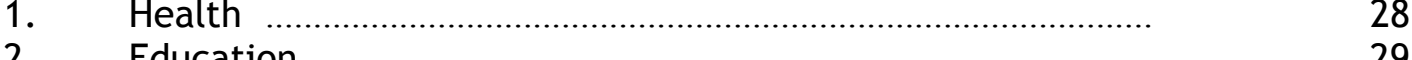

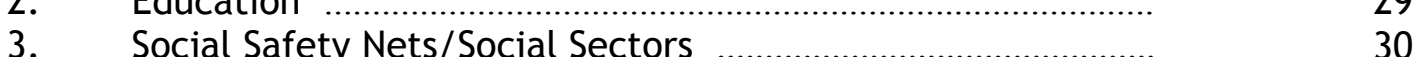

4. Social Safety Nets/Social Sectors ………………...................

4. Housing/Infrastructure .......................................................

5. Institutional ........................................................................

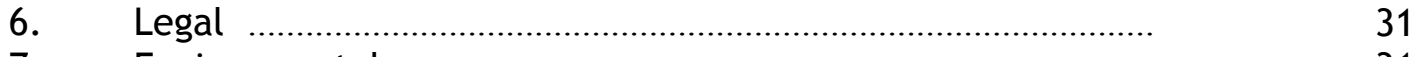

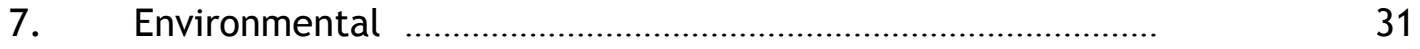


F. Special Focus on the Carib Territory ………………………………………………...

IV. THE ECONOMIC AND FISCAL CONTEXT _.......................................................

V. PROMOTING SUSTAINED ECONOMIC GROWTH _............................................

A. Enabling Environment and the Role of Government ........................... 37

B. Sectoral Strategies for Recovery and Growth ......................................

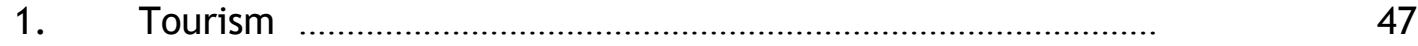

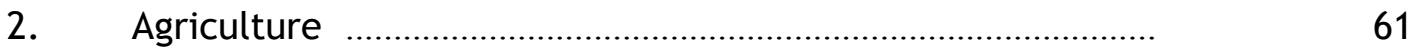

3. Fisheries …………………………………………….......

4. Manufacturing .....................................................................

5. Information and Communications Technology ..............................

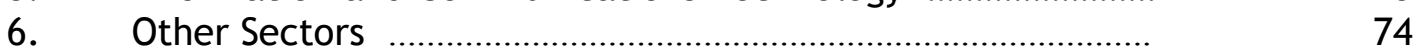

a. Construction and Housing ………………………..............

b. Energy ......................................................................

c. Transportation ............................................................

d. Micro-business development ..........................................

e. Developing our Human Resources …………………......

f. Managing the Environment ............................................

g. The Dominica Diaspora ……………………………….......

VI. RESOURCE REQUIREMENTS FOR IMPLEMENTING THE GSPS …………........

A. $\quad$ Financial and Cost Implications of the GSPS …………………….......

B. Implications for the Public Sector Investment Programme ................

C. Additional Strategic Projects …………………………………….......

D. Recurrent Costs of the GSPS ……………………………………....

E. GSPS Recurrent Costs by Ministries ……………………………….......

VII. IMPACTS, MONITORING AND EVALUATION OF THE GSPS ………………....

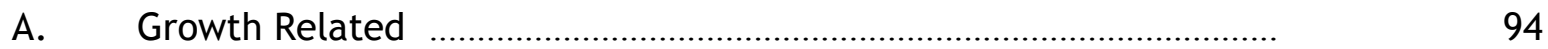

B. Employment, Poverty Reduction and Social Protection Related ........ 94

C. Improved Economic Performance ............................................................

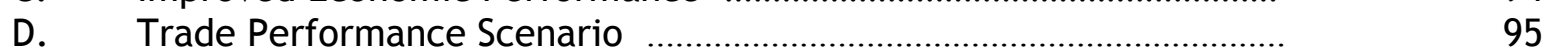

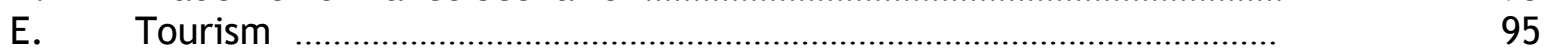

F. Labour force, Employment and Poverty Reduction Prospects ............ 96

VIII. IMPLEMENTING AND MONITORING THE GSPS ………………………….......

A. Performance Indicators for the GSPS ...................................................

B. Institutional Capacity for Implementation of the GSPS ...................... 100 
IX. RISKS TO EFFECTIVE IMPLEMENTATION OF THE GSPS

A. Risks and Uncertainty Analysis …………………………………..........

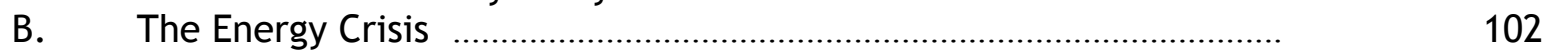

C. Loss of International Donor Support ....................................................

D. Inability to Attract Private Foreign Investment …………………..... 102

E. Failure to Increase Productivity and Competitiveness .........................

F. Time Frame and Scheduling ................................................................

X. IMPLICATIONS AND CONCLUSION ................................................................

\section{TABLES}

1. Millennium Development Goals ………………………………….........

2. The Incidence of Poverty in Dominica ...................................................

3. Geographic Distribution of Household Poverty ............................... 12

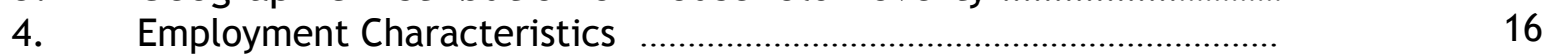

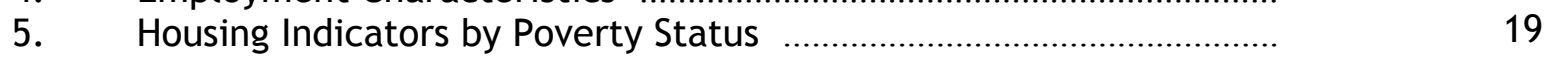

6. Priority Poverty Reduction Actions …………………………………........

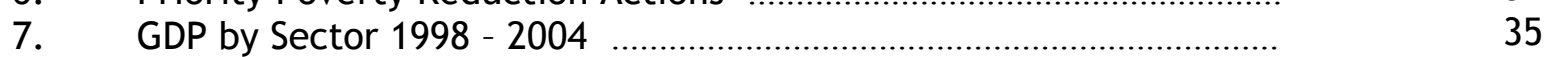

8. Dominica Medium Term Projections 2006 - 2010 ................................. 39

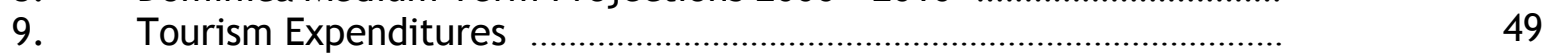

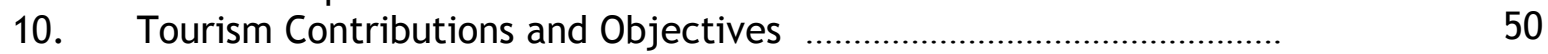

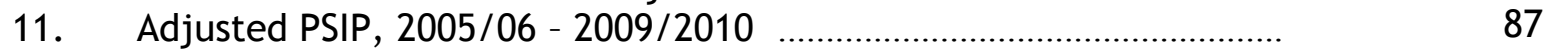

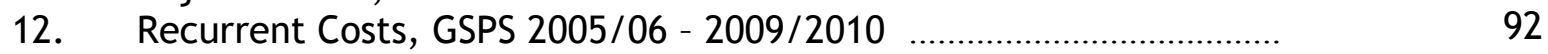

13. Recurrent Expenditure, Ministries, 2004/05 - 2009/10 ......................

14. Commodity Trade Scenarios, Export and Imports, $2004-2009$........

15. Tourism Expenditures and Projections for 2004/05 - 2009/2010 ...... 96

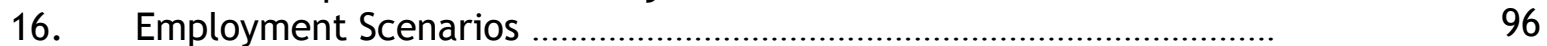

17. Performance Indicators, 2005 - 2009 ……………………………........ 99

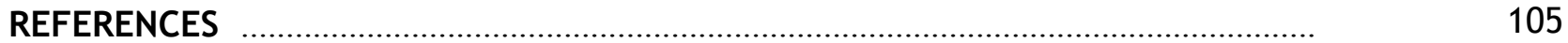

\section{APPENDICES}

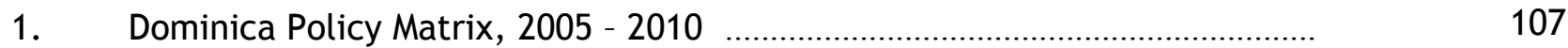

2. Government and Non-government Administered Social Programmes ............ 115

3. Strategic Reform Agenda........................................................................................

4. Investor Roadmap Process Recommendations ...................................................... 119

5. Indicative Financial Implications of Priority Poverty Reduction Actions ...... 120 


\section{LIST OF ACRONYMS AND ABBREVIATIONS}

\begin{tabular}{|c|c|c|}
\hline$A C$ & Alpha Centre & NANGO \\
\hline AID Bank & Agricultural, Industrial and Development Bank & \\
\hline AOSIS & Association of Small Island States & NBD \\
\hline ASYCUDA & Automated System for Customs Data & NDC \\
\hline BERP & Basic Education Reform Programme & NDFD \\
\hline BNTF & Basic Needs Trust Fund & NEMP \\
\hline BPoA & Barbados Programme of Action & NEMS \\
\hline CALLS & Centre where Adolescents Learn to Love and Serve & NEPO \\
\hline CARICOM & Caribbean Community & NGO \\
\hline CBO & Community Based Organization & NHSP \\
\hline CCF & Christian Children's Fund & NISE \\
\hline CDB & Caribbean Development Bank & NIW \\
\hline CDGA & Community Development and Gender Affairs & NTRC \\
\hline CIDA & Canadian International Development Agency & \\
\hline CPA & Country Poverty Assessment & ODM \\
\hline CRFM & Caribbean Regional Fisheries Commission & OECD \\
\hline CSME & Caribbean Single Market and Economy & \\
\hline CSO & Central Statistical Office & OECS \\
\hline DADP & Dominica Association of Disabled People & OPM \\
\hline DESL & Dominica Electricity Services Ltd. & OVI \\
\hline DEXIA & Dominica Export Import Agency & OYQ \\
\hline DFID & Department for International Development & PA \\
\hline DGEN & Dominica Government Enterprise Network & PPIU \\
\hline DHTA & Dominica Hotel and Tourism Association & PPA \\
\hline DNCW & Dominica National Council of Women & PRC \\
\hline DOWASCO & Dominica Water and Sewerage Company & PRGF \\
\hline DPPA & Dominica Planned Parenthood Association & PRSP \\
\hline DREP & Dominica Rural Enterprise Project & PSC \\
\hline DSIF & Dominica Social Investment Fund & PSIP \\
\hline DSS & Dominica Social Security & PSRS \\
\hline ECCB & Eastern Caribbean Central Bank & PTA \\
\hline ECCU & Eastern Caribbean Currency Union & REACH \\
\hline ECSE & Eastern Caribbean Securities Exchange & RMU \\
\hline EEZ & Exclusive Economic Zone & SAP \\
\hline EIA & Environment Impact assessment & SHAPE \\
\hline ESAP & Economic Stabilization Adjustment Programme & SIDS \\
\hline ETF & Education Trust Fund & SFP \\
\hline EU & European Union & SLC \\
\hline EUREPGAP & European Standard for Good Agricultural Practice & SMP \\
\hline FAA & Finance Administration Act & SPAT \\
\hline FAO & Food and Agricultural Organization & SPFS \\
\hline GDP & Gross domestic product & STABEX \\
\hline GOCD & Government of the Commonwealth of Dominica & STD \\
\hline GSPS & Growth and Social Protection Strategy & UN \\
\hline HАCCP & Hazard Analysis and Critical Control Point & UNCLOS \\
\hline HDC & Housing Development Corporation & UNDP \\
\hline HIV/AIDS & $\begin{array}{l}\text { Human Immuno-deficiency Virus/Acquired Immune } \\
\text { Deficiency Syndrome }\end{array}$ & $\begin{array}{l}\text { USAID } \\
\text { USE }\end{array}$ \\
\hline HRD & Human Resource Development & TBS \\
\hline IA & Institutional Analysis & TVET \\
\hline IICA & $\begin{array}{l}\text { Inter-American Institute for Cooperation on } \\
\text { Agriculture }\end{array}$ & $\begin{array}{l}\text { VAT } \\
\text { WFP }\end{array}$ \\
\hline ICCAT & International Commission for Central Atlantic Tuna & WTO \\
\hline ICT & Information and Communications & \\
\hline & Telecommunications & \\
\hline IDP & Integrated Development Plan & \\
\hline IFI & International financial institution & \\
\hline IMF & International Monetary Fund & \\
\hline I-PRSP & Interim Poverty Reduction Strategy Paper & \\
\hline Kwh & Kilowatt per hour & \\
\hline LAN & Local Administrative Network & \\
\hline MCDC & Millennium Construction and Development Company & \\
\hline MDG & Millennium Development Goal & \\
\hline MFB & Minimum Food Basket & \\
\hline MIGA & Multilateral Investment Guarantee Agency & \\
\hline MoFP & ance and $\mathrm{Pl}$ & \\
\hline
\end{tabular}

National Association of Non-Governmental Organizations

National Bank of Dominica

National Development Corporation

National Development Foundation of Dominica

National Environment Management Plan

National Environmental Management System

National Emergency Planning Organization

Non-Governmental Organization

National HIV Strategic Plan

Nature Island Standards of Excellence

Nature Island Water Incorporated

National Telecommunications Regulatory

Commission

Office of Disaster Management

Organization for Economic Cooperation and

Development

Organization of Eastern Caribbean States

Office of the Prime Minister

Objectively verifiable indicator

Operation Youth Quake

Public Assistance

Planning and Public Investment Unit

Participatory Poverty Assessment

People's Republic of China

Poverty Reduction and Growth Facility

Poverty Reduction Strategy Paper

Public Service Commission

Public Sector Investment Programme

Public Sector Reform Strategy

Parent Teacher Association

Reaching Elderly Abandoned Citizens Housebound

Reform Management Unit

Structural Adjustment Programme

Society for Historical and Architectural Preservation

Small Island Developing States

School Feeding Program

Survey of Living Conditions

Special Mortgage Programme

Small Project Assistance Team

Special Programme for Food Security

Stabilization of Export Earnings

Sexually transmitted disease

United Nations

United Nations Convention on the Law of the Sea

United Nations Development Programme

United States Agency for International Development

Universal Secondary Education

Text Book Scheme

Technical and Vocational Education and Training

Value added tax

World Food Programme

World Trade Organization 
DOMINICA'S MEDIUM-TERM

GROWTH AND SOCIAL PROTECTION STRATEGY

\section{INTRODUCTION}

\section{A. Scope and Purpose of the GSPS}

The Government of the Commonwealth of Dominica (GOCD) Growth and Social Protection Strategy (GSPS) articulates a medium-term strategy for growth and poverty reduction over the next five years. Priorities set in this document make poverty reduction the direct focus of the Government's economic and social policy. GOCD regards the pursuit of sustained strong economic growth to be the main strategy to alleviate poverty. The GSPS provides the framework that informs the medium-term macro-economic framework, the structural reform agenda, the medium-term public investment programme, and the annual budgets to be presented to Parliament. The Government's policies and programmes will seek to ensure that opportunities are available to all, and benefits from growth are shared across the society as widely as possible. To this end, targeting and management of the existing social programmes will also be improved.

The GOCD approved an Interim Poverty Reduction Strategy Paper (I-PRSP) in December 2003. The Boards of Directors of the IMF and the World Bank considered the I-PRSP, and were of the view that the document provided adequate foundation for the full Poverty Reduction Strategy Paper (PRSP). Subsequently, the GOCD decided to accomplish the purposes of the PRSP by preparing this GSPS. It is Government's intention to update the Strategy on an annual basis so that the document will be in the nature of a 'rolling' plan that takes account of changing circumstances and is thus of continuing relevance.

\section{B. The Public Consultation Process}

The GSPS benefited greatly from three consultative processes. The first was the Integrated Development Plan (IDP) consultative process and report. The second was the Country Poverty Assessment (CPA) process and report. Both reports were consulted heavily in the formulation of the GSPS. The third was the GSPS's own consultative process that involved four main focus groups: 1) internal-governmental, 2) internal-regional, 3) national, and 4) international and regional.

Internally, an early draft was circulated to technical staff within the Ministry of Finance and Planning (MoFP). Staff was allowed up to two weeks to review the 
strategy paper, and a half-day working session was held at the MoFP's Conference Room where comments were discussed including those that were previously handed to the team. The paper was appropriately adjusted and then circulated to most Heads of Division and Chief Technical Officers within the Public Service. Approximately thirty-six copies of the document were circulated, allowing two weeks for review. Substantial written comments were received that concurred with the contents of the strategy paper, given the fact that some of the strategies contained therein were derived from existing sectoral plans and strategy papers.

Involvement of Permanent Secretaries in preparation of the strategy started in mid-December 2004. The meeting was conducted in the form of a workshop. Presentations were made on the key components of the paper including the Macro-economic framework and sectoral and social protection strategies. Permanent Secretaries provided their reactions to the presentations and forwarded their comments as appropriate.

A series of seven regional focus group discussions took place in January of 2005. These discussions involved representatives of Local Authorities, NonGovernment Organizations (NGO's), Community-Based Organizations (CBO's) and field extension officers of decentralized Government Ministries. Thirty-five Local Authorities, nineteen Community-Based Organizations (CBOs), ten NonGovernment Organizations (NGO's) and nineteen Government Organizations participated in the focus group discussions. The views of over one thousand representatives were directly or indirectly represented at those discussions.

The focus group discussions followed a questionnaire guide containing approximately sixty questions addressing different sectors and thematic areas. The proceedings were recorded and later transcribed. Every effort was made to incorporate into the document, the recommendations that emanated from these consultations. The policy matrix at Appendix 1 contains most of the recommended actions.

The national workshop of Permanent Secretaries, Heads of Regional Organizations based in Dominica and Heads of Local Organizations, took place in the middle of January 2005. ${ }^{1} \quad$ Twenty-nine persons participated. Presentations on Strategies for Growth and Poverty Reduction as contained in the document were made. Pro-growth strategies were presented, followed by the strategies for social protection. There were lengthy discussions on each component of the Strategy Paper, which resulted in improving and extending some of the measures proposed.

\footnotetext{
${ }^{1}$ While the Dominica Hotels and Tourism Association was represented, the Dominica Association of Industry and Commerce was unable to be represented.
} 
A further extension of time was allowed for the ministries to complete their reviews of the draft document, which yielded additional comments and contributions from them. An extension of time to the Dominica Association of Industry and Commerce was not as beneficial to the process, although the Ministry of Finance was afforded the opportunity to make a special presentation on the draft document to members in the business community.

The international and regional consultations took the form of informal submissions of drafts of the GSPS to IMF and World Bank Mission Teams that included representatives from the CDB and the ECCB. On June 23, 2005 a donors meeting was held that included representatives from donor, international and regional agencies and which constituted the formal international and regional consultative stage of the GSPS.

\section{Vision and Objectives of the GSPS}

The GSPS provides the framework for Dominica's economic and social policies over the next five years and sets out the macroeconomic framework; the growth strategy including the enabling environment for private enterprise and sectoral strategies; and poverty reduction and social protection programmes. It also provides for the monitoring and evaluation of the progress in implementing the strategy on an annual basis. The consultative process to which it has been subjected ensures that the GSPS has a high degree of public ownership. The support of the international community, particularly donor agencies, IFI's, and regional organizations for the strategy will also be sought.

Economic growth in Dominica was curtailed by a conjuncture of unfavourable developments, particularly with respect to trade, but there were underlying weaknesses in the economy such as a reliance on one or two sectors, with this lack of diversity exacerbating its vulnerability to economic shocks. Poor fiscal management led to unsustainable debt levels. The last aspect, which had imperiled prospects for investment and growth, has been tackled successfully by fiscal adjustment and debt restructuring supported by the IMF's Stand-by and PRGF arrangements, the World Bank's Economic Recovery Support Operation, Caribbean countries and institutions as well as bilateral development partners. Many other weaknesses remain. Their most serious implications are: Dominica is not internationally competitive; and internally there is a lack of dynamism in the economy. The GSPS attempts to remedy this situation by spelling out GOCD strategy focused on three pillars:

1) Fiscal policy and administrative reform, including creating an enabling environment for private enterprise activity;

2) Sectoral strategies for growth;

3) Strategies for poverty reduction and social protection 
The GOCD intends to conduct prudent fiscal policy that is conducive to growth, based on expenditure restraint, administrative modernizing and reform, and control of borrowing in a manner that reduces government debt to sustainable levels. Administrative reforms aim at a more modern and effective public service that promotes and is supportive of private sector development. Substantial improvements of the enabling environment for private enterprise, by a combination of institutional, fiscal, legislative, regulatory and administrative reforms and improvements are critical to achieving the GSPS objectives. The GOCD has been taking action in this area but considerably more needs to be done, such as: removing impediments to foreign investment and business activity in general, including creating simple and transparent conditions for access to land, construction/renovation and start of new businesses; restructuring of the public sector enterprises; outsourcing and commercialization of some activities now conducted by the Government.

GOCD will aim at achieving a sustained rate of economic growth of $3 \%$ over the medium term, based on increased levels of activity in all sectors, and in particular in tourism, agriculture, fisheries, energy and water. Improving export performance is critical for growth and increasing international competitiveness is a major challenge if Dominica is to succeed in the global economic environment. Eco-tourism, agro-industries, niche-focused agriculture, fisheries and water are natural resource based industries in which Dominica enjoys some comparative advantages, and have great potential to generate employment and income-growth opportunities. Private investment needs to play a major role in mobilizing this potential. However, increasing the attractiveness of the economy to investors requires reducing cost and improving reliability of transportation and energy, and increasing the productivity of the labour force. As a result, infrastructural development and an improved focus on education and training (including upgrading technical, management and entrepreneurial skills) are major aspects of the GSPS.

Even with higher levels of economic growth, targeted and well-managed social protection programmes will be clearly needed. Expert reviews found that Dominica has an appropriate range of programmes and instruments to implement the social protection strategy. GOCD is committed to improving targeting, management, and administration of its social programmes and to providing the framework for better coordination among various programmes and agencies.

It is the Government's hope that the GSPS will serve its purpose of providing an overarching and strategic perspective on the management of Dominica's economy into the medium term, a perspective that is informed by fiscal and debt parameters and considerations of prudential national economic management. 
Government will be giving greater impetus to the growth process in our country. It embraces for our country as:

"A place characterized by a people empowered to contribute to their own well-being and that of our country, through policies of Government geared to facilitating an environment within which private enterprise can flourish to the benefit of our people."

Government is fully committed to pursuing this vision for our country. It is committed to pursuing over the next five years, the improvement of the investment environment, and it will work diligently to bring down levels of poverty all over our country.

\section{Dominica's Medium-term Challenges}

The challenges facing Dominica are those related to attaining growth in the economy that is pro-poor. Largely, this means creating jobs that will activate the unemployed in the rural areas, where poverty is most pronounced. Investment in agriculture, community tourism, and human resource development (skills training etc), and improving environment for private sector activity offer best prospects in this endeavor. The challenges are economic, social, political, and environmental. Some of them emanate from external forces beyond Dominica's control, such as the continuing effects of trade liberalization and globalization; and from regional integration, i.e., the CARICOM Common Market and Economy (CSME) and OECS economic union. These forces make it imperative to put Dominica's comparative advantages to better use and improve its human capital through education and training, thereby making for a more productive labour force and a more competitive economy. This is the main challenge for the country as a whole. Responding to some challenges remains primarily the responsibility of the Government; responding to others is primarily the responsibility of the private sector; and collaborating effectively in combating vulnerabilities and risks facing Dominica, is a shared responsibility.

The main challenges facing Dominica are:

Continuing sound fiscal management to consolidate progress towards reducing the government's financing requirements to sustainable levels and reducing public sector indebtedness;

Continuing reform of the public service that will seek to make the administration a more cost effective "customer driven" service;

Reducing poverty levels through growth and employment generation, and improving the effectiveness of the social services and social assistance programmes; 
Improving the law and order apparatus, including the effectiveness of the judicial and land administration systems in swift enforcement of property rights and contracts;

Improving the execution, focus and effectiveness of the public sector investment in upgrading economic infrastructure;

Upgrading regulation and oversight of providers of energy, water, transportation (seaport and airport) and telecommunication services, to support more effectively improvements in quality (reliability and timeliness) of services and reduction of costs to the rest of the economy;

Improving the efficiency of institutions and simplifying procedures that make the enabling environment for private enterprise with a view to shortening the process and reducing the cost of establishing new and expanding existing businesses; and

Improving the protection and management of the natural environment.

The private sector needs to become a dynamic "engine of growth" for the economy. To this end, the sector needs to respond creatively and courageously to the following challenges:

- Assessing realistically and responding more positively to improved overall economic prospects and investment opportunities resulting from progress towards macroeconomic stability, including a more active and innovative support of the financial sector to business initiatives;

- Increasing owners'/managers' alertness and responsiveness to changes in business environment driven by globalization, technical progress and the changes in the labor market;

- Increasing investment in the use of and development of the country's natural and human resources, including closer collaboration with educational institutions and training of employees to help enhance productivity and sharpen the competitive edge;

- Improving the consultation process within the sector and engaging in a constructive dialogue with the Government on steps to improve the business/investment environment.

A number of institutional and cultural factors that lower productivity and competitiveness have been identified in discussions among social partners, comprising the Government, the private sector and the Unions. These include: resistance and poor attitude to change, low entrepreneurial and marketing skills, lack of accountability and poor work ethics, remnants of the culture of 
dependency, political interference and nepotism, poor communication and low levels of trust among the social partners, large number of public holidays and low number of effective work hours, limited human capital in both numbers and competencies. Removal of these impediments over the medium term is a daunting challenge but it must be accomplished gradually with commitment and a decisive and focused effort from all social partners.

\section{DIMENSIONS AND DETERMINANTS OF POVERTY}

A. Poverty and Social Conditions in the Context of the Millennium Development Goals (MDGs)

Reliable information on poverty in Dominica derives almost exclusively from the 2002 Country Poverty Assessment (CPA) conducted for the Government of Dominica by the Halcrow group and others and sponsored by the Caribbean Development Bank. That assessment comprised three major components-a Survey of Living Conditions (SLC), a Participatory Poverty Assessment (PPA) and an Institutional Analysis (IA).

The 2002 CPA found that poverty in Dominica is high - about 29\% of households and $39 \%$ of the population, which is high by Caribbean standards. Approximately $10 \%$ of households and $15 \%$ of the population are indigent, i.e. very poor. Poverty exists in urban and rural areas. Three quarters of poor households live in rural areas where one in every two households is poor. The remainder $(24 \%)$ is to be found in the main towns of Roseau and Portsmouth. Poverty amongst the Caribs is much higher: $70 \%$ of the Carib population is poor and almost half are indigent.

According to a World Bank Report, the share of Dominica's population living on less than US\$1 a day is below 2 percent. This is considered to be comparatively low (Grenada 4.7\%, St. Lucia 2.97\%, St. Vincent 5.55\%) and the MDG target of halving the proportion of persons living on less than US\$1.00 a day by 2015 is expected to be achieved well before that date. The eight (8) MDG goals are summarized at Table 1 below:

Table 1. MDG Goals

\begin{tabular}{|l|l|}
\hline Goal 1 & $\begin{array}{l}\text { Eradicate extreme hunger and poverty. Halving the proportion of people living on less than US \$1 a day } \\
\text { and halving malnutrition. }\end{array}$ \\
\hline Goal 2 & Achieve universal primary education. Ensuring that all children are able to complete primary education. \\
\hline Goal 3 & $\begin{array}{l}\text { Promote gender equality and empower women. Eliminate gender disparity in primary and secondary } \\
\text { schooling no later than 2015. }\end{array}$ \\
\hline Goal 4 & Reduce child mortality. Cutting the under-five death rate by three quarters. \\
\hline Goal 5 & $\begin{array}{l}\text { Improve maternal health. Reducing the maternal mortality rate by three quarters. } \\
\text { Combat HIV/AIDS, malaria and other diseases. Halting and beginning to reverse HIV/AIDS and other }\end{array}$ \\
\hline Goal 6 & $\begin{array}{l}\text { Ensure environmental stability, cutting by half the proportion of people without sustainable access to safe } \\
\text { drinking water and sanitation. } \\
\text { Develop a global partnership for development. Reforming Aid and Trade with special treatment for the } \\
\text { poorest countries. }\end{array}$ \\
\hline Goal 8
\end{tabular}


Using the MDG goals as benchmarks, Dominica's social indicators appear to stand up well.

- The primary education goal (Goal 2) has been attained. Primary education is universal for boys and girls and Dominica has an enrolment rate of 99 percent.

- The statistics relating to Goal 3 indicates no significant difference in participation rates between boys and girls at the primary level. Females out-perform boys at the primary level, female participation rates are higher at the secondary level and they out-perform boys at that level as well as at the tertiary level.

- The child mortality rates (Goal 4) has been dropping - 23 per 1000 in 1990 to 14 per 1000 in 2000. In 2002, it stood at about 10 per 1000.

- The maternal mortality rate (Goal 5) in Dominica is about one per 1000.

- HIV/AIDS (Goal 6) poses a very serious challenge for Dominica, and the country is facing up to the challenge. The implementation of a national HIV/AIDS prevention strategy is on its way, and funding has been secured for an HIV/AIDS prevention programme. If the implementation of the strategy proceeds as planned, the country expects to realize a significant reduction in the incidence of HIV/AIDS. A reversal will be achieved.

- Goal 7 is partially attained. Approximately $95 \%$ of the households in Dominica have access to safe drinking water. On the other hand, $85 \%$ have access to sanitary toilet facilities. Dominica is determined to reduce this figure and will launch a national programme in the first quarter of 2006.

- As for Goal 8, Dominica will continue to provide support and contribute to efforts at achieving it, in concert with its regional and international partner countries and institutions.

However, the authorities recognize that there is much work still to be done to improve social and economic conditions that go beyond the set of MDG goals, and in particularly in the area of poverty reduction. It is to this objective that the Government's medium-term Growth and Social Protection Strategy is dedicated.

\section{B. Characteristics of Poverty in Dominica}

To determine the extent, nature and characteristics of poverty in Dominica an Indigent poverty line was derived from a Minimum Food Basket (MFB) and a Poverty Line, which included a component for non-food expenditure that was added to the indigent poverty line. The indigence line for an adult was estimated EC\$2,000.00 per annum, while the poverty line was estimated at $\mathrm{EC} \$ 3,400.00$ per adult per annum. 
The Participatory Poverty Assessment (PPA) sought to provide a better understanding of poverty in Dominica from the perspective of the poor. The PPA was conducted in seven communities selected on the following criteria:

Carib Territory:

rural, Carib (indigenous) population

Dublanc:

Grand Bay: progress in community economic diversification and poverty reduction

Petite Soufriere:

rural, land access problems

Scotts Head: rural, poor economic diversification, extensive out migration of working age population

Tarish Pit:

Woodford Hill: rural, fishing community urban, squatter settlement rural, severely affected by decline in banana industry

These communities were distributed throughout the country representing six local government administrative districts and six parishes.

Finally, the institutional analysis was geared at preparing a register of institutions in Dominica administering programmes targeted at poverty reduction. Organizations within the State Sector, Private Sector and Civil Society Sector were analysed on how well they catered for the poor and the effectiveness of their programmes.

The 2002 CPA represents the first major Poverty Assessment to be conducted in Dominica. There was an assessment in 1996. The methodology used then was different. A Participatory Poverty Assessment (PPA) conducted in thirteen communities selected based on indicators generated from the 1990 national census served as the main source of poverty data for the CPA. The 2002 assessment and the 1996 assessment are not comparable. Therefore, there are no time series data on poverty in Dominica.

While poverty trends cannot be ascertained accurately due to the absence of comparable data for previous years, it is generally accepted that the poverty situation has been exacerbated in recent years by the continuing decline in the agricultural sector, and in the banana industry in particular. This decline was accompanied by a marked deterioration in government finances during the years 2000 to 2003 and little expansion in other sectors (e.g. tourism, construction and manufacturing) to compensate. Thus until 2004 both production and demand stagnated, doubtless leading to reduced employment and incomes for a large segment of the population.

Aside from the concentration in rural areas (where those households, especially Carib ones, providing labour to the banana plantations have fared worse), poverty disproportionately affects children: $70 \%$ of poor households have 
children as against only $44 \%$ for non-poor households and half Dominica's children live in poor households. Less than half the households with children have two parents in the home, and $14 \%$ have no resident parents. On the other hand, there is little statistical relationship between poverty and single parenthood, nor the elderly, gender, health, disability and young motherhood. Nonetheless, indigent households mostly exhibit one or more of these characteristics together with an almost total absence of family support.

Poor households in Dominica are characterized by much higher unemployment rates ( $40 \%$ as against $16 \%$ for non-poor households) and lower educational levels amongst adults where $27 \%$ of poor households have an adult with secondary education compared with $45 \%$ of non-poor households. The substantial expansion of secondary education in the last decade should remedy this situation in the long term. The frequency of overcrowding is also far higher in poor households as are the proportions (especially in rural areas) without indoor bathing or cooking facilities.

\section{The Incidence of Poverty in Dominica}

By relating the poverty lines to the household expenditures obtained from the SLC and adjusted for household composition, households can be classified as to whether they fall above or below the poverty line. The headcount ratio is defined as the ratio of households falling below the poverty line to all households. The results are presented in Table 2.

Table 2. The Incidence of Poverty in Dominica

\begin{tabular}{lcc}
\hline \multicolumn{1}{c}{ Category } & Households $\%$ & Population $\%$ \\
\hline Indigent/Very Poor & $11 \%$ & $15 \%$ \\
Poor & $18 \%$ & $24 \%$ \\
\hline ALL POOR & $29 \%$ & $39 \%$ \\
NON POOR & $71 \%$ & $61 \%$ \\
\hline TOTAL & $100 \%$ & $100 \%$ \\
\hline
\end{tabular}

The level of indigence or severe poverty is relatively low at around $11 \%$ indicating that the great majority of Dominicans can satisfy their basic food needs. The incidence of overall poverty, $29 \%$ of households and $39 \%$ of the population, is high reflecting the continuing decline in banana production and the challenges faced in other sectors such as tourism and manufacturing. On this basis, in mid-2002, there would be around 2,500 indigent and 4,400 poor households in Dominica. In all, just fewer than 7,000 households have expenditures below the poverty line. 
The poverty line is to a significant extent determined by the non-food expenditure component. This is based around the non-food expenditure of the lowest $40 \%$ of households. If a more restrictive assumption were used, e.g. the average non-food expenditure of indigent households (approximately \$740), the proportion of poor households would be significantly lower at around $20 \%$ of all households and $28 \%$ of the population.

However, inter-country comparisons are made difficult by the different survey years and the use of a relative measure for non-food expenditure. It is nevertheless clear that the incidence of poverty in Dominica is amongst the highest in the Caribbean with only St. Vincent and Guyana having comparable levels. The St. Vincent information however dates back to 1995. In terms of indigence, Dominica is in a similar situation to several other countries (e.g. St Kitts and Nevis, Belize, and Grenada), with a much lower incidence of severe poverty than Guyana and St. Vincent and the Grenadines.

It is interesting that while the incidence of poverty in Dominica is amongst the highest in the Caribbean, comparing only to Grenada and St. Vincent and the Grenadines, there may be a more balanced distribution of household expenditure in Dominica than in several other countries.

\section{Geographical Distribution}

The incidence of poverty in Dominica varies considerably from parish to parish. The lowest incidence is in St. Peter and Roseau where 17-18\% of households are poor. The highest incidence is in St. David (which includes the Carib Territory) where over half the households are poor followed by St. Patrick (the southeast) and St. Mark (Scotts Head). Over a third of all poor households in the country are to be found in these three parishes yet they contain less than a quarter of all households. St David also contains over twice as many indigent households $(28 \%)$ as any other parish.

The geographic distribution of the poor population is similar to that of poor households; in all cases, the percentages are higher as poor households tend to be larger. In St. Mark and St. David, this means that the overall incidence of poverty exceeds $60 \%$ of the population. It also means that over $30 \%$ of the population is poor in all areas except Roseau. 
Table 3. Geographic Distribution of Household Poverty

\begin{tabular}{|l|cc|cc|c|c|c|}
\hline \multicolumn{1}{|c|}{ PARISH } & Indigent & Poor & \multicolumn{2}{|c|}{ All Poor } & Non-poor & Total & $\begin{array}{c}\% \text { of all } \\
\text { poor }\end{array}$ \\
\hline St. George (Roseau) & $5 \%$ & $13 \%$ & $18 \%$ & $(23 \%)$ & $82 \%$ & $100 \%$ & $12 \%$ \\
Rest of St. George & $11 \%$ & $12 \%$ & $24 \%$ & $(39 \%)$ & $76 \%$ & $100 \%$ & $6 \%$ \\
St. John & $7 \%$ & $21 \%$ & $28 \%$ & $(37 \%)$ & $72 \%$ & $100 \%$ & $9 \%$ \\
St. Peter & $6 \%$ & $12 \%$ & $17 \%$ & $(31 \%)$ & $83 \%$ & $100 \%$ & $1 \%$ \\
St. Joseph & $13 \%$ & $20 \%$ & $33 \%$ & $(44 \%)$ & $67 \%$ & $100 \%$ & $11 \%$ \\
St. Paul & $12 \%$ & $11 \%$ & $23 \%$ & $(36 \%)$ & $77 \%$ & $100 \%$ & $9 \%$ \\
St. Luke & $4 \%$ & $28 \%$ & $32 \%$ & $(48 \%)$ & $68 \%$ & $100 \%$ & $3 \%$ \\
St. Mark & $13 \%$ & $31 \%$ & $44 \%$ & $(62 \%)$ & $56 \%$ & $100 \%$ & $4 \%$ \\
St. Patrick & $9 \%$ & $32 \%$ & $41 \%$ & $(48 \%)$ & $59 \%$ & $100 \%$ & $16 \%$ \\
St. David & $28 \%$ & $23 \%$ & $52 \%$ & $(67 \%)$ & $48 \%$ & $100 \%$ & $15 \%$ \\
St. Andrew & $9 \%$ & $16 \%$ & $25 \%$ & $(32 \%)$ & $75 \%$ & $100 \%$ & $12 \%$ \\
\hline \multicolumn{1}{|c|}{ TOTAL } & $10 \%$ & $18 \%$ & $29 \%$ & $(39 \%)$ & $71 \%$ & $100 \%$ & $100 \%$ \\
\hline
\end{tabular}

- Figures in ( ) relate to population. All other figures related to households.

\section{Urban and Rural Poverty}

The incidence of indigence and overall poverty in urban areas $(6 \%$ and $19 \%$ respectively) is much lower than that prevailing in the rural areas $(13 \%$ and $33 \%$ respectively). However, the urban areas still contain around a quarter of all poor households and population.

About three quarters of poor households live in rural areas and the likelihood of being poor is also much greater - 1 in 3 rural households are poor compared to 1 in 5 urban households. The level of poverty amongst the Caribs is even higher. The reason is simple. For long, agriculture (and bananas in particular) was the mainstay of the economy. Yet this sector has been in decline for several years. Resulting rural unemployment and underemployment is severe not only amongst the banana cultivators themselves but it has also eliminated the previously large requirement for casual but often regular labour. Nevertheless, almost a quarter of poor households reside in Roseau and Portsmouth.

Other employment opportunities in rural areas are limited. Those displaced from banana production have, therefore, little alternative but to seek low and irregular income in casual menial labour and small-scale food production. It is notable that the incidence of second jobs in rural areas is three times higher than in urban areas (15\% as against $5 \%$ of workers with second occupations), and that two thirds of these involve cultivation in some way or other reflecting the fact that $37 \%$ of poor rural households own land that they can cultivate 
compared to only $12 \%$ of urban households. In addition, many, especially rural, households will cultivate their house plots. However, even these opportunities are limited in number, resulting in increasing numbers looking for work in Roseau or on other islands, or becoming dependent on government welfare and/or assistance from family members. On the positive side, rural households are more likely to benefit from a higher degree of community support and solidarity than exists in urban areas

In urban areas, poor households are more likely to have someone unemployed indicating that the issue is more one of employment per se, than in rural areas where inadequate income from those employment opportunities on offer is the issue. The poor in urban areas also tend to lack the level of community support that exists in rural areas and they rarely have the ability to grow their own food. Instead, some resort to scavenging at the dump.

Poor households are also generally more vulnerable to hurricanes as they are more likely to reside in wooden, and thus less robust, structures, than non-poor households. Vulnerability is greater in rural areas where hurricanes are likely to damage, if not destroy, crops - the primary means of income generation for most rural households.

\section{Demographics}

1) Poor households contain proportionately more children than non-poor households; the disparity is most marked for those aged from five to fourteen years; almost half this age group lives in poor households. In consequence, poor households have proportionately fewer persons aged from 25-64 years - the main working ages; under a quarter of this group lives in poor households. Twenty-seven percent of households contain elderly (over 64 years) members. This proportion, unlike in many countries, varies little with the poverty status of the household.

2) There is no significant difference in the gender distribution of poverty. This applies when considering either the population as a whole or the gender of the head of household or the proportion of households with no adult males.

3) The distribution of the household sizes of poor and non-poor households shows dramatic differences. Poor households tend to be much larger than non-poor households.

4) Over $40 \%$ of poor households are multi-generational (i.e. with members of three generations) or extended households (mostly extended families including in laws and/or brothers and sisters). This is consistent with the greater average size of poor households. Single-person and childless- 
couple households are less likely to be poor but there is little difference in the proportions of nuclear or one-parent households. There are also substantial differences in the proportion of households with children. This proportion in poor households is considerably higher than for nonpoor households - $70 \%$ compared with $44 \%$.

\section{Ethnicity}

The incidence of poverty amongst the Carib population is extremely high $70 \%$, with almost half being indigent. The Caribs represent around $4 \%$ of the total population and $7 \%$ of the poor population. Over $90 \%$ of the poor population in Dominica is African or mixed race.

The Caribs have been distinguished from other rural households owing to their ethnicity and higher level of poverty: over half of all Carib households are poor and half of these are indigent. From the preceding tables, it can also be seen that:

- Over half the poor Carib households have no one working. Although it is probable that many Caribs do not consider subsistence cultivation to be proper employment, the fact remains that under-employment is chronic;

- Poor Carib households are less likely than other poor households to include someone with secondary education although this disparity is likely to reduce in coming years as increasing numbers of Caribs graduate from Secondary school. Poor Carib households are also less likely to consist of the elderly living on their own;

o the incidence of disability and single parent households differs little from the majority of poor households;

- Housing conditions amongst the Carib are substantially worse than for other poor households - $39 \%$ do not have access to safe water, virtually none have a flush toilet, and fewer than $30 \%$ have no proper kitchen facilities. Ownership rates of durable goods are also lower; and

- Eighty-one per cent of Carib households have land that they cultivate indicating that, in most cases, they have a fallback means of survival. 


\section{Employment and Economic Activity}

Indicators related to the employment and economic activity of poor and non-poor households do not indicate a straightforward situation. There are proportionately more poor households with unemployed persons and no one else working, and fewer with two employed persons, than in non-poor households. However, the proportions with one or more than three persons working are similar to non-poor households as is the proportion of households with no one in the labour force (e.g. retired persons only, presence of long-term sick/ disabled). Overall, $69 \%$ of poor households have at least one person employed, compared to $77 \%$ of non-poor households.

The difference between poor and non-poor households is however extremely marked in the dependency ratio. The ratio in poor households is 3.4 , which is over double that in non-poor households. This reflects their larger size and the much higher incidence of unemployment - $40 \%$ of the labour force of poor households compared with 18\% in non-poor households. The overall unemployment rate is $25 \%$ compared to around $16 \%$ in 1999 and $10 \%$ in 1991 . While the statistics may not be directly comparable due to definitional issues, the deterioration in the employment situation is apparent. Unemployment was repeatedly cited as a serious problem during the Participatory Poverty Assessments (PPAs).

Age specific unemployment rates are much higher amongst poor households at all age groups. Almost three-quarters of 15-24 year olds (who are not studying) from poor households are unemployed. This age group also contributes almost half of all unemployed persons, implying that the economy is failing to create jobs for those entering the labour force. As the PPAs repeatedly showed, employment is also failing to generate enough income for many of those who do have jobs.

Occupations and industrial sectors also vary between poor and non-poor households. Workers in poor households are more likely to be employed in the construction and agricultural sectors and less likely to be found in the government. Differences between the other sectors are far less significant. In terms of occupation, over half the employed poor are to be found in the skilled and unskilled manual sectors and another quarter is farmers. In contrast, around half the workers in non-poor households have occupations in the professional/managerial/technical groups. Neither of these findings is unexpected but the differences between poor and non-poor households are clearly demarcated. 
Table 4. Employment Characteristics

\begin{tabular}{|llll|}
\hline Industrial Sector & Poor & Non-poor & Total \\
\hline Bananas & $5 \%$ & $6 \%$ & $6 \%$ \\
Other Agric & $26 \%$ & $15 \%$ & $18 \%$ \\
Manufacturing & $3 \%$ & $5 \%$ & $4 \%$ \\
Construction & $18 \%$ & $8 \%$ & $10 \%$ \\
Wholesale/retail & $11 \%$ & $15 \%$ & $14 \%$ \\
Transport & $3 \%$ & $5 \%$ & $5 \%$ \\
Government & $11 \%$ & $20 \%$ & $18 \%$ \\
Other Services & $24 \%$ & $26 \%$ & $26 \%$ \\
ALL & $100 \%$ & $100 \%$ & $100 \%$ \\
\hline Occupational Status & & & \\
Prof/Man/ Tech & $7 \%$ & $24 \%$ & $20 \%$ \\
Sales/Clerical & $14 \%$ & $25 \%$ & $22 \%$ \\
Farmers & $25 \%$ & $18 \%$ & $20 \%$ \\
Skilled manual/ crafts & $29 \%$ & $19 \%$ & $21 \%$ \\
Elementary & $25 \%$ & $14 \%$ & $17 \%$ \\
\hline ALL & $100 \%$ & $100 \%$ & $100 \%$ \\
\hline
\end{tabular}

\section{Disability and Health}

Health clinics are distributed throughout the country and there is no problem of access for community residents. Many services, such as contraception, are offered free of cost and often there is a resident nurse within the community. Due to mass immunization and widespread availability of piped water, the incidences of health conditions commonly linked to poverty, e.g. infectious or waterborne diseases, low birth weights, infant diarrhoea, are low and, in many cases, virtually non-existent. Traditional healthy diets of ground provisions and fish continue to be popular and there is little evidence of malnutrition. Occasionally however, children go to school hungry or remain at home because they have not eaten. In addition, there is some evidence, among the younger generation in particular, of a shift to convenience foods with less nutritional value. The most common problems found during the PPAs were chronic diseases such as diabetes, hypertension, arthritis and cancer. These conditions have traditionally been seen as relating to more rather than less affluent households.

In consequence, it is not surprising that there is little difference between poor and non-poor households in terms of the incidence of long-term sickness and diabetes/hypertension. There is however a significant difference in terms of disability. In just over half these cases, the disability is serious enough to prevent the person from working or attending school. 
Drug use and alcohol consumption, especially amongst youth and the male population cause great concern in all communities.

Also of concern is the persistence of teenage pregnancy and motherhood despite the availability of free contraception at clinics. Amongst households with children under 18 years; teenage pregnancies are found in $17 \%$ of cases; both parents are present in only a fifth of these. Interestingly, this proportion is only slightly higher in poor as opposed to non-poor households - $19 \%$ compared with $15 \%$. The ratio of teenage births as a proportion of total births has remained constant, and the DPPA considers that the overall trend is downward.

Nevertheless, the incidence of teenage sexual activity remains high with over $60 \%$ of adolescents aged 15-19 years having had sexual intercourse while only a quarter stated that they used contraception every time they had sex. STDs make up a large proportion of all medical consultations and the spread of HIV infection is of concern. With the present atmosphere of denial and stigmatization, along with the resistance on the part of males to condom use, an AIDS epidemic could become a major social and economic problem. However, there is a fully functional aids unit tackling this problem head on.

\section{Education}

The education level of heads of household in Dominica is very low -- over three-quarters of heads of household have not been educated above primary level. The situation improves significantly if the indicator used is the highest level of attainment of anyone in the household. Even so, $60 \%$ of households have no one with secondary or tertiary education. This situation is not new and educational policies in the last 20 years have sought to remedy this situation. As a direct consequence, educational levels in Dominica have improved dramatically for the population as a whole. These changes have benefited poor and non-poor alike. On present trends, the overall educational level of the population in general and the poor in particular, will continue to improve.

Nevertheless, there are marked differences in the proportions with no secondary education between poor and non-poor households in all age groups and, particularly, amongst the 15-19 year olds who are just completing their education. Young children from poor households are also less likely to go to pre-school. At the other end of the scale, very few adults in poor households have tertiary education.

On the positive side, virtually all children aged from 5-14 years have attended school and educational standards of the poor have improved considerably over the last 25 or so years. Very few households stated that they had a child who 
did not attend school regularly other than through reasons of sickness. While high levels of school attendance were confirmed by the PPAs, there is also evidence (from the PPAs) that the traditional patterns of absence and attrition persist in that boys are kept from school to assist with agricultural labour and girls to help care for younger siblings or because they are pregnant.

The PPAs also confirmed that the great majority of parents place a high value on education and make considerable sacrifices to ensure that their children attend school. Even so, there is evidence that some cannot afford the extra costs of uniforms, books, school lunches and other essentials. Many therefore depend on educational assistance from the Christian Children's Fund (CCF), and from government administered programmes. In the Carib Territory, reliance on these sources is crucial and even then, attendance, although high, is more

likely to be lower than elsewhere. Teachers interviewed in this area reckoned that some parents still did not encourage their children to attend school although attitudes are changing.

\section{Housing}

Selected housing indicators are presented in Table 5. The majority of households, whether poor or not, own their houses. Furthermore, the incidence of squatting is no more than about $3 \%$; again, this proportion does not vary with poverty.

Housing standards and the provision of basic infrastructure in Dominica are generally reasonable. Around $90 \%$ have electricity and access to piped drinking water. Only $12 \%$ are seriously overcrowded (over two persons per room). Over $60 \%$ of houses are built entirely or partly in concrete; additionally, many wooden houses are solidly constructed although these houses will generally be more prone to hurricane damage. Eighty percent of households use gas as their principal cooking fuel. On the other hand, significant proportions of households do not have an in-house toilet, bathing or cooking facilities. Absence of proper toilets was however only mentioned as a problem in urban areas. 
Table 5. Housing Indicators by Poverty Status

\begin{tabular}{|llll|}
\hline Indicator & Poor * & Non-poor & Total \\
\hline Tenure - House Owned & $77 \%$ & $74 \%$ & $75 \%$ \\
Land squatted & $4 \%$ & $3 \%$ & $3 \%$ \\
\hline Overcrowding & & & \\
Up to 1 person/room & $34 \%$ & $71 \%$ & $61 \%$ \\
Between 1 and 2 persons/room & $37 \%$ & $24 \%$ & $28 \%$ \\
Over 2 persons/room & $29 \%$ & $5 \%$ & $12 \%$ \\
Total & $100 \%$ & $100 \%$ & $100 \%$ \\
\hline 'Defective' Housing & & & \\
House with wood/ plywood walls & $60 \%$ & $28 \%$ & $37 \%$ \\
No safe water* & $16 \%$ & $7 \%$ & $9 \%$ \\
No electricity & $23 \%$ & $8 \%$ & $12 \%$ \\
No toilet or latrine & $29 \%$ & $11 \%$ & $16 \%$ \\
No bathing facilities & $35 \%$ & $14 \%$ & $20 \%$ \\
No kitchen facilities in house & $41 \%$ & $18 \%$ & $25 \%$ \\
Does not use gas for cooking & $38 \%$ & $15 \%$ & $21 \%$ \\
(Uses wood for cooking) & $23 \%$ & $8 \%$ & $13 \%)$ \\
Total & $100 \%$ & $100 \%$ & $100 \%$ \\
\hline
\end{tabular}

* i.e. Water does not come from house connection or standpipe.

Furthermore, all these indicators of poor housing are at least twice as high for poor as opposed to non-poor households. The differences are particularly marked in terms of serious over-crowding, lack of electricity and toilets, and use of wood for cooking. Nonetheless, the majority of poor households is not overcrowded and has a full range of facilities. Most importantly, over $80 \%$ have access to piped water and over three-quarters have electricity.

\section{Ownership of Assets and Durables}

As expected, rates of ownership of assets and durables rates are higher for all goods in non-poor households than in poor ones. Differentials are most marked for washing machines and vehicles. While $50-60 \%$ of poor households have refrigerators, televisions and telephones, only $70 \%$ have gas or electric stoves, implying that $30 \%$ of poor households have to rely on open fires or neighbours.

\section{Children / Single Parenthood}

Approximately half of the children in Dominica live in poor households; $22 \%$ are indigent. Seventy per cent of poor households include children compared with $44 \%$ for non-poor households. The available data indicate the following: 
- Poverty in Dominica disproportionately affects children;

- The incidence of no parent households shows one effect of migration of family patterns. Most of these households are not however poor, indicating an adequate level of support from overseas;

- The support provided by other family members (overseas and locally) to children living with one or no parents is evidenced by both the proportion of single parents living with other family members, and in the non-poor category of many no parent or single parent households;

- The difference between poor and non-poor households is most noticeable in the case of one-parent families living with other family members. In these instances, the number of dependants and the lack of wage earners, means that insufficient income is generated.

\section{The Elderly and the Disabled}

Statistically, poverty in Dominica does not disproportionately affect the elderly as it does in other countries. This reflects continued traditions of adult children looking after their parents as well as a number of relatively wealthy returnees. A higher proportion of poor households have someone with a serious disability. When support is not forthcoming, the link between old age, ill health, disability and poverty is apparent.

\section{The Indigent}

The overall incidence of indigence, severe poverty, is around $11 \%$. The higher incidence of indigence amongst the Caribs has already been mentioned. Other significant differences are that indigent households tend to be larger, have lower levels of educational attainment, worse housing infrastructure, more overcrowding and lower rates of asset ownership. In contrast, there is little variation in terms of household type, disability or sickness and, perhaps most importantly, the incidence of households with no one working.

Despite their poverty, only one of the case studies in the PPA was receiving public assistance. One reason given for this situation is that people sometimes consider themselves stigmatized if they are in receipt of Public Assistance - a throwback to the time that it was known as a "pauper's allowance". Available information on indigents demonstrates the devastating impact that combinations of age, disability, single parenthood, large numbers of children and lack of male and/or family support can have on families. The detrimental impact of migration is also apparent although presence of adult children or a father in Dominica is by no means a guarantee that circumstances would improve. The other point that can be made is that for many of these 
households, the only realistic solutions are government support and improved child maintenance.

\section{Coping Mechanisms and Survival Strategies}

The CPA reports a variety of 'survival strategies' that have been adopted by the poor and these are summarised as follows:

- Seeking employment overseas and in the capital city;

- Undertaking multiple jobs that are usually menial, poorly paid and insecure;

- Increased reliance on support from family members living in Dominica and overseas;

- Reliance on support from government, NGOs, churches, neighbours and friends. Most important of these are probably government and CCF educational programmes targeted at the poor; and

- Strategies to reduce expenditure (use of public utilities such as telephones, standpipes and baths), subsistence food production, home remedies.

Despite these strategies there is growing evidence, especially in rural areas, of households having to cut down on basic expenditures (including utility connections) and reducing their savings to nil leaving them vulnerable to the need for emergency finance.

There are nonetheless certain encouraging features about the poverty situation in Dominica, among which are:

- over two thirds of poor households have at least one person working;

- primary school attendance is high amongst the entire population while around three-quarters of 15-19 year old children from poor households are, or have, attended secondary school - much higher than in previous years;

- $\quad$ the health situation amongst the poor is generally good with low levels of infant mortality, low birth weights, infectious diseases and malnutrition while life expectancy is high; 
- $\quad$ Piped water and electricity are available to the great majority of the poor and non-poor populations. Ownership rates for assets such as refrigerators, televisions and telephones approach or exceed $50 \%$ amongst poor households;

- while the incidence of poverty is substantially higher in rural areas, rural households do have more opportunity than urban households to grow their own food and are more likely to live in closer-knit, more cohesive communities which provide a high degree of mutual support; and

- A large proportion of poor and non-poor households also benefit from income received from family members resident in Dominica and overseas. Non-income support for many needy families is also high - many elderly and single parents with children live in extended families. Without this level of support, the poverty and indigence levels would be higher.

\section{E. The Challenge of Poverty Reduction}

The primary causes of current poverty in Dominica is unemployment and underemployment due to slow economic growth since the mid-1990s and actual contraction of the economy in subsequent years.

That this situation has been building for some time is apparent from the 1996 Poverty Assessment that identified the same poverty-related issues and characteristics as the present study. While a precise indication as to the change in poverty levels is precluded by the lack of comparable data, poverty in rural areas is believed to have increased significantly, as would be expected given that banana production declined by 30\% from 1996 to 2001 and agricultural production in general declined in real terms by almost $20 \%$ over the same period.

For those living below the poverty line but above the indigence line, these economic factors are so dominant at present that other causes of poverty and lack of well-being (such as family breakdown, drug and alcohol abuse, unsafe sexual practices) are of less consequence. However, for the indigent and for the elderly living on their own, social factors, especially sickness and disability remain the major causes of their situation. 
The analysis has also revealed other factors that contribute to the current level of poverty and loss of well-being:

- The detrimental impact of migration on family life;

- $\quad$ Increasing pressures on women who have greater need to obtain employment while still shouldering their child rearing duties;

- The 'abandonment' of the elderly to fend for themselves;

- Increasing pressures on men, some of whom, unable to cope with their inability to provide for their family, resort to flight, crime, alcohol/ drugs and violence;

- Teenage pregnancy (although this is a long-standing problem largely unrelated to the economic crisis).

On a positive note, whilst the conditions of the indigent are sub-standard by any criteria, attitudes amongst the relatively poor are more optimistic. They speak of good infrastructure, housing and natural environment, adequate supplies of food, excellent access to health and education (the result of continuing government development policies and programmes), and a longstanding tradition of well integrated, self-supporting communities. Many strongly decry the idea that they are poor indicating a clear lack of correlation, in this instance, between income poverty and well-being.

However, there is the ever-present threat of destructive hurricanes, the impacts of which are still remembered. Losses included a large part of the housing stock (David, 1979), the banana crop (Hugo, 1989) and coastal infrastructure (Lenny, 1999). The poor economic situation means that any hurricane occurring in the near future is likely to further stretch government resources and result in loss of employment.

In this situation, the most likely outcome is that poverty will increase until the economy (especially agriculture) recovers and starts creating new jobs. In turn, increasing poverty will further threaten the local family and communitybased support networks that are so important to many poor families at present. Prolonged unemployment or underemployment is also an acknowledged cause of family breakdown, crime and social unrest that can lead families into a cycle of poverty from which it is difficult to escape.

Therefore, the challenge of poverty reduction, from human, social and economic standpoints, is the transcending challenge facing Dominica into the medium-term. Reducing poverty and vulnerability will require pro-poor growth over the medium term at above-average levels a focus on better-managed and targeted social protection programmes that deliver benefits directly to the poor and vulnerable. 


\section{REDUCING POVERTY AND IMPROVING SOCIAL PROTECTION}

The Government takes the position that poverty reduction over the long term requires the creation of sustainable employment and income earning opportunities for all Dominicans, an objective that will come about only with increased levels of economic growth and development. To attain and sustain above average and increasing levels of economic growth for the benefit of all Dominicans is the official policy objective of Government, and is irrevocably committed to achieving this objective. Before dealing with core issues of economic stabilisation and sustained growth, and focusing on a poverty reduction strategy going forward, we briefly review the key institutions involved in supporting economic development by improving the human and social infrastructure capacity of the country. ${ }^{2}$

\section{A. The Institutional Framework: Social Protection Systems in Dominica}

Dominica has an extensive social safety net consisting of the following government- and NGO-administered programmes. (Listed at Appendix 2)

Government expenditures in social assistance programmes played an important role in alleviating some of the distress and disruption from the negative growth rates in the economy from 2001 to 2003. The World Bank estimated that the GOCD spent roughly $5.6 \%$ of GDP on social protection in $2000 / 01$ but this increased to about $5.9 \%$ of the GDP in 2004/05. Nearly half of the expenditures were from the Dominica Social Security (DSS), which is self-financing, with the result that government expenditures on social protection amounted to about $3.0 \%$ of GDP. The Report points out that the existing social protection strategy does not address critical vulnerabilities and that coordination between programmes is weak. Low and volatile incomes are a source of risk but the programmes are not well poised to address income volatility and transient spells of poverty. This has been supported by the under-subscription of some social security programmes, where their actual expenditures were below their budgetary allocation, during the period 2001-2004.

Generally, the Country Poverty Assessment 2002 found that Dominica's social protection programmes targeted the poor, directly or indirectly, and were comprehensive in three ways:

They involve activities that are developmental (i.e. that seek to directly increase individuals' capability to participate in economic activity), supportive (i.e. that directly address the needs of poor and vulnerable

\footnotetext{
${ }^{2}$ There are also governance and human rights issues that are relevant to policy formulation for poverty reduction, which are not dealt with in this document.
} 
groups) and preventative (i.e. that seek to prevent individuals from becoming poor.)

They cover all relevant sectors: agriculture, small business development, physical infrastructure and housing, education, health and social sectors.

They target communities, households and individuals including the most vulnerable sub-groups of the poor - the elderly, disaffected youth, the disabled, drug abusers, the indigent, and households with family problems.

"While perhaps every poverty-related issue is not addressed by one or more agencies, certainly the great majority are."

One difficult area with scope for increased effectiveness is the generation of projects dealing directly with employment creation, a difficult area requiring a successful mix of investment, entrepreneurial spirit, local opportunities and market demand. Yet Government accepts that it is an area that it will need to continue to pursue if poverty in the Dominican context is to be reduced.

\section{B. The Medium-Term Poverty Reduction Strategy for Dominica}

In common with most developing countries, Dominica's poverty reduction strategy has the following:

The promotion of economic growth and job creation.

Essential both to provide employment opportunities for all (especially young) Dominicans and to generate government revenues that can be used to target residual poverty and identified social problems.

The development of the skills and health conditions that will enable current and future households to achieve and maintain a sustainable and fulfilling life.

Basic health and education services as well as utilities (e.g. water, electricity, and road access) are essential to sustainable poverty reduction as well as to achieve economic and social development objectives.

The betterment of the conditions of those currently in severe poverty to help them to achieve a sustainable livelihood through a combination of direct income support and other measures. 
There will always be some households (e.g. the elderly, the disabled, some one parent families) who will be unable to support themselves and will need direct income and other support.

The elimination or reduction of the potential causes of future impoverishment.

Social problems have been identified in the preceding Chapters which, even if they are not major causes of poverty at the moment, could lead to impoverishment in the future if they are not addressed.

It is clear from preceding analysis of the Dominica's poverty situation that in the Dominica context, the poverty reduction strategy must give urgent and comprehensive emphasis to:

- The promotion of economic growth and job creation; and

- Maximising the effectiveness of government financial resources available for pro-poor programmes.

\section{Poverty Reduction Policies and Programmes}

An extensive listing of possible actions and strategies for poverty reduction in Dominica emerged from the public consultations, the participatory poverty assessments, and workshops and from written communication, not all of which are prioritised, has available or identified potential funding or represent consensus. As the Country Poverty Assessment reports: "Many of these programmes are already being implemented by both government and nongovernment agencies. Indeed virtually every problem of poverty and well-being discussed in the report is being addressed to greater or lesser extent. Many of these interventions are well targeted, successful and innovative."

Nonetheless it also emerged that:

- Current programmes do not fully address the demand;

- Demand for these programmes will increase in the short-term; and

- Given its fiscal realities, Government may be under pressure to maintain or expand current programmes. 
There is the clear and compelling imperative to set priorities actions and strategies for poverty reduction in Dominica. The GSPS gives priority to:

- Initiatives that will promote economic growth and job creation;

- Existing and effective programmes with a direct or indirect impact on poverty reduction; and

- New initiatives that do not require substantial additional government expenditures unless they can be externally funded.

The priority actions that are set out do not include ongoing projects that are already included in national budgets, such as:

The Basic Needs Trust Fund;

The National Shelter Development Project;

The legal aid project; and

Upgrading of rural health facilities.

\section{Economic Development and Job Creation}

The GSPS takes the position that without economic growth, sustainable and long-term reductions in poverty will not be feasible. The identification and promotion of economic development opportunities is thus essential. Elsewhere in this document the strategy for economic development and job creation is articulated.

\section{E. The Maintenance of Existing Social and Physical Infrastructure Programmes}

Existing health, education and physical infrastructure programmes form the cornerstone of Dominica's policies to develop its human and economic resources. If these programmes are not maintained, not only will the current high levels of education and health be lost but the capacity of the population to take up new job opportunities will be compromised as will the objective of medium and long-term poverty reduction. Yet these programmes, and especially those that are targeted towards the poor and the vulnerable, may well come under intense pressure over the next few years as the government 
continues to work towards fiscal sustainability. This pressure for cutbacks will come just as demand for the several of the programmes is likely to increase.

Government will therefore review the operation of these programmes so as to improve the effectiveness of these programmes through rationalisation and better targeting. This will both make it easier to maintain the programmes to expand them.

Rationalisation is taken to mean reviewing current programmes, improving their operational efficiency, cutting back on those that are less effective, and reducing overlaps.

There are two main aspects to targeting: firstly, improving the targeting of programmes that are already targeted; and secondly, introducing targeting into programmes that are currently open to all. Both aspects are implicit in the following actions and will be based on clear criteria. More targeting will only be implemented where the savings from targeting exceed the administrative costs of implementing them.

\section{Health}

Maintain free immunisation programme and current decentralised distribution of health facilities.

Good health is a cornerstone of a sustainable society. It also ranks highly amongst the concerns of the poor when it is lacking. The current health situation in Dominica is favourable. It must be maintained. These are critical components of the health care system in Dominica.

Examine the Feasibility of introducing graduated health charges for some health services with exemptions for the poor.

Pressures on government finances will threaten the current highly subsidised system where the proportion of user charges recovered is so low. The introduction of some health charges with exemptions for the poor would maintain the sustainability of health care services for the whole population. This applies particularly to Princess Margaret Hospital, which is responsible for over $40 \%$ of total health spending. Although user charges exist for this establishment, the collection rate is low and the amount recovered represents only around $10 \%$ of the hospital's total spending. 


\section{Continue participation in OECS Drug Procurement Programme.}

This programme has proved successful in reducing drug costs in the OECS countries. Participation in this programme will improve the cost effectiveness of Dominica's health service by reducing the cost of one of its key components.

Continue and improve intense public awareness campaign relating to HIV/AIDS and teenage pregnancy.

The economic and social consequences of HIV/AIDS are potentially devastating, and teenage pregnancies are an acknowledged cause of poverty.

\section{Education}

Maintain the Education Trust Fund, School Feeding and Textbook Programmes.

These programmes are targeted at the poor and are welcomed by teachers and parents alike. Without them attendance rates would fall significantly. If children are not provided with basic education, their ability to develop a sustainable livelihood and to contribute to overall society is, at best curtailed; at worst it is fatally compromised.

Review the existing distribution of primary schools.

In the context of small class sizes, falling school rolls (primary school enrolment is likely to fall by around $20 \%$ in the next 5 years) and the pressure on education expenditures, this review could result in a more cost effective distribution of primary schools and teachers.

Continue to implement the strategies of BERP (Basic Education Reform Programme) with particular reference to curriculum development and expanding vocational and technical education.

The need for increased vocational and technical education is recognised by both the authorities and communities as a means of reducing drop-out rates among males and their disaffection with school.

Maintain and expand funding for community education facilities such as Operation Youthquake, CALLS (Centre where Adolescents Love to Learn and Serve) and the Dublanc Youth centre which cater for vulnerable adolescents and dropouts. 
Initiate research and action into male under-performance, disaffection and parental responsibility.

\section{Social Safety Nets/Social Sectors}

Review current criteria and level of public assistance.

The current level of public assistance is below the indigence line. Current criteria exclude many indigent households.

\section{Review Dominica Social Security arrangements.}

Government will explore actions that it will need to take to ensure that DSS is well placed to meet its future obligations to pensioners, and for placing DSS on a sustainable footing.

Develop a programme, in conjunction with NGO's, to provide education in life skills and the availability of counselling services.

A number of problems that can lead to future impoverishment have their origins in adolescence, e.g. teenage pregnancy, substance abuse, low educational achievement, physical abuse and deviant behaviour.

Establish a facility for young offenders.

Funding will be sought to provide a facility for young offenders. The absence of such a facility results in young offenders either being 'lost' in jail or returning to the streets without rehabilitation.

\section{Housing/infrastructure}

Pursue squatter regularisation programme.

Squatting is almost always a response to a legitimate housing demand. Relocation is expensive and is problematic given the lack of easily developable land. Government will continue its regularisation programme with a view to improved housing conditions and a consequent enhancement of well-being. 
Maintenance of water supply and road networks.

The current water supply and road networks have a wide coverage. While further expansion may not be feasible in the short- to medium terms, Government accepts that maintaining these networks is crucial if they are not to deteriorate and result in major future expenditures.

\section{Institutional}

Hold a workshop involving government and NGOs involved with vulnerable groups.

Government and NGO experience in assistance to vulnerable groups will be pooled with a view to better targeting and improved effectiveness of these programmes.

\section{Legal}

Streamline procedures for child maintenance.

Lack of child support is a major cause of financial hardship and vulnerability to single parents. Measures will be drawn up that minimise the need for legal assistance, and provide effective enforcement and collection proceedings.

Establish task force to review law related to families and children.

Current laws are fragmented, often inconsistent and/or outmoded. The OECS is undertaking an initiative in respect of family law and a report dealing with child legislation has also been produced. These will provide a starting-point for the revision of Dominica's laws.

\section{Environmental}

$\underline{\text { Target areas of environmental degradation, e.g. deforestation, soil erosion. }}$

Areas of environmental degradation will be investigated to develop sustainable approaches to natural resource use using existing proposals as a starting point.

\section{Summary of Priority Actions:}

The above priority actions are summarised in Table 6. 
Table 6. Priority Poverty Reduction Actions

\begin{tabular}{|c|c|c|}
\hline SECTOR & ACTION & Responsible Agency (ies) \\
\hline \multirow{4}{*}{ Health } & $\begin{array}{l}\text { Maintain immunization programme and } \\
\text { distribution of primary health care } \\
\text { facilities }\end{array}$ & Finance, Health \\
\hline & $\begin{array}{l}\text { HIV/AIDS/Teenage Pregnancy Awareness } \\
\text { Programme }\end{array}$ & $\begin{array}{l}\text { Health, Education, } \\
\text { CDGA, NGOs, Media }\end{array}$ \\
\hline & $\begin{array}{l}\text { Investigate feasibility of graduated health } \\
\text { charges }\end{array}$ & Health, Finance \\
\hline & $\begin{array}{l}\text { Maintain participation in OECS Drug } \\
\text { Procurement Programme }\end{array}$ & Health, Finance \\
\hline \multirow{4}{*}{ Education } & $\begin{array}{l}\text { Maintain government pro-poor education } \\
\text { assistance programmes }\end{array}$ & Education, Finance \\
\hline & Review distribution of primary schools & Education \\
\hline & $\begin{array}{l}\text { Increase provisional vocational technical } \\
\text { education in primary schools }\end{array}$ & Education \\
\hline & $\begin{array}{l}\text { Maintain funding of projects dealing with } \\
\text { troubled children and drop outs }\end{array}$ & $\begin{array}{l}\text { Education, NGOs, Youth } \\
\text { Quake, CALLS }\end{array}$ \\
\hline \multirow{5}{*}{$\begin{array}{l}\text { Social Safety Nets/ Social } \\
\text { Sectors }\end{array}$} & $\begin{array}{l}\text { Review current criteria and level of public } \\
\text { assistance }\end{array}$ & CDGA \\
\hline & $\begin{array}{l}\text { Ensure integrity of Dominica Social } \\
\text { Security. }\end{array}$ & Finance, DSS \\
\hline & $\begin{array}{l}\text { Initiate research into adolescent and young } \\
\text { adult males. }\end{array}$ & Education, CDGA, NGOs \\
\hline & Introduce courses in life skills education. & Education, CDGA, NGOs \\
\hline & $\begin{array}{l}\text { Prepare funding proposal for a facility for } \\
\text { young offenders. }\end{array}$ & $\begin{array}{l}\text { Finance, CDGA, } \\
\text { Education, NGOs }\end{array}$ \\
\hline \multirow[t]{2}{*}{ Housing/Infrastructure } & $\begin{array}{l}\text { Maintenance of water supply and road } \\
\text { networks }\end{array}$ & $\begin{array}{l}\text { Public Works and Public } \\
\text { Utilities }\end{array}$ \\
\hline & Squatter regularization & Housing Division \\
\hline \multirow{2}{*}{ Institutional } & $\begin{array}{l}\text { Workshop on educational assistance } \\
\text { programmes }\end{array}$ & Education, CDGA, NGOs \\
\hline & Workshops on vulnerable groups & $\begin{array}{l}\text { CDGA, NGOs, Education, } \\
\text { Health }\end{array}$ \\
\hline \multirow{3}{*}{ Legal } & $\begin{array}{l}\text { Improve operation of child maintenance } \\
\text { system }\end{array}$ & Attorney General \\
\hline & $\begin{array}{l}\text { Reform of legal framework related to } \\
\text { children, welfare, family support and small } \\
\text { claims. }\end{array}$ & $\begin{array}{l}\text { Attorney General, } \\
\text { Education, Health, CDGA }\end{array}$ \\
\hline & Reform magistracy operations. & Attorney General \\
\hline Environmental & $\begin{array}{l}\text { Formulate strategies for addressing areas } \\
\text { of environmental degradation. }\end{array}$ & $\begin{array}{l}\text { Environment, CDGA, } \\
\text { NGOs }\end{array}$ \\
\hline
\end{tabular}

While a number of these are already in place, they are however considered those that are most urgently needed in order to achieve sustainable poverty reduction in Dominica. As previously indicated, those actions do not include those dealt with elsewhere in this document, e.g. tourism, business development, agricultural diversification.

The proposed priority poverty reduction actions call for little capital expenditure. Many of the programmes are ongoing and have a range of committed government and 
non-government agencies to implement them. Above all the poverty reduction programme will require committed leadership at all levels, willing and able to implement these changes. Implementation of the proposed actions will contribute immensely to poverty reduction, and complement the growth inducing measures discussed in this document, thus making a most important contribution to putting Dominica on the road to long-term sustainable development.

\section{F. A Special Focus on the Carib Community}

Dominica has the largest population of indigenous people in the Eastern Caribbean, approximately 3,000 or 4 percent of the population are Carib Indians. This group has political autonomy through a Carib Council, which administers a communal land reserve of 3,700 acres on behalf of its 1,700 resident Carib population. However, although the Carib community has its autonomous political structure and communal lands, Caribs are the most disadvantaged group in the country. Caribs play a significant role in tourism through the marketing of their traditional handicrafts, and their reserve is an attraction for tourist visitors. There is a Comprehensive Carib Territory Community Development Programme to be financed by the CDB and the GOCD (\$4.3 million) that covers the four-year period 2003-2007. The programme seeks to diversify the economy of the Carib Territory by providing opportunities for employment creation to improve the well being of the Carib people by undertaking investments in the tourism sector (Carib model village), health sector (construction of a health center), road infrastructure (feeder roads), agriculture and livestock sector, education and housing sector, land reform, community resource centers and other social activities.

The Carib People Development Plan (CPDP) identifies measures for tackling the major problems of the Territory. The objective for the medium-term is to reduce the disparities between the Caribs and other Dominicans so that Carib incomes and poverty indicators are the same as the national average by 2010. The measures to attain this objective during the medium-term are as follows:

- The GOCD will seek financing for project proposals and projects for Carib development from the CPDP and from international financial and donor agencies, such as the World Bank, OAS, and the CBD, that have an interest in development of indigenous peoples.

- Implementing the Comprehensive Carib Territory Community Development Programme.

- Integrating the Carib community more fully into the economic life of the wider community in terms of access to financial services and micro credit for traditional and non-traditional investments.

- Promoting the Carib village as an eco-tourism center and ensuring that the center is operated along viable economic lines. 


\section{THE ECONOMIC AND FISCAL CONTEXT}

The Commonwealth of Dominica experienced serious economic difficulties during the 1990s. These were caused largely by global forces, particularly by trade liberalization that brought about a severe shock to the banana industry, the main source of the country's exports and the largest contributor to agricultural employment. Government attempts to offset the shock by increasing expenditures resulted in a rapid expansion of public debt, while plans to diversify the economy and encourage private investment had not materialized. The sub-regional and regional initiatives to enable Caribbean countries to combat the adverse effects of globalization also had little effect.

By 2000-01, large fiscal imbalances and massive public debt affected adversely both the government operations and private sector activity. As the debt service burden became excessive, the overdue payments to foreign creditors and domestic private sector accumulated, external financial support came to a halt, and public sector investment dropped sharply. The private sector activity weakened, and government revenue decreased. A sharp drop in tourism activity in the wake of September 11, 2001 exacerbated economic difficulties.

Dominica experienced negative economic growth for three years, 2001 to 2003, with real gross domestic product declining by $4.2 \%$ in 2001, $5.1 \%$ in 2002 and $0.1 \%$ in 2003. Estimated per capita incomes declined from $\$ 10,200$ in 2000 to $\$ 9,900$ in 2002 , or by $3 \%$. The unemployment rate increased from $11.6 \%$ in the census year 2001 to about 14\% in 2003 (MoFP estimate). However, the economy bottomed out in 2003; it grew by $3.5 \%$ in 2004 as the unused capacity was partly reactivated, and gives indication of continued healthy growth in 2005.

During the period 2000-2004, output of agriculture, mining and quarrying, and manufacturing declined, and the contribution of these sectors to GDP shrunk from $15.6 \%$ in 2000 to $14.4 \%$ in 2004 . Construction, communications, banking and insurance, and hotels and restaurants also declined. The sectors experiencing growth were: wholesale and retail trade (average rate of growth of $3.8 \%$ a year) followed by electricity and water, real estate and housing, government services and transportation. These developments indicate continued shift in the structure of economy marked by increasing importance of services. 
Table 7. GDP by Sector, 1998-2004

In EC \$million at 1990 constant prices

\begin{tabular}{|c|c|c|c|c|c|c|c|}
\hline & 1998 & 1999 & 2000 & 2001 & 2002 & 2003 & 2004 \\
\hline Agriculture & 84.7 & 82.9 & 82.0 & 76.6 & 76.1 & 73.3 & 75.6 \\
\hline Mining \& Quarrying & 3.4 & 3.5 & 3.7 & 3.6 & 2.7 & 3.0 & 3.2 \\
\hline Manufacturing & 35.3 & 29.2 & 31.3 & 27.1 & 26.5 & 26.5 & 27.7 \\
\hline Elec. \& Water & 18.2 & 19.2 & 19.7 & 20.3 & 20.4 & 20.0 & 21.1 \\
\hline Construction & 33.6 & 34.9 & 37.0 & 36.1 & 26.9 & 29.9 & 32.1 \\
\hline $\begin{array}{l}\text { Wholesale \& Retail } \\
\text { Trade }\end{array}$ & 55.6 & 57.0 & 58.4 & 58.0 & 55.0 & 57.0 & 59.3 \\
\hline $\begin{array}{l}\text { Hotels \& } \\
\text { Restaurants }\end{array}$ & 10.8 & 11.3 & 11.7 & 10.8 & 10.5 & 10.1 & 11.3 \\
\hline Transportation & 44.5 & 45.1 & 44.7 & 42.2 & 36.7 & 38.7 & 44.8 \\
\hline Communications & 49.4 & 55.6 & 53.2 & 49.7 & 48.9 & 39.4 & 41.8 \\
\hline Banks \& Insurance & 54.6 & 58.3 & 58.5 & 56.5 & 53.3 & 54.8 & 55.9 \\
\hline $\begin{array}{l}\text { Real Estate \& } \\
\text { Housing }\end{array}$ & 15.2 & 15.5 & 15.7 & 15.8 & 16.0 & 16.3 & 16.6 \\
\hline $\begin{array}{l}\text { Government } \\
\text { Services }\end{array}$ & 78.3 & 78.5 & 82.0 & 85.8 & 88.7 & 87.3 & 83.1 \\
\hline Other Services & 5.8 & 6.0 & 6.0 & 6.1 & 6.4 & 6.6 & 6.7 \\
\hline $\begin{array}{l}\text { Imputed Service } \\
\text { Charge }\end{array}$ & 46.2 & 46.4 & 47.4 & 51.4 & 52.9 & 49.2 & 50.9 \\
\hline Total & 443.2 & 450.6 & 456.4 & 437.4 & 415.2 & 413.7 & 428.2 \\
\hline GDP Current & 585.0 & 609.7 & 621.6 & 607.5 & 577.0 & 578.4 & 605.7 \\
\hline GDP, Market Prices & 700.5 & 722.8 & 732.1 & 718.6 & 689.9 & 705.7 & 738.9 \\
\hline Growth Rate & 2.8 & 1.6 & 1.3 & -4.0 & -5.1 & -0.4 & 3.5 \\
\hline
\end{tabular}

Source: ECCB National Accounts for the OECS. 
To combat the severe macroeconomic and financial difficulties, GOCD embarked on its Economic Stabilization and Adjustment Programme introduced in the Budget address of June 2002. Initially, the adjustment effort concentrated on measures to strengthen the Government's revenue. They included introduction of a stabilization levy of 4 percent on payroll income and a 5 percent sales tax on telecommunication services, adjustments in fuel prices to reflect international oil prices and ensure annual revenue from the consumption tax equivalent to 0.6 percent of GDP, broadening the coverage of license fees, and limiting of discretionary duty and tax exemptions on imports. The Government programme was supported by the International Monetary Fund (IMF) Stand-By Arrangement. The region also responded to Dominica's shortterm funding needs. In calendar year 2002, assistance amounting to approximately US\$13.2 million was provided by Trinidad and Tobago, Barbados, Grenada, St. Vincent and the Grenadines, Belize, and the Bahamas. Additionally, EC $\$ 5$ million was provided by the Eastern Caribbean Central Bank (ECCB). Multilateral agencies and the friendly governments also provided considerable technical assistance.

In the 2003/04 Budget address, the Government adopted a two-pronged approach to addressing continuing economic difficulties. First, it would strengthen fiscal policy to reduce the financing gap and engender additional external financial support. Second, once the fiscal efforts show results, it would embark on a more comprehensive reform programme to foster growth and move towards debt sustainability. This programme has been supported by a three-year Poverty Reduction and Growth Facility Programme (PRGF) of the IMF. The fiscal programme was balanced between revenue and expenditure measures. The revenue measures primarily aimed at broadening the tax base. The increase in sales tax and the customs service charge rates permitted a reduction in the consumption tax rate (paid in advance), which helped ease the liquidity position of enterprises. Expenditure measures concentrated on reducing the wage bill (salaries, wages and salaried allowances). The Government opted for a 5 percent cut in salaries as a short-term measure because employment reduction would need to be informed by a more comprehensive public service reform, which was not ready for implementation.

Strong performance in the fiscal area permitted removal of the adjustment measures that were causing most hardship to the public. Improved macroeconomic conditions and stronger tax administration, including the expansion of the tax base resulted in higher-than-anticipated revenue collection. Greater financial discipline and increased attention to cash flow management resulted in more effective control of current expenditure. The 2004/05 budget introduced the first stage of rationalization of government employment, which permitted the removal of the stabilization levy benefiting employees in both the private and the public sector. For 2005/06, the Government removed the 5 percent salary cut. At the same time, it announced that it would continue to streamline employment through outsourcing, and 
commercialization of some services and rationalization of line ministries. Timely implementation of these programmes is required to keep the wage bill within the budget limit.

By mid-2003, the Government concluded that the very high level of public debt constituted the most severe obstacle to Dominica's growth prospects and fiscal sustainability. Public debt had doubled over the preceding six years and was equivalent to about 127 percent of GDP. Debt servicing requirements were very heavy, representing about $1 / 4$ of current revenue or 8 percent of GDP. To help restore the basis for growth, Government decided to seek debt relief aimed at reducing the debt-servicing burden. It mobilized technical assistance and in April 2004 launched an offer to exchange outstanding debt to the private sector and bilateral creditors for medium- to long-term bonds carrying a lower interest rate.

Agreements have been reached with creditors holding above 70 percent of the debt eligible for restructuring. The combination of improved fiscal performance and debt restructuring has resulted in a decline of public debt to about 117 percent of GDP at mid-2005 and a reduction in the Government cash outlays for interest by almost 50 percent (from $\$ 34$ million in 2003/04 to estimated $\$ 17.8$ million estimated for 2005/06). In addition, postponement of debt amortization for the next several years and reduced risks associated with the need for debt rollover will result in higher net inflow of funds.

\section{PROMOTING SUSTAINED ECONOMIC GROWTH}

\section{A. Enabling Environment and the Role of Government}

GOCD will aim at achieving a sustained economic growth of $3 \%$ over the medium term, based on increased levels of activity in all sectors, and in particular in tourism, agriculture, fisheries, energy and water. Improving export performance is critical for growth and increasing international competitiveness is a major challenge if Dominica is to succeed in the global economic environment. Eco-tourism, agro-industries, niche-focused agriculture and fisheries, and water are natural resource based industries in which Dominica enjoys competitive advantage, and should provide employment and income-growth opportunities. Private investment will have to play a major role in realizing this potential. However, increasing the attractiveness of the economy to investors requires reducing the cost of doing business and improving reliability of transportation and energy, and increasing the productivity of the labour force. As a result, infrastructural development and improved focus of education and training (including upgrading technical, management and entrepreneurial skills) are major aspects of the GSPS. 
Experience of small countries that achieved rapid economic growth as well as Dominica's below-growth-potential performance indicates that a dynamic export oriented private sector must be the basis of sustained growth. Substantially higher levels of investment, local and foreign, are critical to this transformation. The Government's role and strategy for improving enabling environment for private enterprise and Dominica's competitiveness are informed by the overwhelming evidence that the main components of enabling environment in a country are (i) political and macroeconomic stability; (ii) sound regulatory framework and efficient supporting institutions; and (iii) an adequate physical and social infrastructure. $3 /$

Dominica's political and social stability needs to be more fully valued as an important element of both the overall welfare of our people and investment climate. In the latter sense, it provides an essential prerequisite for making investment decisions with medium- to long-term horizon. By committing to continue improving accountability, transparency in its operations and communication with social partners, GOCD will do all necessary to preserve and enhance political and social stability.

The medium term macroeconomic framework consists broadly of: (i) targeted real GDP growth of about 3 percent a year, with the dynamic growth of tourism contributing to, (ii) improvement in the external current account, and (iii) inflation rate remaining subdued at around 2 percent a year. This scenario implies improving employment opportunities and increases in income per capita over the medium term. The macroeconomic framework also covers such parameters as savings and investment, central government finances, and trade in goods and services; these are presented in Table 8. The targeted growth requires investments that are little higher but of superior quality in their economic impact than achieved in 1999-2002. Public investment at close to 11 percent of GDP that would be consistent with available grant and concessionary loan financing requires strengthening of the implementation capacity. Gradual reduction of the external current account deficits will mean increasing reliance on domestic savings. As public savings stabilize after 2006, mobilization of private savings to finance investment will gain importance. This is why the soundness of the Dominica Social Security and financial intermediaries is important element of macroeconomic stability and investment enabling environment.

\footnotetext{
3 / It is generally accepted that in an increasingly global economy, competitive advantage rests on a country's ability to create a business environment, along with supporting institutions that are conducive to the nation's inputs to be used and upgraded in a most effective manner. The World Bank report: "Towards a New Agenda for Growth", April 2005.
} 
Table 8. Dominica: Medium-Term Projections 2006 - 2010

\begin{tabular}{|c|c|c|c|c|c|c|c|c|}
\hline & 2003 & 2004 & 2005 & 2006 & 2007 & 2008 & 2009 & 2010 \\
\hline & \multicolumn{7}{|c|}{ (Annual percent change) } & \multirow[b]{2}{*}{3.0} \\
\hline \multirow{2}{*}{$\begin{array}{l}\text { GDP at Constant } \\
\text { (1990) } \\
\text { Prices }\end{array}$} & 0.1 & 3.5 & 2.5 & 3.0 & 3.0 & 3.0 & 3.0 & \\
\hline & \multicolumn{7}{|c|}{ (In percent of GDP) } & \\
\hline \multicolumn{9}{|l|}{$\begin{array}{l}\text { Savings and } \\
\text { Investment }\end{array}$} \\
\hline $\begin{array}{l}\text { Gross domestic } \\
\text { investment }\end{array}$ & 25.4 & 28.9 & 24.9 & 26.7 & 27.7 & 27.7 & 27.7 & 27.7 \\
\hline Public & 9.4 & 11.8 & 9.9 & 10.7 & 10.7 & 10.7 & 10.7 & 10.7 \\
\hline Private & 16.0 & 17.1 & 15.0 & 16.0 & 17.0 & 17.0 & 17.0 & 17.0 \\
\hline Gross National Saving & 19.7 & 21.6 & 12.5 & 18.2 & 20.4 & 21.6 & 22.6 & 23.7 \\
\hline Public & 5.9 & 10.8 & 8.4 & 8.6 & 9.0 & 9.3 & 9.5 & 9.6 \\
\hline Private & 13.8 & 10.8 & 4.1 & 9.6 & 11.4 & 12.3 & 13.2 & 14.1 \\
\hline $\begin{array}{l}\text { Central Government } \\
\text { Finances }\end{array}$ & ‘02/’03 & ‘03/’04 & ‘04/’05 & ‘05/’06 & ‘06/’07 & ‘07/’08 & ‘08/’09 & ‘09/’10 \\
\hline Current revenue & 28.0 & 31.0 & 32.9 & 30.9 & 29.4 & 29.4 & 29.4 & 29.4 \\
\hline Current expenditure & 33.1 & 31.2 & 31.1 & 30.1 & 29.2 & 29.4 & 29.4 & 29.4 \\
\hline Grants & 4.5 & 8.8 & 5.9 & 8.1 & 8.1 & 8.1 & 8.1 & 8.1 \\
\hline Capital spending & 5.1 & 10.1 & 8.5 & 10.1 & 10.1 & 10.1 & 10.1 & 10.1 \\
\hline Primary Balance & -1.6 & 5.6 & 4.4 & 3.0 & 3.0 & 3.0 & 3.0 & 3.0 \\
\hline $\begin{array}{l}\text { Overall Balance } \\
\text { (after grants) }\end{array}$ & -5.4 & -1.3 & -0.6 & -2.5 & -1.7 & -1.6 & -1.3 & -1.0 \\
\hline $\begin{array}{l}\text { Public sector debt / } \\
\text { GDP (\%) }\end{array}$ & 130.6 & 116.7 & 109.1 & 103.9 & 99.5 & 95.3 & 91.1 & 87.1 \\
\hline $\begin{array}{l}\text { Balance of } \\
\text { Merchandise Trade }\end{array}$ & -27.4 & -31.2 & -33.0 & -32.7 & -32.0 & -31.2 & -30.5 & -29.9 \\
\hline $\begin{array}{l}\text { Exports of goods and } \\
\text { services }\end{array}$ & 45.8 & 47.5 & 49.5 & 49.6 & 49.7 & 49.8 & 17.6 & 18.2 \\
\hline $\begin{array}{l}\text { Imports of goods and } \\
\text { services }\end{array}$ & 60.6 & 63.9 & 66.5 & 66.2 & 65.4 & 64.4 & 63.6 & 62.9 \\
\hline $\begin{array}{l}\text { GDP, Constant \$ } \\
\text { million }\end{array}$ & 413.7 & 428.2 & 438.9 & 452.1 & 465.6 & 479.6 & 494.0 & 508.8 \\
\hline GDP, Market Prices & 697.1 & 731.7 & 761.2 & 795.8 & 832.0 & 869.8 & 909.4 & 950.7 \\
\hline Population & 69,332 & 69,261 & 69,187 & 69,103 & 69,005 & 68,909 & 68,824 & 68,700 \\
\hline
\end{tabular}

Figures on fiscal data relate to the fiscal year beginning on July 1 of the preceding year. Source: Ministry of Finance and the IMF staff estimates and projections. 
Dominica's statistical base is weak and substantial improvements in coverage, reliability and timeliness are needed to support effective monitoring, sound analysis and policy formulation. Priority will be given to improving quality and timelines of data on real sector economic activity, employment and wages and surveys of living conditions. GOCD will seek technical assistance to the Statistical Office from ECCB, UNDP and others to help remove these deficiencies.

The achievement of economic targets and social objectives of the strategy will be susceptible to considerable risks. Dominica's geography, fragile economic structure and poverty levels make it vulnerable. The island is prone to natural disasters and other external shocks. The country's small size and remoteness add to the transportation costs. High degree of openness and the degree of dependence on two sectors (tourism and banana) result in heavy exposure to events in global markets and trade regimes. To reduce vulnerabilities and improve the odds of sustained progress the Government will assign high priority to:

- Improving disaster preparedness and mitigation;

- Protecting and enhancing the environment by improving environmental management;

- Upgrading port, road and airport infrastructure; and

- Diversifying the economic base and sources of people's income.

Further fiscal consolidation will ensure continued progress towards sustainable public debt levels and thus buttress macroeconomic stability. It will be pursued by the GOCD adherence to fiscal discipline and the primary balance target of 3 percent of GDP.

Increases in current expenditure will continue to be contained so that the government's recurrent operations are brought in balance without raising tax levels or introducing new taxes. The weight of the government's wage bill needs to be reduced further, and this will be pursued in the context of continued comprehensive reform of the public sector. The GOCD is committed to making public service more efficient and smaller but better paid. To this end, the Government will keep under review the scope for, and implement outsourcing, commercialization and privatization of services that the private sector can provide more efficiently. Following the outsourcing of the security and janitorial services the Public Service Reform Unit is preparing proposals for outsourcing or commercialization of the maintenance of national parks, printing services, road maintenance and Public Works Garage, and grounds and general maintenance. Employees in these services will be encouraged to form small enterprises or join the existing private companies that win bids for providing these services. These steps will not only save the taxpayers' money but will open additional space for private sector led growth. In addition, the functions and structure of Government ministries and departments are being 
reviewed with a view to their streamlining. The review now under way is examining the scope for improving service delivery and achieving efficiencies in the social sectors of Government.

The strength of recurrent revenue will be enhanced by further broadening the tax base and improving tax administration. Introduction of the value added tax (VAT) in March 2006 represents a major step in modernizing the system of indirect taxation. It will simplify the system by replacing the consumption tax, sales tax, the hotel occupancy tax and make indirect taxation consistent with the international practice of providing tax relief to exporters. It will broaden the tax base and make the system more equitable by better covering services and having fewer exemptions. The VAT has been designed to be revenue neutral, which means that its introduction will not involve an increase in the overall tax effort by the public. A study on implications of VAT for various income groups indicates that that the lower-income households are likely to benefit from the introduction of VAT. ${ }^{4}$ / If revenue from VAT over time proves to be more buoyant than now cautiously envisaged, this would permit a reduction in personal income taxes in the future.

The Government has mobilized resources to help the tax collection departments implement important programmes that will simplify and speed up the assessment process and thus ease the administrative burden on businesses. The new subdivision of the Inland Revenue Department for VAT implementation has trained hundreds of likely registrants. The Customs Service is proceeding with a programme to accelerate processing by putting in use risk assessment based on a computer programme - ASYCUDA, designed to handle customs procedure and facilitate electronic interaction between Customs and participating businesses.

The GOCD is determined to take steps to speed up the rate of implementation of its investment programme. In addition, project formulation and implementation will be improved to enhance the projects' positive impact on overall economic activity. To this end, in developing their proposals, the line ministries will conduct analysis, consult stakeholders and take timely actions to maximize the project's linkages and benefits for the private sector activity. Organizational and financial preparations for operating and maintaining projects will be undertaken well before completing construction.

The Government intends to enshrine in legislation sound fiscal management with more clearly specified responsibilities, accountability and transparency. This will be done by introducing the Public Finance and Accountability Act. The Act will also set the fiscal targets of a primary surplus consistent with reducing public debt over time. It also will regulate Government and government

\footnotetext{
4/ Essentially because relatively more revenue than before will be collected on services, which constitute smaller part of the lower income households' consumption.
} 
guaranteed borrowing (addressing process of contracting, management and disclosure of public debt, including contingent liabilities). The legislation will serve to improve credibility of fiscal policy and anchor public expectations regarding the stance of public finances over the medium term. Its implementation will require improvements in financial management, which will elevate the quality of governance in Dominica.

DSS is facing financial problems manifest in large and growing unfunded liabilities in the pension system. Unless corrective action is taken early DSS will, in time, run massive deficits putting at risk the benefits of future pensioners and the results of fiscal adjustment. The Government intends to implement a gradual and equitable reform early in order to avoid a drastic adjustment when the system's finances are exhausted. To this end, Cabinet will approve an action plan for putting DSS on a sustainable footing during this fiscal year. The plan will consist of a balanced combination of gradual adjustments to the replacement rate, the contribution rate, and the number of years over which average earnings are calculated, and the retirement age. The plan will also allow gradual portfolio diversification to better protect and enhance returns on its investments.

The GOCD will intensify implementation of its comprehensive Public Sector Reform Strategy (PSRS). The strategy has been a catalyst for formulating the vision of the roles of government and the private sector, and through consultation process, for building an understanding and consensus among social partners for transition that is under way. The PSRS aims at improving effectiveness of service delivery, enhancing accountability through greater openness and improved access to information, streamlining government regulations and procedures that may hinder the private sector economic activity, and strengthening local government.

When implemented, the PSRS should result in a smaller, more competent, efficient and better-paid Public Service fit to provide strong support to a sustained economic and social progress of Dominica.

The following measures will be taken to improve the efficiency and effectiveness of the public service over the next 2-3 years:

- Streamlining the functions and structure of the ministries and departments, particularly those interacting with the growth sectors, and providing social services.

- Strengthening middle management and senior management (Permanent Secretaries) capacity to provide high quality social services and competent support to the private sector. 
- Reviewing of legislation by individual Ministries to indicate areas requiring amendments to enhance achievement of the strategy objectives for growth and social protection.

- Amending legislation that will facilitate modernization of Public Sector management, policies, and procedures to improve performance and productivity.

- Devolving responsibility for human resource management from the Public Service Commission (PSC) to Permanent Secretaries for the recruitment, discipline and termination of staff from middle management levels down.

- Implementing an accountability and merit pay system.

- Reducing unnecessary bureaucratic practices (red tape).

- Adopting practices that ensure greater transparency of government operations through improved access to and greater coverage of disseminated information on work of ministries and departments.

To improve the environment for private enterprise, the Government intends to:

- Streamline regulations and procedures relating to private sector activity;

- Strengthen public service delivery mechanism;

- Improve the judicial and land administration systems; and

- Encourage the private sector to identify and articulate issues and proposals for other improvements in business environment.

The Ministry of Finance, Cabinet and the NDC receive requests and pressures for granting tax incentives beyond what is warranted by criteria and limits set in the legislation and stated Cabinet policy.

Cabinet policy has been to strictly limit the granting of discretionary incentives, and to publish the decisions (the reasons, coverage and the beneficiary), which is in line with the policy of improving transparency. In addition, it is likely that some long-standing statutory incentives have not resulted in expected job creation and income generation. This is why GOCD will review the statutory and non-statutory tax exemptions with a view to making them more effective and repealing those found unnecessary.

Instead, the Government's structural reform agenda and the public sector investment programme seek to improve substantially Dominica's competitive standing with regard to the more fundamental aspects of the investment climate. ${ }^{5}$

Administrative transparency and efficiency that affect the required time and cost of starting and expanding business are essential aspects of the investment

5 / Companies expanding oversees indicate that fundamental factors, the quality of infrastructure, clarity and fairness of law and regulations, level of tax rates, and labor issues dominate their investment sight considerations. The Multilateral Investment Guarantee Agency (MIGA) survey of 191 companies (MIGA, 2002). 
climate. The clarity of Cabinet policies and consistency and predictability of officials' interpretation of rules for business registration, licenses and permits are very important. Transparency of conditions and duration of procedures for access to land and buildings is critical. GODC is committed to improving the effectiveness of mechanisms for attracting private investment. To this end, the strategic reviews of NDC and DEXIA seek to develop an action plan to facilitate progress along the investment road map, facilitate the potential investors' access to land and other real estate by amending the alien landholding policy and introduce a One-Stop-Shop for investment approvals.

To be successful, the setting up of a One-Stop-Shop cannot be limited to simply re-allocating parts of the process but will to require a re-engineering of the process with less direct involvement of Cabinet and line ministries. The OneStop-Shop will make available clear criteria, rights and obligations for investors and specify the maximum time for the administration's response at each stage of the approval process. Cabinet would specify the threshold value and sectors for projects, which it needs to consider, and the Shop will be authorized to give final approval in all other cases. The One-Stop-Shop will also serve members of Dominica Diaspora by providing information on re-settlement concessions and investment opportunities and conditions. A more pro-active policy for attracting the return of Diaspora members and their reintegration into Dominica's economy should serve to turn the problem of "brain drain" into an advantage of "brain circulation", whereby the returned migrants act as catalysts for transfer of professional and managerial skills to Dominica.

A comprehensive analysis of Dominica's investment climate conducted on behalf of Government by a team sponsored by the USAID, found that there were four overarching issues that required governmental action, and Government will take action accordingly, to: ${ }^{6} /$

Create more comprehensive guidelines for business activity - to include information on critical procedures, including the process of receiving incentives, and on the whole finding how to start and operate a legal business;

Improve the availability of legislation - making copies of important legislation more easily available;

Establish timeframes for government decisions, on the basis of a process reengineering exercise that will identify constraints and bottlenecks; and

Improve dialogue between the public and private sectors with a view to increasing mutual understanding and beneficial engagement.

\footnotetext{
${ }^{6}$ See The Investor Roadmap and Sectoral Analysis of Dominica, USAID, 2004, Volume 1, pp. iii - xi.
} 
In addition to the foregoing four areas, Government will pursue a number of recommendations emanating from the Investor Road Map exercise, with a view to improving the climate for starting and conducting business in Dominica. These are categorized under procedures relating to Employing, Reporting, Locating and Operating, and are listed at Appendix 4 of this document.

Dominica will negotiate and conclude bilateral investment promotion treaties; become a member of the Multilateral Investment Guarantee Agency (MIGA) and the International Centre for the Settlement of Investment Disputes; and, subscribe to international conventions on intellectual property rights.

Reductions of the cost of doing business will be pursued by taking policy and regulatory measures seeking to lower transport costs (including port costs), lower costs for electricity, water, and communications, and the streamlining and removal of unnecessary bureaucratic practices. A National Telecommunications Regulatory Commission (NTRC) already exists for telecommunications. In implementing the Strategy, the Government will establish an independent regulatory commission for electricity and water. The regulators will be charged with working with the utility enterprises on ensuring reliable, quality supply at fair prices for both consumers and producers.

The GOCD will provide direct support and be involved in larger, socially very beneficial investments that might not take place without such support. To this end it will utilize Government-owned lands; offer execution of an increasing share of the PSIP to private participation by outsourcing services that now constitute bottlenecks for PSIP implementation; and privatize some Government organizations and services, including some services of inspection and maintenance of some areas of infrastructure.

Dominica's prospects of maintaining and elevating standard of living hinges on increasing the productivity in both the Government and the private sector. This requires changes in work attitudes away from pressuring for higher wages, improved working conditions and perquisites in holidays and other benefits without a commensurate contribution in increased productivity. To help strengthen competitiveness the GOCD will:

Pursue in its negotiations with the Public Service Unions a wage policy increasingly based on performance and accountability as criteria for salary increases;

Raise and apply consistently higher qualification standards for new employees; Encourage and require training of current employees; and.

Amend labour legislation and regulations, as appropriate, to enhance flexibility in the labour market. 
Improve focus of education; strengthen public training programmes and redirect them towards the needs of export activities.

Soundness of the financial system, with its effects on macroeconomic stability, liquidity, credit supply, and interest rates, is an important element of the enabling environment for private enterprise. The banking system has been little affected by the government debt restructuring and is broadly sound. While the banks are liquid, common complaint of emerging businesses is that they are credit constrained. Banks point to inadequate collateral and financial information supporting loan proposals, and large number of over-leveraged businesses. As a result, banks have increased consumer lending and have placed excess liquidity offshore. To help strengthen financial intermediation, companies need to raise accounting standards to provide appropriate information to banks or equity investors, and the Government will address administrative and judiciary issues to facilitate the realization of collateral. Government will also be conducting a financial inspection and strategic review of AID Bank operations. An action plan is being implemented, with a view of enhancing its efficiency and improving accountability (including strengthening of the loan approval process and reducing administrative expenditures).

Generally, the Government of Dominica commits itself to taking action on a number of structural measures that have been identified as essential to completing the process of laying a platform for economic growth and providing expanded opportunity for private sector expansion. Work is ongoing on the implementation of a number measures, strengthening the financial sector, improving the regulatory framework for utilities, ensuring the efficiency of the country's growth institutions, improving the efficiency of capital spending, improving cash control and management and increasing the efficiency of the public service.

Going forward, Government has committed itself to implement, over the next two-three years the specific measures indicated at Appendix 3, under public sector reform, budgetary and fiscal management, labour market reforms, social protection, improving the investment climate and the regulatory frameworks for energy and agricultural exports.

\section{B. Sectoral Strategies for Recovery and Growth}

The sectoral strategies for the medium-term indicate the most likely growth sectors in the economy. Improvements in the enabling environment for private enterprise would support these sectors in playing a leading role in development. In Small Island Developing States (SIDS), the sectors that contribute most to export-led growth are the sectors that will make the most telling impact. In Dominica, these sectors are the natural resource based sectors of tourism, agriculture, fisheries, and water; manufacturing (agro- 
industries); and information and communication technology (ICT). These sectors are capable of exerting synergistic influences on each other and, in turn, forging strong linkages on the infrastructure and service sectors of the economy.

\section{Tourism}

By all accounts, tourism has the potential for the most rapid growth in the economy because of Dominica's comparative advantages and the current low stage of the sector's development. Government accepts the imperative of paying attention to the development of the tourism sector, both because of its established potential and uniqueness, and the limited opportunities that may be available in other economic sectors. Owing the potential linkages between tourism and other economic and social sectors, a vibrant tourism sector can make a major contribution to increased dynamism in the total economy.

While work is proceeding on a Tourism Master Plan, the Tourism 2010 Policy document will underpin the strategic actions that Government will seek to implement into the medium-term with a view to making a profound positive on the sector, and it is this policy document that forms the basis of this section of the GSPS.

\section{Challenges Facing the Sector}

Dominica's approved "Tourism 2010 Policy" identifies four main challenges facing tourism in Dominica. ${ }^{7}$ These are:

1. The imperative of a "focused commitment to tourism", to be reflected in the inadequacy of a "competitive destination management and marketing budget, and continuing tourism infrastructure constraints;

2. The challenge of positioning its destination and its product to meet the demands of its specialty market;

3. Successfully incorporating local community involvement in tourism and fostering opportunities for local entrepreneurs;

4. Dealing with constraints in investment in the sector, such as limited air access and high energy costs;

Generally, the Tourism 2010 Policy recognizes that Dominica has an excellent opportunity to grow its tourism sector in the light of market trends, and the

\footnotetext{
${ }^{7}$ This section of the Strategy is based on "Dominica - Tourism 2010 Policy", a document that has been officially accepted by the Cabinet as reflecting its tourism strategy into the medium-term.
} 
overriding challenge is to "realize this potential while ensuring that tourism is sustainable ... “.

\section{The Vision for Tourism}

Dominica's vision for the tourism sector as articulated in the approved Tourism 2010 Policy document is as follows:

"Dominica will pursue sustainable tourism that enriches the lives of all citizens by creating economic, social and cultural opportunities, protecting the natural resources and scenic, heritage and cultural features of the country, nurturing community involvement in tourism at sustainable levels, and by creating career paths for the young people of Dominica."

\section{Guiding Principles}

Dominica will be guided by several principles to shape how tourism is developed and managed in order for the tourism sector to achieve the country's vision for tourism. These guiding principles are as follows:

1. Tourism policy and development programmes will be integrated with national economic, social and cultural policy.

2. Government will foster a positive environment for the tourism sector and for meaningful local participation in the sector.

3. Tourism sector planning and management will be based on partnerships and collaboration.

4. Local communities will play a meaningful role in the tourism sector, one that ensures economic, social and cultural benefits to each participating community.

5. All tourism activity will be designed to improve the quality of life enjoyed by Dominica's citizens.

6. Development of the tourism sector will be market-driven.

7. Government will adopt a business model to fulfill their role in tourism sector management - that of destination management.

8. Tourism activity will be private sector-driven. 
9. Tourism policies programme and standards will be integrated with the principles and directions required of the tourism sector arising form Green Globe certification.

\section{Growth Objectives}

Government believes that in light of the robust market, a relatively small tourism sector (particularly the export ready component), and the impending improvements in air and road infrastructure, a target of about a 70\% increase in expenditures by both stay over and cruise arrivals is realistic. The policy will be direct the majority of new cruise business to the Portsmouth area, thereby helping to generate revenue generation for development of new attractions. Because data on the contribution of tourism to the economy is not available, the sector's growth objectives are expressed in direct expenditures by visitors.

The 2010 target for tourism is direct expenditures by visitors of EC $\$ 227$ million with a EC $\$ 200$ million annual contribution by stay over market and EC $\$ 27$ million by cruise arrivals, as indicated in Table 9 .

Table 9. Tourism Expenditures

\begin{tabular}{|c|c|c|c|}
\hline Market Segment & $\begin{array}{c}\text { Current (2004) } \\
\text { Expenditures (\$EC) }\end{array}$ & $\%$ of Total & $\begin{array}{c}2010 \text { Target } \\
(\text { SEC) }\end{array}$ \\
\hline Stay over & $\$ 104$ million & $78 \%$ & $\$ 177$ million \\
\hline Cruise Arrivals & $\$ 30$ million & $22 \%$ & $\$ 50$ million \\
\hline Total & $\$ 134$ million & $100 \%$ & $\$ 227$ million \\
\hline
\end{tabular}

Our country's sustainable tourism objectives will be achieved through its contribution to social and economic development, heritage and cultural protection, and environmental management, and will require focused attention to the following three areas: product development, improvement of tourism infrastructure and strengthened destination marketing.

\section{Product Development Policy}

$\underline{\text { Re-position Dominica }}$

Government will seek the advice of specialist branding and promotion experts with a view to determining whether the "nature island" destination positioning may be too limiting in terms of expanding market positioning from a nature destination to one that encompasses adventure and cultural tourism.

$\underline{\text { Tourism Development Priorities }}$ 


\section{$\underline{\text { Area Priorities }}$}

Government will designate the following as priority areas for tourism sector development, infrastructure development and positioning and marketing campaigns:

a. The Roseau area, where the greatest concentration of internationally competitive tourism attractions is located and which is in close proximity to Dominica's World Heritage Site.

b. Roseau itself as the capital city and home to the greatest concentration of heritage buildings in the country along with waterfront areas, tourism services and a variety of amenities.

c. The Portsmouth area, where more attractions development are expected to take place to accommodate cruise arrivals, visiting yachts and increased stay over facilities.

Table 10. Tourism Contribution and Objectives

\begin{tabular}{|c|c|}
\hline $\begin{array}{l}\text { Contribution by } \\
\text { Tourism To: }\end{array}$ & Objectives \\
\hline $\begin{array}{l}\text { Social and Economic } \\
\text { Benefits }\end{array}$ & $\begin{array}{l}\text { - Creation of job and business opportunities in tourism, and } \\
\text { through enhanced linkages, in agriculture, arts and crafts, } \\
\text { entertainment and music, and service sectors; } \\
\text { - Widespread involvement of communities in the tourism } \\
\text { sector including community resource management; and } \\
\text { - Creation of career paths for Dominica's youth to enter the } \\
\text { tourism sector. }\end{array}$ \\
\hline $\begin{array}{l}\text { Heritage/Cultural } \\
\text { Protection }\end{array}$ & $\begin{array}{l}\text { - Protection of heritage and cultural resources throughout } \\
\text { Dominica with particular attention on community-based } \\
\text { resources; } \\
\text { - Incorporation of heritage interpretive programmes into the } \\
\text { tourism product mix including Roseau, Dominica water mills, } \\
\text { and other features of Dominica heritage; } \\
\text { - Incorporation of community based heritage and cultural } \\
\text { products into scenic parkway programmes; } \\
\text { - Generation of tourism revenues for Dominica's cultural } \\
\text { - } \quad \text { Fosterprises and groups; and } \\
\text { - }\end{array}$ \\
\hline $\begin{array}{l}\text { Environmental } \\
\text { Management }\end{array}$ & $\begin{array}{l}\text { - Enhanced commitment to Dominica's nature resources } \\
\text { including completion of the Green Globe certification; } \\
\text { - Enhanced interpretive programmes at nature sites; } \\
\text { - Development of scenic viewscape protection policies for } \\
\text { - Lominica's coastline routes; and } \\
\text { important viewscapes, scenic corridors and the intimate } \\
\text { feel of the destination as 'the Caribbean as it used to be". }\end{array}$ \\
\hline
\end{tabular}


d. The Melville Hall to Roseau corridor, as a tourism attraction in its own right in the form of a parkway with the central forest reserve, rest stops/viewing/photography pull-offs, and locations for food and beverage/craft purchases and interpretive experiences.

e. Scenic parkway designations for coastal roads enhancing coastal area touring, including the Carib Territory, the Southeast, and the West Coasts, all where specialty lodges, adventure and cultural tourism product experiences should be enhanced.

\section{$\underline{\text { Tourism Standards }}$}

Under the provisions of the NISE Programme, Government has engaged the Bureau of Standards in the development of tourism standards and certification processes. This will foster market-driven tourism standards at all times and ensure that all tourism suppliers meet minimum standards. The national tourism agency will develop and manage a certification and inspection system for this purpose, pursuant to the Tourism (Standards and Regulations) Act.

\section{Export Ready Policy}

In addition to these market-driven standards, Government will adopt an export ready product standard that ensures international market acceptance of its product and enhances the capacity of the country's tourism suppliers to do business internationally. This policy is important for Dominica to pursue, given the emphasis that will be placed in the short term on developing a strong relationship with international specialty tour operators.

Government will focus its destination marketing around its export ready product (accommodation, tours, attractions), and will implement programmes to assist businesses to become export ready as quickly as possible to ensure their participation in destination marketing.

\section{Priority on Stay over Market}

Government will emphasize the development of the stay over market by implementing a programme to upgrade existing rooms where possible to export ready status, and establish an effective investment promotion initiative to add new accommodation facilities in Dominica to meet the tourism policy objectives. 


\section{Cruise Market}

Government will take action to ensure that Dominica remains a competitive cruise destination and will continue to encourage a balanced distribution of cruise arrivals between Roseau and Portsmouth to reduce capacity issues around Roseau and its nearby attractions.

Government policy will foster a cruise market that is matched as closely as possible to Dominica's product strengths, and a market that is encouraged to visit Dominica in the future as stay over customers.

\section{$\underline{\text { Attractions }}$}

Within the context of national development priorities, Government policy will be to enhance and strengthen existing tourism attractions as a matter of priority before proceeding with extensive new attractions. It will proceed with new attractions only where it this is consistent with the national tourism priority niche markets of Dominica, and where there is adequate management capacity. Pursuant to this policy, priorities include:

a. the tourism attractions managed by the public sector (the Ministry of Tourism and National Parks),

b. resolving management of these sites including transferring authority for all sites to the Parks unit,

c. Developing and implementing a business model for public sector attractions management, including market-driven fee structures, product quality control, and cooperative marketing with the NDC.

Government will seek to ensure that public sector tourism attractions are marketed, managed and maintained consistent with global best practices and that the visitor experience including access, hospitability services and interpretive programmes is among the best in the world.

\section{Niche Markets}

Dominica will continue to develop niche markets and prioritize these according to the overall priorities for Dominica's tourism sector, by:

a. building on the success of the dive, adventure and nature niche markets and fostering their expansion;

b. enhancing the development of adventure tourism products throughout Dominica, including consideration for specialty 
adventure products such as camping, tent platform lodges and similar facilities;

c. developing a vibrant community tourism product consistent with the policy directions established in this report;

d. facilitating the development of a yachting segment, focusing on Portsmouth;

e. enhancing cultural tourism including festivals, villages feasts, and local cuisine experiences;

f. developing the health tourism potential including spa and wellness facilities;

g. strengthening and develop product in the sports tourism and agrotourism areas;

h. pursuing the potential for another major travel generator such as golf for Dominica, in the Portsmouth area; and

i. Exploring the country's potential for taking advantage of the bridal tourism market.

In developing these product areas for the stay over and cruise markets, consideration will be given to the day visitor, visitors arriving by ferry or yacht, as well as the domestic market.

\section{Touring and Related Specialty Niche Markets}

In addition to those niche markets above, Government will pursue the development of touring markets for those segments interested in exploring the destination, either as part of packaged tours, independently using rental vehicles, and/or bicycling and walking tours. Government believes that the rich diversity of Dominica's natural and scenic resources, together with its fascinating villages and communities, places the country at the forefront of scenic and cultural touring in the Caribbean.

Dominica has excellent potential for the development of mountain biking specialty products both for touring and in combination with trail systems and adventure tourism products. Government will seek to take advantage of this potential by pursuing special events related to the biking sector (e.g. road races, mountain biking, off-road trails, etc). 


\section{$\underline{\text { Roseau Development }}$}

Government will foster the development of Roseau as a significant tourism experience-combining heritage, culture and city experiences. In so doing, consideration will be given to enhancing an understanding of, and appreciation for, the Roseau Heritage District, introducing themed signage, developing walking tours, ensuring that the proposed road re-instatement project does not compromise the historic "feel" of the community, and upgrading the waterfront to a more user-friendly environment with an excellent waterfront walkway area. A visitor-friendly Roseau will also include provision for access to the river system (e.g. riverside walkways and bicycle trails) and provision for a safer night time experience for dining and entertainment activities.

\section{Community Tourism Policy}

The promotion of community tourism is a high priority for Government because of its potential as both a significant tourism product development and a means of community empowerment.

A community tourism policy was prepared under the Eco-Tourism Development Programme and subjected to wide review. This policy forms an important part of Dominica's national tourism policy and consists of the following:

- actively opening up opportunities for rural communities, local people and informal sector to increase their involvement in the tourism industry, particularly in tourism planning and the running of enterprises;

- ensuring that rural communities, local people and the informal sector have greater access to the benefits from tourism on their land, by creating appropriate legal mechanisms and establishing appropriate incentives;

- ensuring that development of tourism on State lands takes place in areas and in forms acceptable to local people;

- encouraging the formal tourism sector to co-operate and work with the informal sector, and to recognize that as well as being in the long-term self interest of the tourism industry, this is a social responsibility and contribution to Dominica's national development objectives of improved equity, poverty alleviation, and sustainable growth; and

- Ensuring that tourism development within Dominica is environmentally sustainable. 
In implementing this policy, priority will be given to the following activities:

- Development of an inventory of cultural product experiences and work with communities and enterprises to strengthen the cultural product and its accessibility by tourists.

- Preparation of a guide to cultural tourism products and amenities such as restaurants serving local cuisine throughout Dominica.

\section{Environmental Responsibility}

Dominica is far more advanced than most destinations in pursuing environmental protection through a significant national parks and protected areas programme and the Green Globe designation. This progress needs to be matched by environmental practices of private sector operators.

Dominica will encourage the application of environmental walk-through and related programmes to increase the awareness and foster implementation of sound environmental practices by private sector operators. This will include consideration of energy alternatives where feasible and where such alternatives do not compromise national interest and present environmental concerns.

\section{STRENGTHENING TOURISM INFRASTRUCTURE}

As a matter of policy, Dominica will place a priority on continually improving air and marine access and on transforming the country's road systems into touring opportunities to strengthen Dominica's tourism product.

\section{$\underline{\text { Air Access }}$}

Dominica will place the highest priority on enhancing air access to the country, recognizing the improvements in this area are essential to grow the tourism sector. In the immediate term, Dominica will pursue this priority through the following actions:

a. Upgrade the Melville Hall airport to lengthen the runway, construct a new terminal and install night lighting;

b. Provide certainty to the tourism sector and potential investors, regarding the completion date of the airport access project to

c. Initiate discussions with airline suppliers to Dominica to announce the Melville Hall dates, introduce the tourism policy, and commence discussions on enhancing air access consistent with Dominica's tourism policy. 
In the longer term, Dominica will work with the tourism industry to pursue an international airport providing jet access. Such an approach is regarded by Dominica as essential to attract significant investment in tourism sector projects as well as in other economic sectors. In pursuing international air access facilities, Dominica will seek to establish an appropriate public-private sector partnership and financing package for implementation.

\section{Parkway System}

Government will ensure that the proposed two-lane roadway between Melville Hall and Roseau commences as a matter of urgent priority. The roadway upgrading will be reviewed to enhance its development as a national Dominica "parkway" consistent with the national tourism product development policy.

A comprehensive upgrading of the country's road system will be pursued that will foster greater exploration of Dominica's many attractions and communities as well as scenic parkways.

\section{Marine Infrastructure}

Government will seek to capitalize on the potential that its strategic location in terms of marine access from Guadeloupe, Martinique, St. Lucia to Dominica, offers for tourism activity and packaging multi-country tourism vacations. Pursuant to this policy, Government will give priority to upgrading marine access facilities including the creation of a welcoming arrival facility at the ferry terminal that meets international market expectations.

In the Portsmouth area, Government will develop and implement a marine infrastructure facilities plan to support existing marine tourism activities and the creation of a yachting sector to diversify Dominica's tourism economy in this area.

\section{POLICY ON DESTINATION MANAGEMENT}

Government's approach is to undertake Dominica's destination management activities in partnership with the country's private sector. Government's policies are set out below.

\section{Destination Marketing Policy}

Government will adopt a market-driven orientation to destination marketing, including the maintenance of performance indicators and a monitoring system, market research in priority market segments and locations, and a market intelligence function. In the marketing programme, there will be a focus on marketing export ready products to both international and regional markets 


\section{$\underline{\text { Investment Promotion Policy }}$}

Government will align its investment promotion approach to be fully consistent with the national tourism policy. In so doing, it will take into account tourism priorities by type of tourism investment and priority areas and the need to enhance transparency in the application of investment incentives.

In concert with the ongoing restructuring of the NDC, there will be a new focus on the investment promotion function, with the following operating guidelines:

a. an emphasis on attracting investment consistent with the country's national tourism policy and, specifically, investment for new rooms at existing hotels or new hotel development, resolving investment issues related to upgrading existing rooms to market ready status in Dominica where appropriate, and attracting investment for nature, adventure, community and cultural tourism experiences; and

b. development of specific investment promotion strategies pursuant to the National Tourism Policy for the following areas:

Portsmouth

ii. Roseau and the Roseau Valley area

iii. The proposed scenic parkway routes, prioritized by the timing of road upgrading for each.

\section{Policy on Tourism Awareness Programmes}

Government will continue to strengthen its tourism awareness programmes, including at the community level throughout the country.

Pursuant to this policy, a comprehensive programme of tourism awareness will be implemented, consistent with the Tourism 2010 theme, and in implementing the policy, consideration will be given to the following elements:

public awareness programmes including "Tourism Week" events each Fall;

industry awareness programmes, particularly related to market and product trends influencing Caribbean and Dominican tourism;

a programme targeted to Government and the financial and business sector related to tourism and fostering linkages throughout the economy; and 
The introduction of tourism into the school curriculum, modeled after best practices suggested by such organizations as the Caribbean Tourism Organization.

In addition to these initiatives, a comprehensive media and communications programme will be developed and implemented annually as a normal part of the programme of the tourism agency. This will include the maintenance of a Dominica tourism news web site and regular media releases.

\section{Human Resources Development Policy}

Dominica will develop a comprehensive approach to human resources development in the tourism sector, including a partnership with the Dominica State College for training, programme delivery and the delivery of skills training as part of Dominica's effort to provide an internationally competitive tourism product. Dominica will modernize its approach to training for currently needed skills needs and for career path training for young people interested in tourism as a career.

Government will seek to rationalize human resources development in the tourism sector as a matter of policy through:

- initiating discussions with the OAS on delivery of the Skills for Success (small hotels) training programme at the Dominica State College;

- funding delivery of the Tour Guide programme through the Dominica State College and enhancing the programme with best practices from recent initiatives such as the aerial tram guide programme; and

- Developing a comprehensive menu of training programmes for the industry, consistent with the product development and destination management priorities of this National Tourism Policy.

\section{Crime Reduction Policy}

The increasing incidence of crime is having a negative effect on tourism sector growth potential and can jeopardize investments by Government and the private sector in infrastructure, facilities and programmes.

Government will work to enhance visitor security and reduce the impacts of crime on the tourism sector, by fostering a partnership of all stakeholders in the industry as well as communities, the police and the judiciary to develop effective initiatives for crime reduction. 


\section{Cultural Tourism Policy}

Government will ensure that its tourism and cultural policies are complementary and mutually supportive. Pursuant to the national vision for tourism and the repositioning of Dominica as a nature, adventure and cultural tourism destination, Government will foster the development of cultural tourism products and experiences. Specific initiatives will include:

1. Alignment of the National Tourism Policy with Dominica's cultural policy framework to ensure complementarity and consistency;

2. Partnering with the cultural community to identify cultural tourism product development initiatives for consideration by the NDC and the private sector;

3. A working group of Government and cultural tourism stakeholders to work with communities to identify cultural tourism products for the proposed scenic parkways throughout Dominica. This could include both community-based tourism products and cultural experiences such as roadside fruit stands, restaurants and bars;

4. An enhanced calendar of cultural events, including community-based events, as demand dictates and in parallel with growth of the tourism sector; and

5. A special cultural programme for Roseau that features everything cultural from Roseau's heritage to its local cuisine, specialty bakeries, arts, crafts, music, performing arts and other entertainment.

\section{Tourism and Land Use Planning Policies}

Government will ensure that physical planning policies developed during the outline physical plan preparation in 2005 are integrated with and support the implementation of this national tourism policy.

Recognizing the importance of this plan to guide all future land use development, it shall be Government's policy to:

Ensure that the plan is positioned as a physical development plan for approval by Dominica; and

Ensure that the planning process includes provision for a tourism development "plan within the plan", providing a land use policy framework that both guides the growth of the tourism sector and 
protects Dominica's natural, heritage and cultural resources for future generations and as assets for tourism enterprises (both public and private sector).

Recognizing also that the land use plan will take some time to prepare, Government will develop and adopt a series of tourism-related planning policies in the short-term. Government believes that this is important to alert the investment and development community to the directions that Dominica is taking in physical planning as it relates to tourism. These are broad policies and will be detailed as part of the physical development plan and are as follows:

Use the tourism development priorities as a guide in consideration applications for development and discussing investment possibilities with potential investors;

Develop comprehensive policies on viewscapes for all touring routes in Dominica, with particular emphasis on coastal routes;

Develop a policy on quarry development;

Develop a signage policy taking into account impact on aesthetics throughout the country; and

Formally adopt the Roseau Heritage District Plan.

\section{$\underline{\text { Heritage Protection Policies }}$}

Government regards the heritage and cultural resources of the country as important components of Dominica's destination appeal. Accordingly, Government will foster coordination between the tourism sector and those involved in heritage protection to identify tourism interests, ensure collaboration between Government, property owners and heritage NGOs, and facilitate the development of heritage tourism products including interpretation and guided tour activities.

\section{Disaster Preparedness}

Recognising the potential for annual weather-related tourism sector disasters, Government will develop a disaster preparedness programme for its tourism sector that it can apply when necessary to reduce the scope and the extent of negative impacts from such disasters. This will be developed in collaboration with emergency preparedness authorities. 
IMPLEMENTING THE NATIONAL TOURISM POLICY

Government recognizes the critical importance of putting in place mechanisms for the effective implementation of the national tourism policy. Led by the Ministry of Tourism, effective implementation will require the productive engagement of a variety of stakeholders including the private sector, local government and communities, other ministries and agencies of Government, the media as well as non-governmental organisations.

Government will put in place a high-level task force to include relevant government agencies as well as the various stakeholders to oversee implementation of the tourism policy and to implement the detailed action plan that has already been formulated, and which will be reviewed on an annual basis. The task force will submit an annual report to the Cabinet to include recommendations for adjustments to the action plan.

\section{Agriculture}

Agriculture has the potential and opportunity for rapid growth because of under-utilized capacity due to declines in banana production and the abandonment of lands. Agricultural objectives for the medium term are to achieve sustained growth in production and exports, and to increase employment and incomes, which would enable agriculture to play a more dynamic role in the economy. Critical to the attainment of these objectives is increasing productivity in agriculture. Growth in agriculture is dependent on diversification, because the prospects for bananas are poor because of Dominica's low productivity per acre as well as exogenous external conditions. However, diversification requires similar conditions to those enjoyed by the banana industry, i.e., considerable attention and support, risk management, easy marketing and financing. For smallholdings, intensive agriculture that concentrates on high-valued crops such as spices, peppers, flowers and selected vegetables can yield higher economic returns than can be realized from bananas. Diversification through the production of other crops mentioned can be accelerated by the utilization of idle lands and constitutes the main means of increasing agricultural production during the medium-term.

The major obstacle to agricultural development is the relatively high cost of production per acre in comparison with other Windward Islands OECS countries. This is due to a combination of land conditions (the hilly terrain, small uneconomic sized lots) and the low productivity of agricultural labour, which results in high real wage rates in agriculture. Improving labour productivity is one of the most significant challenges of agricultural development in Dominica. There are other challenges and obstacles relating to land use, availability and ownership. A critical impediment to the development of agriculture, tourism, and housing is the lack of a land-use planning or wider Human Settlement 
Policy. This aspect will be dealt under the section of this document entitled 'Construction and Housing'.

Over the medium-term, the objective of sustainable growth of the sector will be pursued through three key result areas:

1. Sustainable growth and development of the sector;

2. An enhanced enabling environment for investment in agriculture; and

3. Sustainable use of natural resources;

The sustainable growth of the sector will be pursued by:

a) Proactively working to enhance agricultural production, productivity and competitiveness through:

Crop diversification into passion fruit, hot peppers, plantains, culinary herbs, exotic crops as well as new crops with potential value as food crops;

Assisting in the preparation of client business plans;

Providing irrigation infrastructure;

Rehabilitation of farm access roads;

Providing product development support through technical assistance, auditing, post harvest and other support;

Renewal of the citrus rehabilitation programme;

Establishment of a fodder bank and pasture at the Central Livestock Farm as well as crop and livestock input revolving schemes;

Facilitating the use of idle lands through favorable leasing or rental conditions; and

Introducing technologies that will increase productivity and attract young people to agriculture.

b) Facilitating trade and investment in the agricultural sector through:

Production of HACCP plans for agriculture and fisheries;

Ensuring EUREGAP certification and monitoring for all banana farmers;

Assisting in the preparation of at least 20 investment proposals; and

Giving focused attention to improving the marketing of agricultural produce and encouraging the export of these products in primary or processed forms;

Pursuing more aggressively niche market investigations and penetration for specialized products such as organics, herbs and spices, and fruits and vegetables;

Embarking on Programme of action to establish Dominica as an 'Organic Island' with a view to establishing and agricultural practices that will 
reduce the introduction of harmful substances into rivers and soils and establish a sound and sustainable basis for the growth of the agricultural sector;

Improving micro-credit in existing financial institutions for small-scale operators and re-cropping of idle lands; and

Focusing public investment in agriculture in areas that will elicit or are supportive of private investment.

c) Promoting sustainable development of natural resources, through:

Working to increase by $50 \%$ the number of agro-forestry farmers; Implementation of projects to expand organic banana production, improve integrated pest management; and increase the utilization of farm organic waste.

d) Improving food security, through:

Proactively supporting increased food and livestock production; and Completion and effective implementation of the SPFS project.

e) Ensuring that research and development, and information dissemination effectively promote the competitiveness of investments in agriculture.

As in every other aspect of the economy growth of the agricultural sector will only result from increased investment in the sector, with consistent and facilitative support from Government. It is a major responsibility of Government to work to provide an enabling policy and regulatory environment in support of the growth objectives of the sector. An enhanced enabling environment for investment in agriculture will be achieved through:

- Modernizing the legislation governing plant protection, animal health, food safety and other relevant legislation;

- Gazetting of new fisheries legislation;

- Completing a land use plan for the country, the preliminary version to be completed by mid-2006;

- Formulating and implementing a policy for use of Dominica's biological resources for bio-prospecting;

- Reviewing and streamlining all procedures for investing or starting a business in the agricultural sector; including the appropriateness of the incentives regime as applies to the sector;

- Formulation and implementation of clear policies on organic agriculture and food security;

- Improving enforcement of and reviewing legislation pertaining to praedial larceny; and

- Amending wage legislation to provide for an hourly rate for agricultural workers. 
It is critically important to the future development of Dominica that Government promote the sustainable use of the country's natural resource base, and that the use of the country's natural resource base be optimized, and long-term sustainability considerations not compromised for the sake of short-term needs.

The objective of improving the sustainable use of the country's natural resources will take into account the role of forestry in adding value to the tourism product, and in preserving wildlife and water resources. It will be achieved through:

- Implementation of a targeted public awareness and education campaign;

- Development and implementation of the (NEMS) National Environmental Management System;

- Conserving genetic diversity, and ensuring sustainable use and proper management of the island's system of national parks and eco-tourism sites, through inter alia taking appropriate action in regard to the occupancy and use of lands on national parks and forest reserves, development and maintenance of trails, collection of user fees; maintaining the wildlife population at sustainable levels;

- Reducing user conflict and promoting sustainable use of all natural resources, through greater collaboration with other agencies of Government and formulation of a coastal zone management plan.

- Promoting land conservation and rehabilitation for agricultural production, through, inter alia, preparation of a national action plan for the reclamation of degraded lands and the conservation of areas at risk;

- Maintaining ecological processes and life support systems in forest reserves, national parks etc., through data collection and appropriate policy interventions;

- Improving water management through preparation and execution of a national water management policy; and

- Promoting the sustainable utilization of forest products.

In support of the foregoing strategic objectives for agriculture, improvements will continue to be made to Government's capacity for data gathering, analysis and utilization to inform and facilitate policy formulation and planning in the sector. A necessary complement to the other strategic objectives of the sector is the enhancement of the capacity of Government to undertake its responsibilities and pursue its commitments, and Government will continue pay attention to this area through taking maximum advantage of opportunities for specialized training in areas of relevance.

It is not the purpose of this document to provide a full analysis of the myriad of problems afflicting the sector, but it is clear that Dominica's agricultural sector certainly has some major challenges to face - issues of production, 
productivity, the cost of labour, competitiveness, marketing and transportation. These issues are all inter-related, thus pointing to need for a comprehensive approach to the sector. It is also true that the policy responses to these issues do not rest exclusively with the sector itself. Indeed the Ministry of Agriculture is working on a comprehensive long-term plan for the sector that should be available in mid-2006. In the meantime, it is expected that the strategic actions identified in this section will contribute to increasing the output and productivity of the sector if the necessary resources are sourced and the actions are effectively executed. The issues of marketing and transportation reside in the domain of the private sector, although these areas have proven to be especially difficult. An ongoing strategic review of DEXIA is expected to be completed by end 2005 and will assist Government both to define its role in marketing and transportation and the specific areas of engagement of DEXIA itself. Government recognizes the critical importance of transportation in the marketing of Dominica's agricultural commodities, especially to neighbouring Caribbean islands, and will to do everything possible to increase private sector interest in this area.

All indications are that the banana industry that has been Dominica's lifeblood for more than 50 years will not be in a position to contribute to growth and poverty reduction at anything nearing past levels. A realistic vision for the sector is of a greatly reduced industry - 400 banana farmers producing high quality bananas that qualify under 'fair trade' or 'organic' labels, and satisfying niche markets that will pay a higher price than is traditional. The challenge is to produce and market 'niche' bananas, (much as the tourism challenge is to differentiate Dominica from other destinations based on a tourism product that is special and different).

Government will facilitate this process by:

- Continuing to intervene with the European Union to make grant funding available for infrastructural support to the banana industry, in particular the continuation of the Irrigation and Drainage Programme;

- Through the European Union-supported Enterprise Development Programme, to make resources available to farmers who need to invest in irrigation equipment in order to bring water onto their farms; and

- Actively promoting the interests of the banana industry in regional and international forums; and

- Continue to partner the Dominica Banana Producers Ltd. in its comprehensive Banana Development Programme, which aims to increase levels of production.

The limited expectations regarding the performance of the banana industry place a greater performance burden on non-banana agriculture, if the sector as a whole is to increase its contribution to GDP over the medium- to long-term. The expectation is that agriculture will continue to have an important role to 
play in the realization of Dominica's growth prospects, and Government will be an enabler in this process. The hope is that public investment will demonstrate Government's confidence in the sector and serve to conduce to, and facilitate, increased level of private investment

\section{Fisheries}

\section{Characterisation of the Sector}

Dominica's fishing industry is relatively small and artisanal in nature, employing just over 3,100 fishers, 996 on a full-time basis. The majority of fishers are opportunistic (farmers), operating on a part-time and subsistence level, targeting various species within the twelve mile territorial sea limit. They sell any surplus in catch to supplement their income. The sector is predominantly dominated by men who engage in all of the components of the industry including fishing, vending, boat building, and gear construction operations among others. Fragments of women's involvement at the family level as vendors and secondary processors of fish are emerging at the more prominent fishing communities of Scotts Head, San Sauveur, Newtown and Portsmouth.

The fishing fleets consist of traditional floating rafts, dough-out canoes, and variations of wood and fiberglass vessels ranging from five to 27 feet lengths. These vessels are characterized as day-boats because of their open hull structure, limited space, an absence of navigational aids and amenities to allow for longer fishing trips beyond twelve hours. Intermediate fishing vessels capable of spending up to five days at sea although present in very small numbers (only four registered) are considerably under-utilized. In most cases, fishing operations are centered along coastal communities where land base sea access is feasible. There are thirty-two recognized fishing communities on the island. Fishing operations have predominantly occurred within the twelve-mile territorial waters, however with the re-introduction of fish aggregating devices in the late $90 \mathrm{~s}$, increasing effort is being registered up the forty-five mile radius from the coastline. The modern fleet consists of about 735 registered pirogues made of wood encased with fiberglass and fiberglass vessels.

Fish landings have been increasing in recent years but only amount to about 1,400 tonnes. This volume of landings is unable to meet domestic demand for fish, resulting in considerable imports of fish and fish products. In recent times, the characteristics and dynamics of the industry have shifted to constitute a greater emphasis on the offshore pelagic species of tuna and marlin. Emphasis on inshore net fishing operations and traps are of lesser importance due in part to development programmes aimed at reducing the fishing effort in the near shore areas. These fisheries will however continue to be of importance contributing to employment creation, poverty reduction and food security, and livelihood needs. 
Fish spoilage and relatively low fishing effort are common phenomena of the fishery. Spoilage issues that stem from a multitude of factors can be characterized as resulting from persistent traditional attitudes of fishers, low levels of technology incorporated into the fishing operations and a general unwillingness on the part of the consumers to demand/accept higher standards of quality for landed fish. Further, structural limitations of the fishing vessels (lack of chill storage capacity) contribute to this effect.

Fishing effort of 2.35 days weekly has been estimated as the national average. This is in part a result of the high proportion of part-time operators who of ten view limited fishing activities as one part of their livelihood portfolio that includes a mix of other subsistence activities. In addition, few fishers see the potential of fishing a potentially viable major occupation/enterprise and are content to continue engaging in fishing as a low input/low output activity.

Biological and environmental factors including seasonal variability and distinction in the fishery types alongside issues of access to and from the resource may be a significant constraint.

The unilateral involvement of fishers in all aspects of the industry is being transformed by the demands for greater efficiency, effectiveness and productive outputs. As a result, a greater degree of compartmentalization in the sector is being realized. Operational units that clearly demarcate roles and functions within the industry are emerging. These include functions such as fishing, marketing, and support services (such as procurement of equipment, repair and maintenance of equipment); provide windows of opportunity for the establishment of new enterprises that provide prospects for employment creation, contributions to food security, greater economic activity and increased contributions to the Gross Domestic Product (GDP). This changing dynamism within the industry is attributed to recent advancements in fisheries infrastructural development reflected in the Roseau and Marigot Fisheries Complex as well as FAO and Dominica Rural Enterprise Project (D-REP) based landing site improvements around the island.

\section{Prospects for the Fisheries Sector}

The Fisheries sector is poised for expansion because of government's commitment to improving the basic fisheries infrastructure through the development of seven zonal centers and to enact an appropriate legal framework to achieve the management targets for the sector. In the strategic fisheries infrastructural plan, government seeks to develop greater centralization of fishing activities by consolidating limited resources and upgrading the facilities at Marigot, San Sauveur, Anse De Mai, Portsmouth, Fond St Jean/Stowe, Roseau and Scotts Head to serve as the major centers for fishing operations island wide. The recently completed fisheries complex at 
Marigot is instructive of the type of development to be undertaken with assistance from the donor community and friendly governments.

Such developments are critical to meeting Dominica's integrated development goals in areas of tourism development (equitable allocation of finite coastal resources for alternate uses), sustainable use of our limited physical and biological marine and coastal resources, domestic and international requirements for trade in fishery products (Sanitary and Phytosanitary Standards), and prudent use of scarce financial resources. It is anticipated that the fisheries sector will allow for greater contribution to GDP, through creation of optimal employment opportunities and disposable income earnings in the sector, provide for greater social and economic stability at the community level (poverty reduction), food security and reduction in the nation's import bill as well as the earning of foreign exchange from fish export.

While the near-shore fishery operations are expected to decline in production out and employment opportunities, the offshore fishery is expected to grow at a rate of three to five percent annually given existing trends. The decline in coastal fishery operations will be cushioned by an anticipated rapid increase in water-sport activities as more and more of these areas are allocated for alternative uses. The extent of growth in the sector will be hinged to the rate of implementation of the fisheries infrastructure improvements to meet requirements of international standards to facilitate fish export trade, improve access to and from sea, and the overall capacity to process greater volumes of catch.

The advent of the CARICOM Single Market and Economy (CSME) will create new challenges for the fisheries sector. Local operators in the sector will be challenged to maintain a competitive advantage and viable market shares in a hostile environment. The effects of dumping of cheaper products originating from Guyana and Trinidad \& Tobago for example on the local market will compromise efforts towards poverty reduction, and social and economic stability at the community level due to their lack of capacity to produce at competitive cost.

\section{Constraints}

While the fisheries sector remains poised for expansion in the medium-term, the realization of appreciable growth is dependent on the ability of its human resource quickly to adopt modern-day skills and technologies, and to evolve from present cultural practices that hinder meaningful progress. The availability of accessible investment capital to fishers and potential investors in the sector is severely challenged by existing policies of lending institutions and insufficient willingness on the part of international donor to provide support for developing fisheries. This is further compounded by cultural influences and a 
general lack of capacity on the part of the players in the fishery sector to culture good entrepreneurial practices and skills.

Other factors affecting fisheries development in Dominica are:

an unwillingness on the part of fishers to engage in cooperative management of their limited resources;

the sector is dominated by a high percentage of part-time operators with low productive outputs, very poor entrepreneurship skills, inadequate equipment and a general resistance to adopting new technologies and higher standards of operations;

poor management of the resources (open access fishery), including the lack of effective surveillance of Dominica's EEZ;

rapid rate of habitat degradation from multiple factors including poor fishing practices;

lack of appreciation by the general populace of the potential and importance of the sector;

inadequate written policies for the fisheries sector; and

Lack of adequate legislation to manage the fisheries sector.

\section{$\underline{\text { Strategies for a way forward }}$}

Government will put in place a number of measures to ensure fisheries development during the medium-term, and these will include the following:

- Improving fisheries management by putting in place appropriate fisheries regulations under the Fisheries Act and implementing a licensing and fees system for vessels and fishers, including foreign vessels. This system will also cover sport fisheries and water sport activities (including whale watching, and scuba diving etc.). Revenues potential from these operators fees could easily exceed $\mathrm{EC} \$ 100,000$ annually during the medium-term.

- The establishment by GOCD of a policy on the commercialization of the sector in order to manage and operate fisheries complexes along viable lines and to stimulate entrepreneurship among stakeholders. The policy will allow for the establishment of public /private sector investment arrangements, which might require initial government subsidies or establishment of an easy access development fund that would allow the private sector entities to be responsible for the commercial use of the complexes and the associated developments, thereby enabling the Fisheries Division to concentrate on the management and regulation of the primary fisheries and at the same time improve the investment climate in the sector. 
- The development of offshore fishing capability by encouraging private sector investments in intermediate-sized fishing fleets by establishing an enabling environment for investment primarily in areas where artisanal fishermen do not operate.

- Increasing the surveillance of fisheries by the Coast Guard, particularly in offshore areas within Dominica's EEZ, by contributing to the costs of this surveillance.

- Development of the infrastructure essential for the stimulation of private sector interest in the sector. This will include the construction a fishing complex in Portsmouth, San Sauveur, Scotts Head, Anse De Mai, and Fond St. Jean/Stowe.

- Upgrading the knowledge, skills and technology of fishers by ensuring minimum standards for entry into the fishery and establishing an institution for the transfer of knowledge, technology and skills through public sector led initiative, and develop and implement educational programmes targeting fishers and consumer of fish.

- Encouraging regional integration of fisheries management and strengthen national management authorities. This will allow for greater and better participation at the regional and international forums on fisheries and fisheries related issues.

- Eliminating trade barriers to allow better access to external markets. This will be accomplished through the establishment of the various national standards required to ensure international compliance and certification of national institutional and operations.

- Broadening the window of opportunities in the sector through compartmentalization and reallocation of resources for alternate and new uses; and

- Encouraging greater involvement of women in the operations of the sector through incentive driven approaches.

\section{Manufacturing}

a. $\quad$ Agro-industries

Agro-industries play a part in Dominica's manufacturing industry. An AgroProcessing Sector Policy was formulated in July 2002, (Agro-Processing Sector Policy Paper to Promote Agro-Industrial Development, Ministry of Agriculture \& the Environment) and a number of specific measures were identified for boosting agro-processing output. Agro-processing provides good opportunities 
for employment generation during the medium-term since it is a natural resource based industry that can be internationally competitive, and there are good market prospects for agro-industry products (tropical fruits and vegetables) in North America, Europe and in the CARICOM region. Agroprocessing can play an important role in reducing post-harvest losses in agriculture that are very significant for fruit and vegetables and which adversely affect returns and incomes in agriculture. Agro-industries are also amenable to small-scale cottage type industrial development. Despite these advantages, agro-processors face many difficulties: the high cost of sourcing agricultural raw materials in Dominica; the obtaining of capital for development, particularly for small-scale enterprises; transportation and marketing problems, including lack of market intelligence; and inadequate institutional support by DEXIA.

Government's strategy towards agro-processing is broadly the same as for the manufacturing sector as a whole - to reduce barriers to growth and create an environment that will enhance the performance and competitiveness of manufacturing firms and contribute to efforts to attract investment.

The strategy will be achieved through:

Agreeing on a private sector strategy for facilitating development of manufacturing, including the creation of a business incubator service;

Improving the operating environment from a policy and regulatory perspective, including the streamlining of business-related bureaucratic processes;

Improving the competitiveness of its economic infrastructure, particularly in regard to transportation and electricity;

Ensuring that the education system prepares individuals to make effective contributions to a modern, productive workforce;

Assisting small firms with market research and intelligence through national and regional institutions; and

Working with the private sector organization towards improved and institutionalized relations between the private sector and Government.

\section{b. Water}

Water is a natural resource that Dominica has in abundance, and its quality ranks with the best in the world. Dominica's fresh water resource is managed 
by the Ministry of Agriculture and is largely utilized by the Dominica Water and Sewerage Company (DOWASCO), which uses fresh water catchment areas to operate numerous water supply systems to provide safe pipe borne water to the population, and the Dominica Electricity Services Limited (DESL), which operates one hydro-electric plant with the capacity to generate almost fifty percent of required kwh annually. There is a close linkage between water and tourism and agriculture. Dominica's Fresh Water Lake, the Emerald Pool, and Trafalgar Waterfall among many others, attract high numbers of tourist visitors. The need to utilize Dominica's water for irrigation in the agricultural sector is receiving increasing attention because of periodic dry spells that have had the effect of reducing output in agriculture, including bananas.

Dominica's water resources also face a multiplicity of risks from natural and manmade causes. The country's vulnerability to natural disasters results in soil erosion, sedimentation, and a reduction in basal flow. There is therefore an increasing need to protect fresh water catchment areas through reforestation and regulation. Agriculture has also posed its own set of risks to the water resource. The penetration into the mountainous forestlands during the lucrative years of the banana industry destroyed many watersheds. The continued use of dangerous chemicals in agricultural production has had negative implications for fresh water and the ecosystems. Finally, developments in infrastructure and tourism pose other risks. These indicate that overall management of water is essential to the sustainable development of Dominica's water resources. An important aspect of this management is that water is a public property resource, and the GOCD is entitled to obtain some resource rents, in the form of royalties and environmental levies, from the exploitation of the water resources, (this is also pertinent to fisheries).

Given the high quality of Dominica's water, there is tremendous potential for exports of bulk and bottled water from Dominica. Large investments in bulk water infrastructure were undertaken by DOWASCO many years ago but this infrastructure remains largely unutilized. Bottled water is produced by two companies, Dominica Brewery and Beverages Company Limited and Josephine Gabriel and Company Limited. Their products are marketed mainly in the domestic market but they also export products to the regional markets. One company is now finalizing market access to the United States and the other is negotiating a joint-venture arrangement with a French company that might lead to market access in Europe. Recently a joint venture with DOWASCO has been established to market bulk and bottled water. These developments may suggest that the water industry can become a major commodity export and play a significant role in Dominica's development in the medium term.

Government will seek to facilitate further development of the water industry by taking action on the following measures:

Protecting the forests reserves and catchment areas for water and monitoring more closely fresh water levels and quality; 
Establishing a royalty and / or environmental levy regime for water for private sector enterprise operators based on the value of their water sales; and

Facilitating the production and marketing agreements for bulk and bottled water, including the sourcing of bulk water and the upgrading of the bulk water facility for exporting bulk water.

\section{Information and Communications Technology (ICT)}

The GOCD recognizes that ICT can play a critical role in Dominica's development since it can improve the performance of the private sector, increase access to and the quality of education and health care, increase the transparency and accountability of government institutions, improve service delivery to the poor, and give the poor a voice in decisions that shape their lives [OECD (2003), Policy Brief: Integrating Information and Communication Technologies in Development Programmes]. In recent years, the GOCD undertook a feasibility study, financed by CIDA, which considered the potential for a fully integrated ICT agenda. The result was the formulation of a project proposal, Dominica Government Enterprise Network (D-GEN). This proposal envisioned the application of a state-of-the-art broadband wireless system capable of adapting easily to technological changes, commencing with the government sector (D-GEN) but also extending to NGOs and the private sector. The proposal was not implemented due to lack of funding and corporate direction. However, it provides a model for ICT development in Dominica, aspects of which are incorporated in an ICT policy for Dominica that is being developed in conformity with an OECS Policy and Strategic Plan [GOPA Consulting Services, (2002), Final Report and Strategic Plan, OECS.], which has as its objective the development of ICT as a leading sector in OECS economies.

The strategy for this development during the medium-term includes the following:

The GOCD will give formal approval to its ICT policy and strategy that will include areas for intervention, and considerations of human resource development, marketing, interagency collaborative mechanisms and fiscal incentives.

GOCD will enact E-commerce and anti-competitive legislation and review the Telecommunications Act with a view to making any necessary amendments to facilitate development of the ICT sector. 


\section{Other Sectors}

The growth strategy in effect is based on the premise that the growth sectors and sub-sectors covered will induce growth in other sectors of the economy. However, with the exception of the government services sector and the financial sector that have been dealt with above, the other sectors and subsectors of the economy critical to growth are construction, energy, and transport.

\section{a. Construction and Housing}

Construction is an important economic and employment sector in Dominica. In 2004, it was the fourth largest employment sector and the seventh largest sector in terms of GDP in the economy. Residential buildings (Housing) account for about $75 \%$ of all construction activities. The demand for new and replacement housing, for all income groups, is estimated to average 400 units a year [A report on the Preparation of Shelter Development Projects - Dominica, commissioned by the Caribbean Development Bank, August 2000] but housing starts account for less than 35\% of this, mainly because of relatively high construction costs and difficulties in obtaining financing. The GOCD's policy for housing is one of encouraging people to build their own homes, i.e., relying essentially on private enterprise, with government involvement focusing on the utilization of government-owned lands and delivering serviced lots.

During the period covered by the GSPS, Government aims to develop the following housing projects:

$\checkmark$ The Union Estate Housing Development;

$\checkmark$ Jimmit Housing Development Phases III and IV;

$\checkmark$ Hillsborough Housing Development;

$\checkmark$ Geneva Housing Development;

$\checkmark$ Chance Housing Development;

$\checkmark$ New Chance Housing Development;

$\checkmark$ Charlotte Valley Housing Development;

$\checkmark$ Canefield East Extension Phases I and II;

$\checkmark$ Plat Mapier Housing development;

$\checkmark$ Bellevue Chopin Village Extension;

$\checkmark$ Cotton Hill Housing Development;

$\checkmark$ Bath Estate Housing Project; and

$\checkmark$ Fond Thomas Development at Pointe Mulatre.

Achievement of these objectives will obviously depend on private sector response, but Government will be doing everything possible to facilitate their achievement in the ways identified above. 
In the Budget Address of July 2005, Government announced its multi-pronged approach to generating activity in the housing sector:

- Continued implementation of the Shelter Development Project. This three-year project commenced in 2004 and consists of three main components: 1) the development of a National Shelter Policy; 2) a Special Mortgage Programme (SMP); and 3) technical assistance.

- For very low-income earners, Government through the Housing Development Corporation (HDC) has conceptualized and will implement a cooperative strategy to increase the provision of affordable housing to the low-income earners in our country. The HDC will implement an approach that will build on the coup de main traditions of our country to construct housing shelters for this target group of Dominicans. Government expects that 60 units per year will be made available through this method, making for 300 such units over the next five years.

- Government embarking on public-private sector partnerships for purposes of two of the housing projects identified above, i.e. the construction of 247 houses at Hillsborough Gardens and 92 apartments at Bath Estate.

- Government will be taking action to solve the problem regarding unregistered land and land ownership without title. There are presumptive 'land owners' in this country who have inherited or otherwise 'own' land in this country, but are unable to use these lands for housing construction or other development or for collateral for purposes of obtaining loans from commercial or development banking institutions. Government will make the services of its Lands and Surveys Division available to assist persons who are unable to pay for the services of private surveyors and who are therefore deprived, by dint of their financial circumstances, of putting these lands to work for them.

- Government has decided to grant to low-income earners a one-year waiver of the transfer fees that would normally be applicable.

- Government was working closely with its Physical Planning Division with a view to speeding up the process of obtaining planning approval for housing projects, and to otherwise rationalize and improve the functioning of the Housing Division.

- Finally, in the context of its evolving policy on the Dominica Diaspora, Government will be encouraging these Dominicans to invest in retirement homes by creating an enabling environment for their doing so. 


\section{b. Energy}

The rising world oil prices that commenced in 2004 constitute an economic shock for Dominica's economy. These increased prices will increase transport costs internationally and nationally, and will accentuate Dominica's problems with competitiveness. On the other hand, they will lead to energy conservation, and the development of alternative sources of energy. Dominica has potential in geo-thermal energy, and the economic feasibility of this potential is being examined in light of the world energy price situation.

The objectives for the energy sector are to minimize price increases for energy in the economy, to diversify energy sources and reduce the reliance on fossil fuels, and to conserve energy. The GOCD has taken action with respect to electricity with the privatization of the DESL in 2004 with the sale of shares to WRB Enterprises, a US company. An extensive expansion programme will be implemented during the medium-term. The GOCD will enact the Electricity Supply Act that will de-monopolize the energy sector and intends to establish a Regulatory Commission for electricity that will put in place a tariff structure that will be more reflective of production costs. The measures for energy during the medium term are:

The GOCD establishing the Regulatory Commission for electricity and energy.

The GOCD reexamining the feasibility of thermal energy development and encouraging development by private enterprise.

The utilization of the licensing and tax system to favour the use of energy efficient vehicles and energy saving devices such as solar equipment and batteries.

\section{c. Transportation}

Dominica suffers from high external and internal transport costs that adversely affect its international competitiveness. There is little control of external sea and air transportation where rates are established internationally and are influenced by world fuel prices. Internal transport costs, as mentioned earlier, are high because of the poor state of the road network. Dominica has a total road network of $812 \mathrm{~km}$ subdivided into three categories: main roads $(336 \mathrm{~km})$, feeder roads $(350 \mathrm{~km})$ and secondary/village roads $(126 \mathrm{~km})$. The present stock of roads consists of $572 \mathrm{~km}$ of asphalt, $33 \mathrm{~km}$ of concrete, $64 \mathrm{~km}$ of gravel and $145 \mathrm{~km}$ of dry-weather roads. A 1995 survey revealed that $45 \%$ of the roads were poor or fair. They have since deteriorated further because of a reduction in expenditures on road maintenance by the Ministry of Communications and Works. The GOCD policy on roads is oriented to improving the quality of the present road stock, but has been unable to do so because of the lack of an appropriate maintenance strategy and funds for its implementation. 
The measures for transportation during the medium-term are:

The development of a Strategic Plan for Road Maintenance and Enhancement for the Ministry of Communications and Works with the objective of attaining an $80 \%$ quality rating within five years and the securing of donor assistance for its implementation.

Improving the efficiency and productivity of the ports by the Dominica Ports Authority (DPA) to keep handling charges stable.

Airport improvements and improved access roads (already mentioned under tourism).

DEXIA encouraging cooperative private sector activity for bulk transportation of Dominica's exports and imports.

\section{d. Micro-business Development}

For the poor (especially in urban, but also in rural areas), micro and small businesses can be an important source of income and employment (including self-employment). Micro and small businesses also cater to all citizens, not just the poor. Currently, programmes aimed at assisting people to establish and operate micro and small businesses focus on providing credit and associated training (e.g. NDFD).

Studies indicate that micro and small businesses face more problems than just access to credit: "access to growing markets, new technologies and appropriate training are often as important as or more important than financial constraints" ${ }^{\prime 8}$ Among the types of services that micro and small businesses may need are:

○ Training;

- Business advisory/consulting services;

- Market development services for both inputs and outputs, including market intelligence and facilitating linkages with buyers and suppliers;

- Support facilities (business incubators, association-based services); and

- Product research and development.

In light of these potential needs, Government will seek donor agency support for the creation of a micro and small business development centre. Its functions would be to:

\footnotetext{
${ }^{8}$ Barton, Clifton, Micro-enterprise Business Development Services: Defining Institutional Options and Indicators of Performance, U.S. AID, 1997
} 
1. Assess the needs for specific services (including services for individual businesses as well as for community-run businesses in rural areas);

2. Develop programmes to meet identified needs and secure donor funding for each programme;

3. Retain private sector businesses and individuals to provide the programme services under contract;

4. Co-ordinate programmes with other institutions that provide credit to micro and small businesses;

5. Promote the availability of these services, in association with NGOs such as SPAT, in local communities emphasising the need for committed communities and individuals to develop business opportunities that the centre could then support ${ }^{9}$,

6. Develop a national ideas competition for new business opportunities.

7. Establish an association of micro and small business owners to access supplies and services on the most favourable terms.

This centre would be staffed by two international specialists in micro and small business development under contract for a two year period, with support staff seconded from existing NGOs and institutions such as SPAT, NDFD, and AID bank. It is recommended that two of the support staff should be trained so that they could take over the centre at the end of the specialists' contracts.

\section{e. Developing our Human Resources}

It is widely accepted that global economic reforms, together with the rapid increase in knowledge-based economic activity and the increasing pace of improvements in science and technology, are fundamentally reshaping the priorities for the education system. While Dominica has made considerable strides in the delivery of education and training to its citizens, including the attainment of universal secondary education in late 2005, Government will continue to seek improvements in quality and relevance.

Government accepts that: "The skill endowments of the labour force are indispensable for technology absorption, productivity improvement, diversification and overall competitiveness. Building a strong skill base is particularly important for competitiveness in the OECS because of their reliance on services and niche manufacturing." 10

\footnotetext{
${ }^{9}$ One possibility would be promoting a craft development project in the Carib Territory. The Caribs have a long tradition of producing elegant baskets and such like. These however can be inconvenient for tourists to carry. Developing easily portable products could significantly increase sales. Other examples could be providing guides, developing trails and other services for tourists visiting the National Parks and forest areas.

${ }^{10}$ World Bank, Organization of Eastern Caribbean States: Towards a New Agenda for Growth, 2005, p.54
} 
The education system also has an important role to play in structuring the social and cultural system. The system must continue to play its traditional role in the social sphere, of reducing social disparities and fostering upward mobility of the lower social strata, while also ensuring a learning environment and educational experience that builds social cohesion and conformity.

The following observations emanate from studies and reviews of the skills and labour market situation in the OECS countries: ${ }^{11}$

\section{A. SKILLS, EDUCATION AND TRAINING}

Skills are important for achieving and maintaining competitiveness.

Building a strong skill base is particularly important for competitiveness in Dominica and other OECS countries, because of the potential future reliance on services and niche manufacturing.

Firms have cited the shortage of skilled labour as a major constraint to improving competitiveness.

The shortage of skills is also reflected in increasing returns to education.

The shortage of skilled labour from a number of compounding factors including relatively low educational attainment and emigration.

\section{B. BASIC AND SECONDARY EDUCATION}

Dominica has made remarkable progress on expanding access to education, but quality remains a major issue.

Poor education outcomes have emerged despite high spending, indicating serious inefficiencies in the education system.

Secondary school curricula are in dire need of reform.

High spending on education also masks inequities in the system.

There is a common tendency in the OECS countries to spend relatively more public financing on better performing schools, instead of concentrating spending where needs are highest.

One outcome of the low quality and inequitable secondary outcomes is high youth unemployment.

\section{TERTIARY EDUCATION}

- The OECS countries as a whole have a serious shortfall in tertiary education output.

\footnotetext{
${ }^{11}$ These reviews include the OECS Development Strategy, the Dominica Education Development Plan, in addition to the World Bank document identified above.
} 
- Both supply and demand factors explain the shortfall in tertiary education.

- Supply of tertiary education has been predominantly public-financed and publicly provided.

- Relying predominantly on either private or public investment has pitfalls in term of equity.

- Public spending on tertiary education may not be sufficiently geared to the needs of the private sector, although attracting additional private tertiary education providers to the OECS may be difficult given the small market size.

- To address the shortages, the OECS will need to ensure that the few public tertiary institutions contribute efficiently and effectively to solving the skills shortages that affect competitiveness, and to find ways to increase the private supply of tertiary education.

D. JOB TRAINING

- Job training is an important part of the supply chain for skilled labour.

- Job training appears to be lower in the OECS than in the rest of the Caribbean and Latin America.

- Job training is a complement, not a substitute for basic education.

- Public training programmes are not well geared toward the needs of the private sector.

- Despite the apparent willingness of private firms to train their workers, the under-provision of job training in the OECS will persist if left entirely to the private sector.

- The international best practice is to separate public financing from provision of training, e.g. by providing incentives for firms to use private providers, although here again small market size may hinder entry of private training providers to the OECS countries.

\section{POLICY ACTIONS}

The challenge for Dominica in terms of building and improving the skills base of its workforce is two-fold: (i) improve the quality of education; (ii) expand access to tertiary education; and (iii) refocus the education and training systems on building skills demanded by employers.

A. Government will continue working to improve the quality of education, by taking action to improve the efficiency of public spending on education through:

- Reforming teacher training and deployment schemes, by seeking the adoption of a sub-regional approach to teacher training (i.e. common curriculum, delivery modality, and certification system). This will help 
to conserve limited resources, achieve economies of scale and facilitate teacher mobility/deployment across the sub-region.

- Shifting resources from better performing schools to those where there needs are greatest in order to raise the average quality of schooling, address youth unemployment and youth-at-risk issues at the source, and limit later labour market segmentation.

- Accelerating the reform of secondary education curriculum to provide youth with appropriate competencies and skills for the further education and/or the transition from school to work.

- Improving monitoring and international benchmarking of, and public information on, education outcomes across the sub-region. This is intended to increase accountability of education providers for educational outcomes, and deepen involvement of the public in achieving education goals.

B. Government will continue working to expand access to secondary and tertiary education by:

- Encouraging greater participation of the private sector in tertiary education while ensuring that adequate standards are maintained. A sub-regional approach to accreditations that emphasizes integration with regional and international standards will help to both make the OECS market more attractive to external service providers, and stimulate greater demand by students.

- Improving the efficiency of spending on tertiary education by increasing cost-sharing and appropriately targeted loan or scholarship programmes.

- Negotiating better terms of trade for tertiary education services to increase spillovers to domestic needs. In promoting further the development of exports of education services, Dominica and the other OECS countries will target those areas that also have an impact on domestic needs, such as tourism, IT and other areas.

- Accelerating implementation of distance learning efforts. Greater use of ICTs will help Dominica and the rest of the sub-region overcome the issue of small market size and remoteness.

C. Government will continue working to refocus education and training systems on the skills demanded by employers by: 
- Strengthening the involvement of the private sector in the secondary school curriculum reform, governance of tertiary institutions, and the design and provision of job training programmes.

- Expanding skills training in some key areas such as IT, hospitability, non-hotel tourism services, accounting and management.

- Refocusing public spending on training by targeting vocational training and micro-enterprise skills on linkages with export sectors, and promoting in-firm training through the judicious use of financial incentives.

Within the frame of the foregoing strategic objectives and policies, Government will be pursuing its more objectives and priorities as articulated in its Education Development Plan 2000-2005 and Beyond, with its mission to:

"Guarantee equitable access to high quality education and training to develop in all its citizens the capacity to lead productive and fulfilling lives in a complex and changing society."

These key policy objectives are to:

Change the culture of the Ministry of Education to that of a service provider, reposition institutional responsibility and strengthen systems to deliver the Education development Plan;

Facilitate expansion of early childhood care and development activities including family and community interventions, especially for disadvantaged and disabled children;

Promote qualitative improvements in primary education through a more student-centred approach to teaching and learning;

Ensure universal access to secondary education and develop relevant curricula to meet the needs of diverse students;

Improve access to tertiary and continuing education, and ensure quality and efficiency through structural transformation of existing institutions within the social and economic context;

Establish an integrated national information system;

Provide increased opportunities for personal development and effective use of leisure time;

Improve the quality of education through enhancing teachers' capacities and commitment and the provision of support; and

Recognising and utilizing science and technology as a strategic asset for sustainable national development. 


\section{f. Managing the Environment}

Dominica is extremely vulnerable to natural disasters and economic shocks, which makes it the seventh most vulnerable country in the world.[3] The UN, WTO and many donor agencies have recognized SIDS vulnerability as an issue requiring "Special and Differential Treatment," and the Government is seeking and largely receiving the corresponding treatment for Dominica. Associated with vulnerability is risk and uncertainty that affects both the Government and the private sector. The environmental vulnerability has meant that the cost of maintaining infrastructure has been much higher than in most countries because of landslides and erosion caused by extreme weather and earthquakes. The economic shock brought about by globalization and trade liberalization led to the collapse of the banana industry, and has been largely responsible for the poor growth performance in the 1999-2003 period. Looking forward, the Government will seek to reduce the environmental vulnerability by measures to maintain and enhance the environment, and economic vulnerability will be reduced through diversification.

The following measures will reduce environmental vulnerability over the medium-term:

Approval and implementation of the OECS Physical Planning Act and on its National Environmental Management Strategy and Action Plan (NEMP). The Plan articulates the environmental management priorities of Dominica and aims at improved management of land and sea space (forest reserves, national parks, marine parks and diving areas, fisheries conservation zones), waste management, disaster management and mitigation and adaptation to climate change. It contains the steps, resource requirements, and time frames for implementation and envisages the use of environmental impact assessments (EIAs) for large public (PSIP) and private investment projects. The GOCD will strengthen its physical planning capability to preserve the historic and cultural integrity of Roseau, Portsmouth, and villages and sites thus maintaining and enhancing their attractiveness for tourists and locals alike.

Developing Alternative Sources to Fossil Fuels: Oil Price shocks always bring on a spurt of interest in alternative sources of energy and in energy conservation. In Dominica's case, there is the potential for geo-thermal energy, for the extension of hydropower, and the increased use of solar power (e.g. Barbados). The Government will encourage exploiting the potential for geo-thermal energy and for the extension of hydropower. These will be pursued by inviting participation of foreign and local private investors.

Improving the Capacity for Disaster Management: The Office of Disaster Management (ODM) falls short of meeting its stated mission and 
objectives in preventing, mitigating and preparing for potential disasters in Dominica The measures recommended included: reassigning NEPO as a Prime Ministerial responsibility and relocating the ODM to the Prime Minister Office (OPM); upgrading the staff of the ODM and providing Disaster Management (DM) training for NEPO agencies; developing DM policies and Plans acknowledging the volcanic threat and planning for the timely and orderly move of the population from threatened areas; designing and implementing a sustained public information and education programme; and conducting extensive mitigation activity.

Establishing an Environmental Mitigation Fund within the PSIP: Apart from hurricanes and volcanic eruptions, Dominica is prone to earthquakes, landslides, river floods, and heavy seas that often cause damage to the transportation network and cause environmental degradation. Provision will be made under the PSIP for a fund to cover the costs of repairs and environmental enhancements necessary after such environmental mishaps. The fund would be a "contingency" of the PSIP to which initially $5 \%$ of the cost of the PSIP would be allocated. The GOCD will seek initial financing of the fund from donor agencies (the EU and PRC's assistance programmes).

The Establishment of a Vulnerability Fund for SIDS: For combating environmental vulnerability, the GOCD will explore, under the aegis of the Barbados Programme of Action (BPoA) or the Association of Small Island States (AOSIS), the establishment by the World Bank of a special fund for SIDS stricken by hurricanes. Other international financial institutions and donor agencies can enhance the fund as part of their contribution to the BPoA. The fund can then seek environmental insurance for small islands. This would result in a relatively speedy response to hurricanes and other environmental disasters and reduce dependence on ad hoc and sometimes slow donor and international assistance for this purpose.

\section{g. The Dominica Diaspora}

Dominicans in the Diaspora more than double the existing population. It has been conservatively estimated that between 150,000 and 160,000 adult Dominicans migrated from the island since the 1940's to the UK, Canada and the United States. ${ }^{12}$ They have contributed significantly to poverty alleviation by remittances, by providing food and other essentials to relatives by means of the barrel trade, and by investments in real estate by emigrant Dominicans. Remittances contribute to economic growth as a source of foreign exchange and in assisting with the balance-of-payments. Remittances to Dominica are not officially recorded, but it is likely that they account for over $10 \%$ of

\footnotetext{
${ }^{12}$ Dominica Academy of Arts and Sciences, (2004), Draft Dominica-Diaspora Policy Paper.
} 
Dominica's GDP. Based on Latin American and Caribbean Immigrant remittance expenditure from the United States, which average US\$ 2,500 a year, ${ }^{13}$ Dominica's Diaspora population's remittances are estimated at EC $\$ 80-\$ 90$ million a year, or about 12\% of GDP in 2004.

The GOCD is committed to a Diaspora Policy based on the objectives of: a) increasing investment and participation of the Diaspora in Dominica's development; and b) encouraging Diaspora Dominicans to work or retire in Dominica. The measures for the medium-term are:

Articulating and implementing the Diaspora Policy.

Utilising the NDC's one-stop shop to promote investment in Dominica.

\section{RESOURCE REQUIREMENTS FOR IMPLEMENTING THE GSPS}

The implementation of the growth and social protection strategy (GSPS) will depend on the GOCD a) attaining the necessary financing for its programme, b) improving its institutional capacity to implement the programme, and c) successfully creating the enabling environment that will attract private investment. ${ }^{14}$

\section{A. The Financial and Costs Implications of the GSPS}

The strategy and measures outlined in III and V above are based largely on a continuation or reorientation of existing programmes and activities of the GOCD with some new elements or programmes added. The costs of the GSPS will therefore be based on these new elements and programmes, which constitute new demands for a) capital expenditures of the PSIP, and b) recurrent expenditures of the GOCD.

\section{B. Implications for the Public Sector Investment Programme}

The effective and efficient implementation of the PSIP is the most growthgenerating activity of the GOCD. However, the efficiency in implementing the PSIP has been adversely affected by two factors: 1) difficulties in assessing committed funds in a timely manner from donor agencies, a particular problem with EU projects because of its complicated and long-winded approval process; and 2) internal bottlenecks such as poor scheduling, difficulties with carrying out soil tests and securing engineering and technical drawings, poor reporting

\footnotetext{
${ }^{13}$ Manuel Orozo, (2003), "The Impact of Migration in the Caribbean and Central American Region," Focal Policy Paper.

${ }^{14}$ Indicative financial implications of the poverty reduction priority actions are provided at Appendix 5.
} 
and monitoring, etc. by implementing Ministries. The GOCD will improve the latter situation by out-sourcing for engineering and technical works, and by improving management of the PSIP. With regard to the former, the World Bank will work in partnership with other donors towards better donor coordination and harmonization of procedures to minimize the transaction costs of accessing donor funds.

A number of the approved projects have not yet been implemented and these will be reviewed in light of the GSPS's priorities with respect to either their retention or rejection from the medium-term PSIP. However, the GSPS will affect the PSIP most significantly by the introduction of new programmes or projects. The following projects, most of them new, are priority ones for the GSPS: 1) the establishment of the Environmental Disaster Fund on a revolving fund basis; 2) the Road Enhancement and Maintenance Programme; and 3) the establishment by the GOCD of its own ITC network (D-Gen).

1) The Environmental Disaster Fund: This fund can be considered a contingency fund for the PSIP. Based initially on about $5 \%$ of the PSIP, the cost of the fund is $\$ 20.4$ million for the medium-term period.

2) The Road Maintenance and Rehabilitation Programme: This will provide financing for equipment and materials for the implementation of the Road Maintenance and Rehabilitation Plan. Based on an upgrading of 50 $\mathrm{km}$ of roads a year, the estimated cost of this programme for the medium-term is $\$ 12.4$ million.

3) Establishing a GOCD ITC Network, D-GEN: The GOCD will establish its own local area network in conjunction with private service providers. The GOCD will seek donor assistance to establish D-GEN using a broadbased wireless system, which is estimated to cost $\$ 10.6$ million during the medium-term period.

If these three additional projects are included, the total cost of the adjusted PSIP amounts to $\$ 43.4$ million for the medium-term. The contribution of these costs to the PSIP, and the financing of the PSIP, based on the agreed fiscal parameters is given in Table 11. 
Table 11: Adjusted PSIP, 2005/06-2009/10

\begin{tabular}{|l|r|r|r|r|r|r|r|}
\hline & $2005 / 06$ & $2006 / 07$ & $2007 / 08$ & $2008 / 09$ & $2009 / 10$ & Total & $\begin{array}{c}\% \text { of } \\
\text { Total }\end{array}$ \\
\hline & & & & & & & \\
\hline NEW & 5.4 & 9.3 & 11.4 & 10.1 & 7.2 & 43.4 & 10.4 \\
\hline Env. Fund & 3.5 & 3.9 & 4.1 & 4.4 & 4.5 & 20.4 & \\
\hline RIP & 1.9 & 2.4 & 2.7 & 2.7 & 2.7 & 12.4 & \\
\hline D-GEN & & 3.0 & 4.6 & 3.0 & - & 10.6 & \\
\hline Current PSIP & 73.3 & 70.0 & 72.9 & 76.3 & 81.7 & 374.2 & 89.6 \\
\hline Total PSIP & 78.7 & 79.3 & 84.3 & 86.4 & 88.9 & 417.6 & 100.0 \\
\hline Financing & & & & & & & \\
\hline Grants & 55.1 & 55.0 & 54.0 & 55.3 & 56.9 & 276.3 & 66.2 \\
\hline Local Counterpart & 6.3 & 6.8 & 10.1 & 10.4 & 10.7 & 44.3 & 10.6 \\
\hline Loans & 17.3 & 17.5 & 20.2 & 20.7 & 21.3 & 97.0 & 23.2 \\
\hline
\end{tabular}

The table shows that the three new projects would contribute about $10.4 \%$ to the PSIP's projected expenditures for the medium-term period; and about $66 \%$ of the financing of the PSIP is expected to come from grants, $23 \%$ from loans, and $11 \%$ from local counterpart funding. From the GOCD's standpoint, its contribution of counterpart funding will amount to $\$ 44.3$ million for the period $2005 / 06$ to $2009 / 10$, an average of $\$ 9$ million a year. However, the implementation of the PSIP will depend on the GOCD securing the required donor support for the PSIP during the period.

\section{C. $\quad$ Additional Strategic Projects}

Quite apart from the projects listed above, Government is fully aware that it may have the responsibility to be rather more entrepreneurial than may be exactly consistent with its basic philosophy of facilitating business development in various ways, including fixing the enabling environment. Two additional considerations may be relevant in this context:

The first is the high level of risk aversion on the part of the domestic private sector, including as relates to partnering potential foreign investor partners; and

Secondly, there may be a very high initial capital outlay required to undertake certain projects that may be strategic to the country's development goals and prospects.

On the basis of these considerations, Government will seek prudently to partner private investors or otherwise be proactive in the development of certain projects, where there appears to be compelling national interest considerations. 
In this context, two projects that come to mind are the continuation of the Pointe Michel Sea Wall and construction of the Scotts Head Sea Defence Project, and construction of two mini marinas along the West Coast of the island.

The former would be multi-faceted - coastal defense, social and community cohesion, fisheries protection, tourist village and people empowerment. Government considers this a potentially important project in the context of the country's imperatives of fisheries and tourism development, and poverty reduction.

The recommendations for the construction of two mini marinas spring from an expert review on the subject conducted by the United Nations ECLAC. These recommendations are that while Dominica should not seek to compete with the already established marinas in neighbouring islands, it had excellent competitive potential for the viable establishment of two mini marinas. Government will engage the private sector regarding the construction of these marinas, and will consider partnering the private sector if necessary.

Another project that is of national cultural and development significance is the proposed Canefield Cultural and Entertainment Complex (C-CEC), a combined permanent home for Dominica's cultural calendar, a multi-stage venue for an increased number of visiting artistes and cultural events, a conference centre for the hosting of regional and international conferences, and a two building car park -- all of this in the area currently occupied by the Canefield Airstrip. This multi-faceted project is expected to be commercially viable but may be unlikely to attract private sector financing ab initio, in which case Government will need to make a determination as to the nature and extent of its engagement, in the national interest.

Government previously announced the reconstruction of the West Coast Highway, a project of major strategic importance to the commercial, agricultural and touristic development of the country. This project is projected to cost approximately EC $\$ 150$ million and will include important bypasses at Massacre and Mahaut, expansion of the Tarreau Road, a bridge across the Layou River and significant streamlining of the road from Layou to Portsmouth. Government has received a commitment from the People's Republic of China to meet the capital costs involved in this project, which should be started in late 2006.

Major refurbishment of the island's main hospital, the Princess Margaret Hospital, is another project previously announced by Government, and to be funded by the People's Republic of China at a possible cost of $\$ 12$ million. This project is expected to be completed within the time frame of the GSPS and will make for enhanced health care and a reduction in costs associated with obtaining medical card overseas. 
There may be additional areas where governmental partnering may be necessary, e.g. contributing land as equity in large hotel/resort projects, There may need to be a financial outlay for this purpose where the desired land is not owned by Government and may need to be purchased, or where otherwise a financial outlay is necessary to make good on Government's contribution to the project.

In this context, Government is targeting the town of Portsmouth for special attention. Efforts are already underway, in a joint public-private sector endeavour, towards the development of a marina project in the Portsmouth area. This project will include a hotel as well as duty-free shopping that will cater to the expected additional number of cruise ships calling at Portsmouth.

Government is giving priority to the establishment of a central sewage system in the town of Portsmouth. The limitations of the existing sewage system will continue to constitute a brake on future private sector growth in the Portsmouth, unless the system is completely overhauled. In collaboration with the Portsmouth Town Council and other interested parties, Government will be actively exploring opportunities for putting in place a modern central sewage system in the town of Portsmouth.

Still in the Portsmouth area, it is proposed in the medium term to pay attention to the town's road network. Government intends to embark on a road rehabilitation project in Portsmouth as part of its overall thrust to improve living conditions for the residents of the town, and also to improve the climate for business development and economic growth.

This development thrust will involve the reconfiguration of the pattern of land use in the area, with specific parts of the Portsmouth area being allocated to commercial uses, tourism, holiday homes, and housing. Road development will be an integral part of this Portsmouth development project, as it will involve the construction of a highway that will by-pass the existing major road, thus moving the traffic away from the city centre and facilitating the planned development.

These additional government investments need to be more carefully costed, and in any event they will only be implemented if the necessary grant or concessionary financing can be secured. They also need to be properly integrated into the PSIP going forward, in a way that makes for consistency with Government's fiscal programme into the medium term. The Budget Address of July 2005 indicated that Government anticipated capital spending, within the PSIP, of close to EC\$300 million over the three-year period July 2005 to June 2008, which may take the total capital expenditure to at least $\$ 500$ million by 2010. Government will be making a careful determination of the extent to which donor/external financing is required, additional to amounts already committed, to achieve its plans concerning public investment, 
including public-led or public-partnered investments. Taking into account its borrowing limitations, Government will be making a determined effort to seek continued grant or concessionary financing to place the country in a position to meet its capital expenditure programme into the medium term.

\section{Recurrent Costs of the GSPS}

The implementation of the GSPS will exert a significant influence on recurrent expenditures by Ministries during the medium-term. The recurrent costs of the GSPS pertain to: 1) institutional strengthening of the Ministries involved with its implementation; 2) increasing expenditures on the services required; and 3) making provisions for temporary financial support for certain agencies or institutions that have to be established.

\section{E. GSPS Recurrent Costs by Ministries}

The major recurrent costs of the GSPS by Ministry are the following:

Ministry of Agriculture and the Environment: There are three recurrent costs projects:

The institutional strengthening of the Department of Agriculture by enhancing its extension services to emphasize agricultural diversification.

The establishment of a parastatal commercial company for fisheries, Dominica Fisheries Ltd, to manage and operate the fisheries complexes along viable lines and to market and export fish handled by the complexes. The estimated cost for its establishment and operation is $\$ 520,000$, which will require an increment of $\$ 220,000$ over the recurrent GOCD expenditures of about $\$ 300,000$ a year for the Roseau and Marigot complexes. Every effort will be made to enable the company to operate on viable lines thus reducing, if not eliminating the burden on Government. Assuming that it would take about two years to reach viability, provision is made for incremental costs for 2005/2006 and 2006/07.

Financing fuel costs of fisheries surveillance patrols by the Coast Guard. Based on four offshore EEZ surveillance trips per month, these costs are estimated at $\$ 50,000$ a year for a total of $\$ 250,000$ for the medium-term period.

Ministry of Communications, Works and Housing: The institutional strengthening of the Ministry of Communications, Works and Housing to improve its capacity to implement the Road Maintenance and Rehabilitation Plan. The cost, based on the proportion of management and administrative cost to capital costs for road works, amounts to $\$ 6$ million for the period. 
Ministry of Finance and Planning: Institutional strengthening of the Ministry with regard to policy formulation, planning and administration of the GSPS and the PSIP, and institutional strengthening of the Inland Revenue Department by the creation of a VAT Section. The former, for which provision has already been made in the 2004/05 Budget, will require a net addition of two positions; and the latter will require a net addition of 14 staff members. The net costs of these positions amount to $\$ 3.4$ million for the medium-term period.

Ministry of Tourism: The institutional strengthening of the Ministry of Tourism, particularly in the areas of promotion, destination management and marketing. The estimated cost is $\$ 5.5$ million, most of which is for tourism promotion.

Ministry of Community Development \& Gender Affairs: Institutional strengthening of the Ministry to strengthen and widen the powers and responsibilities of municipal and village councils (regional Councils); conduct the public consultative process on an annual basis; and provide for improvements in services to village communities. The estimated cost for these amounts to $\$ 550$ thousand for the medium-term period.

Ministry of Health and Social Security: Institutional strengthening for upgrading the administrative and information systems of social assistance and for implementing the National HIV/AIDS Strategic Plan at an estimated cost of $\$ 3.2$ million a year, or $\$ 1.6$ million for the medium-term period.

Ministry of Education, Youth Affairs, Sports and Human Resource Development: The costs pertain to the administrative and educational costs associated with the implementation of distance learning in the Dominica State College, estimated at $\$ 50,000$ a year; and the costs of establishing a private sector management structure for the Sports Stadium in Roseau, including some provision for meeting part of the operational costs during its first year of operation. These latter costs are estimated to be approximately $\$ 500$ thousand in its first year of operation. The total cost amounts to $\$ 1$ million for the medium-term period.

Ministry of Legal Affairs: Institutional strengthening of Legal Affairs to modernize existing legislation and to introduce new legislation associated with the enabling environment for private enterprise and for the environment. Provision is made for the hiring of two legal officers (State Attorneys) during the period at an estimated cost of $\$ 100$ thousand.

The recurrent costs of the GSPS to the GOCD amount to $\$ 17.9$ million for the medium-term. The distribution of these costs over this period is given in Table 12. The impact of the GSPS is greatest in the first year, i.e., 2005/06, when these new costs have to be accommodated within the budgetary constraints. The task gets easier in subsequent years when they are incremental, with the 
result that their impact is not severe, particularly if the wage bill is controlled. For example, there is a $\$ 17.2$ million increase in recurrent expenditures between 2004/05-2009/10 that will meet most of the recurrent costs of the GSPS.

Table 12. Recurrent Costs, GSPS, 2005/06-2009/10

\begin{tabular}{|c|c|c|c|c|c|c|}
\hline & $2005 / 06$ & $2006 / 07$ & $2007 / 08$ & $2008 / 09$ & $2009 / 10$ & Total \\
\hline & \multicolumn{6}{|c|}{$\$, 000$} \\
\hline $\begin{array}{l}\text { Agriculture \& the } \\
\text { Environment }\end{array}$ & 320 & 320 & 100 & 100 & 100 & 940 \\
\hline $\begin{array}{l}\text { Institutional Strengthening } \\
\text { (Extension Services) }\end{array}$ & 50 & 50 & 50 & 50 & 50 & 250 \\
\hline Est. Fisheries Parastatal & 220 & 220 & - & - & - & 440 \\
\hline Fisheries Surveillance & 50 & 50 & 50 & 50 & 50 & 250 \\
\hline Finance \& Planning* & 660 & 660 & 660 & 730 & 730 & 3440 \\
\hline Planning and Priorities Unit & 130 & 130 & 130 & 200 & 200 & 790 \\
\hline $\begin{array}{l}\text { Inland Revenue Institutional } \\
\text { Strengthening, VAT Unit }\end{array}$ & 530 & 530 & 530 & 530 & 530 & 2650 \\
\hline $\begin{array}{l}\text { Communications, Works \& } \\
\text { Housing }\end{array}$ & 1000 & 1200 & 1400 & 1400 & 1400 & 6000 \\
\hline $\begin{array}{l}\text { Institutional Strengthening, } \\
\text { Road Maintenance }\end{array}$ & 1000 & 1200 & 1400 & 1400 & 1400 & 6000 \\
\hline Tourism & 1000 & 1050 & 1050 & 1100 & 1150 & 5350 \\
\hline Institutional Strengthening & 50 & 50 & - & - & - & 100 \\
\hline $\begin{array}{l}\text { Promotion \& Public } \\
\text { Awareness }\end{array}$ & 950 & 1000 & 1050 & 1100 & 1150 & 5250 \\
\hline $\begin{array}{l}\text { Community Dev, Gender } \\
\text { Affairs }\end{array}$ & 100 & 105 & 110 & 115 & 120 & 550 \\
\hline Institutional Strengthening & 100 & 105 & 110 & 115 & 120 & 550 \\
\hline Health \& Social Security & 320 & 320 & 320 & 320 & 320 & 1600 \\
\hline HIV/AIDS & 320 & 320 & 320 & 320 & 320 & 1600 \\
\hline $\begin{array}{l}\text { Education, Youth, Sports \& } \\
\text { HRD }\end{array}$ & 50 & 300 & 550 & 50 & 50 & 1000 \\
\hline Distance Learning, DSC & 50 & 50 & 50 & 50 & 50 & 250 \\
\hline $\mathrm{L}$ & - & 250 & 500 & - & - & 750 \\
\hline $\begin{array}{l}\text { Legal, Immigration \& } \\
\text { Labour }\end{array}$ & 50 & 50 & - & - & - & 100 \\
\hline Institutional Strengthening & 50 & 50 & - & - & - & 100 \\
\hline Total & 3450 & 3705 & 3640 & 3765 & 3820 & 17980 \\
\hline
\end{tabular}

* These cost are provided for in the 2004/05Budget.

Implications for Recurrent Expenditures

The recurrent costs of the GSPS have implications for recurrent expenditures by Ministries during the medium-term period. The effects of these changes on recurrent expenditures by Ministry are given in Table 13. The distribution of recurrent expenditures between the economic and social service Ministries indicates that the economic Ministries are projected to grow at an average rate 
of $2.0 \%$ a year in comparison with $1.9 \%$ for the social service Ministries, and for total expenditures of all Ministries. Growth in the economic Ministries is highest for Tourism, Industry and Enterprise Development (6.9\%), followed by Communications and Works (2.2\%), Finance and Planning (1.6\%), and Agriculture and the Environment (1.6\%). For the social service Ministries, it is highest for Health and Social Security (3.0\%) and for Community Development and Gender Affairs (2.0\%).

Table 13. Recurrent Expenditure, Ministries, 2004/05-2009/10 ${ }^{15}$

\begin{tabular}{|l|c|c|c|c|c|c|c|}
\hline & $2004 / 05$ & $2005 / 06$ & $2006 / 07$ & $2007 / 08$ & $2008 / 09$ & $2009 / 10$ & A.G.R \\
\hline & \multicolumn{5}{|c|}{$\$$. } \\
\hline
\end{tabular}

\footnotetext{
${ }^{15}$ Excludes interest payments.
} 


\section{IMPACTS AND OUTPUTS OF THE GSPS}

Prior to 2004, scenarios for Dominica's medium-term prospects indicated: (a) relatively low GDP growth rates, less than 3\% a year for the medium-term period; and (b) the debt overhang continuing to retard growth during and beyond the period 2005-2009. With regard to the latter, the debt situation has been somewhat improved with restructuring that has eased the burden of debt service. Thus, the medium-term growth prospects for Dominica from the vantage point of 2004 are more favourable, based on an upturn of the economy after three years of negative growth. The expectation is that, with the unused capacity of the economy, there would be higher than 3\% a year growth rates during the first half of the medium-term period and $3 \%$ afterwards. However, an average rate of real growth of $3 \%$ a year is the growth target for the medium-term period.

The outputs of the GSPS pertain to its two main goals: 1) improved performance for the economy; and 2) increased employment, poverty reduction, and improved social protection. They are as follows:

\section{A. $\quad$ Growth Related}

- Growth in GDP with annual growth rates of 3\% or more.

- Expansion in trade with growth rates of exports of goods and services exceeding that of imports, which will improve the balance-of-trade and balance-of- payments.

\section{B. Employment, Poverty Reduction and Social Protection Related}

- Increasing employment opportunities for the labour force and reducing the unemployment rate to fewer than $10 \%$ by $2009 / 2010$.

- Decreasing levels of poverty from over $40 \%$ of the population to about $25 \%$ by $2009 / 2010$ and indigent levels proportionally.

- Improving the delivery of the social services (education, health and social protection programmes) that increase the welfare of the population on the whole.

\section{Improved Economic Performance}

The sectoral strategies for growth outlined in section $\mathrm{V}$ aim at attaining a $3 \%$ average annual rate of growth for the economy. This will be brought about by the performance of the growth sectors identified and their influence, by means of linkage effects, on the other sectors of the economy, i.e., the infrastructural and service sectors. It is not possible to determine sectoral performance and structural changes with any degree of accuracy. However, a major objective of the growth agenda of the GSPS is the re-attainment of export-led growth. The impact of the GSPS will therefore be assessed in terms 
of trade performance, which reflects the impact of the sectoral strategies outlined and their employment-generation effects.

\section{D. $\quad$ Trade Performance Scenario}

The re-attainment of export-led growth will be brought about by increased commodity exports and by tourism, which is an export industry. The mediumterm situation for commodity exports, shown in Table 14 provides for two scenarios: i) exports based on traditional exports; and ii) the possible impact of water exports on commodity exports. In the first instance, the growth rate for traditional commodity exports is $6.7 \%$ a year for the medium-term period; and in the second, the growth rate averages $15.2 \%$ a year. The second is used to represent the medium-term commodity export situation.

Table 14: Commodity Trade Scenario, Export \& Imports, 2004-2009

\begin{tabular}{|c|c|c|c|c|c|c|c|}
\hline & $\begin{array}{c}\text { Exports } \\
\text { (Without } \\
\text { Water) }\end{array}$ & $\begin{array}{c}\text { Water } \\
\text { Exports* }\end{array}$ & $\begin{array}{c}\text { Total } \\
\text { Exports }\end{array}$ & Imports & $\begin{array}{c}\text { Visible } \\
\text { Balance } \\
\text { of Trade }\end{array}$ & $\begin{array}{c}\text { Exports \% } \\
\text { of GDP }\end{array}$ & $\begin{array}{c}\text { Imports } \\
\text { as\% of } \\
\text { GDP }\end{array}$ \\
\hline & \multicolumn{7}{|c|}{ \$ million } \\
\hline 2004 & 111.3 & - & 111.3 & 390.8 & -279.5 & 15.1 & 52.8 \\
\hline $2005^{*}$ & 116.3 & - & 116.3 & 395.6 & -279.3 & 15.1 & 51.2 \\
\hline 2006 & 125.0 & - & 125.0 & 415.6 & -290.6 & 15.5 & 51.5 \\
\hline 2007 & 134.4 & 40.0 & 174.4 & 436.0 & -261.6 & 20.6 & 51.7 \\
\hline 2008 & 144.5 & 80.0 & 224.5 & 458.8 & -234.3 & 25.4 & 52.0 \\
\hline 2009 & 155.3 & 85.0 & 238.3 & 473.1 & -234.8 & 26.2 & 52.1 \\
\hline A.R.G & 6.7 & & 15.2 & 3.8 & & & \\
\hline
\end{tabular}

* This is based on a conservative interpretation of sales expectations for bulk water exports.

Commodity imports, assuming that they remain a relatively constant proportion of GDP, would grow at an average rate of $3.4 \%$ a year during the medium-term. The adverse balance of visible trade can be reduced considerably if the growth rate for exports can be attained.

\section{E. $\quad \underline{\text { Tourism }}$}

The GSPS identified tourism as the industry that has the most potential for growth during the medium term. The scenario projected for Dominica in Table 15 is based on the tourism sector sustaining the growth rate for stay-over visitors of $5.5 \%$ for the period $2001-2004^{16}$ over the medium-term period, with the number of cruise visitors remaining stable at about 300,000 a year. The main reason for the latter is that cruise ship visitors and expenditures fluctuate. In 2004, there were 380,000 cruise ship visitors with estimated

\footnotetext{
${ }^{16}$ This is not a conservative assumption given existing hotel capacity and the fact that improvements in this capacity and in the tourism infrastructure (airport and road) will not be felt until the middle to the end of the medium-term period.
} 
expenditures of nearly EC $\$ 25$ million in that year, but this was the result of a diversion of cruise ships from Grenada after Hurricane Ivan.

Table 15: Tourism Expenditures and Projections for 2004/05-2009/10

\begin{tabular}{|l|l|l|l|l|l|c|c|}
\hline & $\begin{array}{l}\text { No. of } \\
\text { Stay over } \\
\text { Visitors* }\end{array}$ & $\begin{array}{l}\text { Stay } \\
\text { over } \\
\text { Exp }\end{array}$ & $\begin{array}{l}\text { Cruise ship } \\
\text { Visitors, } \\
\text { No. }\end{array}$ & $\begin{array}{l}\text { Cruise } \\
\text { ship } \\
\text { Exp }\end{array}$ & $\begin{array}{l}\text { Total } \\
\text { Tourism } \\
\text { Exp** }\end{array}$ & of GDP & $\begin{array}{l}\text { Contribution } \\
\text { to GDP }\end{array}$ \\
\hline & & $\$, 000$ & & $\$, 000$ & $\$, 000$ & & \\
\hline 2004 & 74,595 & 138,631 & 380,608 & 24,739 & 162,370 & 22.0 & 4.3 \\
\hline 2005 & 78,698 & 149,181 & 300,000 & 19,890 & 169,071 & 22.0 & 4.4 \\
\hline 2006 & 83,026 & 160,533 & 300,000 & 20,288 & 180,821 & 22.4 & 4.5 \\
\hline 2008 & 87,592 & 172,749 & 300,000 & 20,694 & 193,443 & 22.9 & 4.6 \\
\hline 2009 & 92,409 & 185,894 & 300,000 & 21,107 & 207,001 & 23.5 & 4.7 \\
\hline A.G.R & 97,491 & 200,039 & 300,000 & 21,529 & 221,569 & 24.4 & 4.9 \\
\hline
\end{tabular}

${ }^{*}$ Projection based on an av. Growth rate of $5.5 \%$ a year, the average growth rate for 20012004. ${ }^{* *}$ Assumes a $2 \%$ growth rate a year in per capita tourist expenditures.

During the medium-term, the growth in tourism expenditures could average $6.1 \%$ a year. This rate of growth will increase tourism expenditures from $22 \%$ of GDP to $24.4 \%$ and the contribution of the industry from $4.3 \%$ to $4.9 \%$ of GDP.

\section{F. $\quad$ Labor Force, Employment and Poverty Reduction Prospects}

Successful implementation of this Strategy should bring about sustained economic growth and poverty reduction resulting in both increased employment opportunities and slowing of economic emigration. On conservative assumptions that recent migration trends continue, Dominica's population would continue to decrease during the medium-term, from estimated 69.2 thousand in 2004 to 68.7 thousand in 2009 , at or by $0.1 \%$ a year. (See Table 16). Current population and labor force projections do not project continued immigration from Haiti and Dominican Republic at the rate observed in the latest 18 months.

Table 16. Employment, Unemployment, and Poverty Scenarios, 2004-2009

\begin{tabular}{|c|c|c|c|c|c|c|c|}
\hline & $\begin{array}{c}\text { Population } \\
\text { (mean)* }\end{array}$ & $\begin{array}{l}\text { Labour } \\
\text { Force** }\end{array}$ & Emp $^{* * *}$ & Unemp & $\begin{array}{l}\text { Unemp } \\
\text { Rate }\end{array}$ & $\begin{array}{l}\text { Poverty } \\
\text { Levels }\end{array}$ & $\begin{array}{c}\text { Percent of } \\
\text { Population }\end{array}$ \\
\hline & No. & No. & No. & No. & $\%$ & No. & $\%$ \\
\hline $\mathbf{2 0 0 4}$ & 69,261 & 28,010 & 23,860 & 4,150 & 14.8 & 32,100 & 46.3 \\
\hline $\mathbf{2 0 0 5}$ & 69,187 & 28,050 & 24,370 & 3,610 & 13.1 & 30,600 & 44.2 \\
\hline $\mathbf{2 0 0 6}$ & 69,103 & 28,080 & 24,880 & 3,070 & 11.4 & 29,000 & 42.0 \\
\hline $\mathbf{2 0 0 7}$ & 69,005 & 28,110 & 25,350 & 2,570 & 9.8 & 27,500 & 39.9 \\
\hline $\mathbf{2 0 0 8}$ & 68,909 & 28,140 & 25,900 & 1,980 & 8.0 & 25,800 & 37.4 \\
\hline $\mathbf{2 0 0 9}$ & 68,824 & 28,180 & 26,420 & 1,420 & 6.2 & 24,200 & 35.2 \\
\hline A.R.G & -0.1 & 1.2 & 2.0 & -2.1 & & -5.7 & \\
\hline
\end{tabular}

* Source: Central Statistical Office Ministry of Finance and Planning. ${ }^{* *}$ This was based on the labour force increasing its proportion from $40.4 \%$ of population in the Census year 2001 to about $41 \%$ in 2009 . ${ }^{* * *}$ The per capita GDP per person working of $\$ 17,355$ (constant \$) in 2001/02 was increased by $0.86 \%$ a year (the average rate of growth of GDP per person working for the period 1991-2001) to estimate job creation or job loss to arrive at employment and unemployment levels. 
The poverty assessment suggests that a significant reduction in unemployment rate would be a major contributor to poverty reduction in Dominica. A sustained level of economic growth would be the main conduit in this process. Projections by experts suggest that a sustained (uninterrupted) GDP growth of $3 \%$ a year would generate about 2,500 jobs during 2005-09, assuming labor productivity growth of $.9 \%$ a year. The unemployment rate would drop from 14.5 percent in 2004 to 6.2 percent in 2009 on the assumption that the labor force participation increases only marginally (from $40.4 \%$ in 2001 to $41 \%$ in 2009). In this base case scenario, the estimated number of the poor should decrease from 32 thousand in 2004 to 24 thousand by 2009 , or by $25 \%$.

Dominica's economy and labor market conditions will continue to depend largely on services and agriculture. The employment opportunities are expected to increase most in trade (retail and wholesale), hotels and restaurants, construction, transport, banking and insurance. Agriculture and fishing will provide considerable additional employment opportunities even if growth of agriculture continues to lag that of other sectors. The expected more dynamic growth of water, electricity, communication, and manufacturing would provide well paid but smaller number of new jobs because of high capital intensity of additional capacity in these sectors.

The growth and employment projections carry considerable risks. The 3\% a year GDP growth can be interrupted by external shocks (climate). Marginal productivity is likely to be higher than the historic average because new investment is more capital and technology intensive than in the past. This would result in fewer additional jobs even if GDP does grow by $3 \%$ a year on average. In addition, continued immigration of workers who accept lower wages and tougher work conditions may contribute to the labor force and economic activity while limiting the decrease in unemployment and poverty of native population. All these risks point to critical importance of improving effectiveness of the community development and social protection programmes to improve the odds of real progress in reducing poverty.

\section{IMPLEMENTING AND MONITORING THE GSPS}

The strategic objectives and actions of the GSPS during the medium term are given in Appendix 1. The priority aspects are: a) putting in place the enabling environment as quickly as possible; b) making administrative reform an ongoing activity of the Ministries; c) amending their action plans to reflect the private sector focus of the GSPS; c) accelerating PSIP implementation by improved planning, scheduling and the removal of bottlenecks; and d) improving the targeting of the social programmes. 
Monitoring and evaluation will ensure that the GSPS keeps on track with respect to its objectives and goals, and, if there is some slippage, to enable remedial action to be taken quickly. The monitoring will be an exercise of the PPU that will be incorporated into the budget exercise. There will be a midterm evaluation in 2007/08 and an end-of-period evaluation in 2009/10. The evaluations will determine, based on the findings from monitoring and changes in circumstances, e.g., economic or environmental shocks, whether there is the need to make changes in direction of the strategy and to make recommendations for doing so. A basic requirement for monitoring and evaluation of the GSPS is the establishment of performance criteria, such as objectively verifiable indicators (OVIs) and qualitative indicators of the inputs and outputs of the GSPS.

\section{A. $\quad$ Performance Indicators for the GSPS}

The performance indicators cover the following categories: macro-economic growth, employment and poverty, education and social welfare, health and community development, and infrastructure and the environment. They conform largely to existing data sources and monitoring systems of line ministries in Dominica. They are shown in Table 17.

Specifically with regard to poverty reduction, Government will work towards the following:

- The involvement of many government and non-government organisations;

- A much increased degree of inter-agency co-ordination and cooperation, especially between government agencies and NGOs;

- The establishment of inter-sectoral ad hoc committees to tackle key social issues such as HIV/AIDS and unsafe sexual practices, male adolescent under-achievement and anti-social behaviour, assistance to vulnerable women and families;

- A clear set priorities, including re-evaluation of existing programmes leading to their rationalisation;

- Improved targeting and the introduction of targeting into programmes where none now exist;

- The preparation of thorough and convincing proposals for external funding agencies; and

- Commitment at the highest level of government to these processes. 
Table 17: Performance Indicators, 2005-2009

\begin{tabular}{|c|c|c|c|c|c|c|}
\hline & 2005 & 2006 & 2007 & 2008 & 2009 & Measurement \& Target \\
\hline \multicolumn{7}{|l|}{ Macro Economic } \\
\hline Real GDP Growth Rate & $3 \%$ & $3 \%$ & $3 \%$ & $3 \%$ & $3 \%$ & 3\% \& over per annum \\
\hline GDP Per Capita & $3 \%$ & $3 \%$ & $3 \%$ & $3 \%$ & $3 \%$ & \% Growth \\
\hline Sectoral Composition & & & & & & $\%$ of GDP by sectors \\
\hline Exports & 15.7 & 15.8 & 15.9 & 16.0 & 16.1 & $\%$ of GDP \\
\hline Imports & 48.7 & 48.5 & 47.9 & 47.2 & 46.6 & $\%$ of GDP \\
\hline Tourism Expenditures & 22.2 & 22.2 & 22.7 & 23.3 & 24.4 & $\%$ of GDP \\
\hline Agricultural Production & & & & & & \% Growth rate \\
\hline $\begin{array}{l}\text { Manufacturing } \\
\text { Production }\end{array}$ & $4.5 \%$ & $4.5 \%$ & $4.5 \%$ & $4.5 \%$ & $4.5 \%$ & $\%$ Growth rate \\
\hline $\begin{array}{l}\text { Government Primary } \\
\text { Balance }\end{array}$ & $3 \%$ & $3 \%$ & $3 \%$ & $3 \%$ & $3 \%$ & Maintain $3 \%$ of GDP \\
\hline Current Revenue & 32.9 & 29.4 & 29.2 & 29.1 & 29.0 & $\%$ of GDP \\
\hline Current Expenditure & 28.9 & 28.4 & 28.8 & 28.8 & 28.8 & $\%$ of GDP \\
\hline Public sector debt/GDP & $103.9 \%$ & $99.5 \%$ & $95.3 \%$ & $91.1 \%$ & $87.1 \%$ & $\%$ of GDP \\
\hline \multicolumn{7}{|l|}{ Employment and Poverty } \\
\hline Population & $\begin{array}{l}\text { Labour } \\
\text { Force } \\
\text { Survey }\end{array}$ & & $\begin{array}{l}\text { Labour } \\
\text { Force } \\
\text { Survey }\end{array}$ & & $\begin{array}{l}\text { Labour } \\
\text { Force } \\
\text { Survey }\end{array}$ & $\%$ Growth or Decline \\
\hline Net Migration & & & & & & $\begin{array}{l}\text { No. greater or less than } \\
700 \text { per year }\end{array}$ \\
\hline Labour Force & $\begin{array}{l}\text { Labour } \\
\text { Force } \\
\text { Survey }\end{array}$ & & $\begin{array}{c}\text { Labour } \\
\text { Force } \\
\text { Survey }\end{array}$ & & $\begin{array}{c}\text { Labour } \\
\text { Force } \\
\text { Survey }\end{array}$ & $\%$ of population \\
\hline Employed & $40.4 \%$ & $40.5 \%$ & $40.6 \%$ & $40.7 \%$ & $40.8 \%$ & $\%$ of Labour Force \\
\hline Unemployed Rate & $13.1 \%$ & $11.4 \%$ & $9.8 \%$ & $8.0 \%$ & $6.2 \%$ & $\%$ of Labour Force \\
\hline Poverty Head Count & $36 \%$ & $32 \%$ & $27 \%$ & $24 \%$ & $20 \%$ & $\%$ below poverty line \\
\hline Indigent Poverty & $15 \%$ & $13.5 \%$ & $12 \%$ & $11 \%$ & $9 \%$ & $\%$ below indigent line \\
\hline Poverty Gap Ratio & $10.2 \%$ & $9.5 \%$ & $8.5 \%$ & $8 \%$ & $7 \%$ & $\%$ Gap \\
\hline $\begin{array}{l}\text { Education as a \% of } \\
\text { Gov't Expenditure }\end{array}$ & $24.1 \%$ & $24.0 \%$ & $23.7 \%$ & $23.5 \%$ & $23.5 \%$ & $\begin{array}{l}\text { \% Government } \\
\text { Expenditure }\end{array}$ \\
\hline $\begin{array}{l}\text { Primary School Net } \\
\text { Enrollment Ratio }\end{array}$ & 90 & 95 & 95 & 100 & 100 & \\
\hline $\begin{array}{l}\text { Secondary School Net } \\
\text { Enrollment Ratio }\end{array}$ & 85 & 90 & 95 & 100 & 100 & \\
\hline $\begin{array}{l}\text { Pupil: Teacher Ratio - } \\
\text { Primary School }\end{array}$ & $1: 18$ & $1: 18$ & $1: 18$ & $1: 18$ & $1: 18$ & \\
\hline $\begin{array}{l}\text { Pupil: Teacher Ratio - } \\
\text { Secondary School }\end{array}$ & $1: 17$ & $1: 18$ & $1: 19$ & $1: 19$ & $1: 19$ & \\
\hline $\begin{array}{l}\text { Secondary School Results } \\
\text { - CXC }\end{array}$ & $80 \%$ & $82 \%$ & $84 \%$ & $85 \%$ & $86 \%$ & $\begin{array}{l}\% \text { of students passing five } \\
\text { or more subjects }\end{array}$ \\
\hline $\begin{array}{l}\text { Public Health as a \% of } \\
\text { Government expenditure }\end{array}$ & $16.5 \%$ & $16.7 \%$ & $17.3 \%$ & $17.5 \%$ & $17.7 \%$ & $\begin{array}{l}\text { \% of Government } \\
\text { Expenditure }\end{array}$ \\
\hline Clinics & 0.78 & 0.78 & 0.79 & 0.80 & 0.81 & Per '000 population \\
\hline
\end{tabular}


The proposed inter-agency committees and working groups will, as part of their remit, develop a limited number of key poverty-related indicators that can readily be derived from the information that they routinely compile.

The quantitative indicators will be supplemented by annual workshops of relevant agencies to discuss perceived poverty-related trends and panel discussions with teachers, health personnel and community development officers working in the communities.

\section{B. Institutional Capacity for Implementation of the GSPS}

The GOCD will institutionalize the GSPS so that the process will be conducted on a rolling-plan basis. This will permit the GSPS to be flexible in its implementation in terms of adapting to changes that affect growth, facilitating the GOCD in meeting IMF/World Bank reporting requirements, and providing donor agencies and IFl's with the priorities and needs of the economy on a continuing basis. A rolling-plan GSPS could therefore contribute to growth stability. However, the implementation of the GSPS will require the establishment of an effective agency for its management and planning, as well as for monitoring and evaluating its performance.

The GOCD will establish a GSPS Steering Committee and a Planning and Public Investment Unit (PPIU) within the MOFP will serve as the Secretariat to the Committee. The PPIU will be the implementation arm of the Steering Committee, which will have the following major responsibilities:

- To direct the implementation of the GSPS;

- To monitor the impact of the GSPS;

- To propose revisions that may be required in the GSPS; and

- To ensure that the public is informed about the progress of the GSPS.

Recognising that a wide representation is desirable, the Steering Committee will be headed by a designated Minister and will consist of not more than 15 members, including the following:

The Financial Secretary;

The Head of the PPIU (Secretary);

The Social Development Planner;

All Permanent Secretaries;

A representative of the Private Sector-Chairman of DAIC;

A representative from the National Association of Local Authorities;

Chairperson of the Credit Union League; and

President of the National Association of Non-Governmental Organizations (NANGO). 
The GSPS Steering Committee will meet quarterly, in comparison with the monthly meeting of the PSIP Committee. However, the PSIP Committee will be required to submit quarterly reports on its operations to the GSPS Steering Committee.

The PPIU will be the central point for leadership on planning for growth, poverty reduction, and the PSIP. Its main responsibilities will be the following:

Initiating analyses of the economic and social performance of Dominica; Monitoring poverty levels and establishing a Poverty Reduction Monitoring and Evaluation Management System (PROMISE);

Liaising with the Ministries and coordinating their action plans in conformity with the GSPS;

Appraising and approving project proposals from the Ministries; Initiating project proposals; and

Submitting approved project proposals to IFls and donor agencies.

The PPIU will consist of the following personnel:

Head, PPIU (Chief Development Planner);

Social Development Planner;

Senior Economist;

Two Economists and

A Statistician (social statistics).

Budgetary provision has been made for the first five professionals of the PPIU in the MoFP, with the result that budgetary provisions will have to be made for two new positions and operating costs. The recurrent costs amount to about $\$ 80,000$ a year ( $\$ 50,000$ for salaries and $\$ 30,000$ for operating expenses).

\section{RISKS TO EFFECTIVE IMPLEMENTATION OF THE GSPS}

\section{A. Risks and Uncertainty Analysis}

During the medium-term period, Dominica will be faced with risk and uncertainty, problems for which the GSPS has to make provisions. The major problems will be due to economic and environmental shocks that relate to the great vulnerability of the country. Environmental shocks, particularly a hurricane or volcanic eruption, can disrupt growth and exacerbate the poverty situation in Dominica for years, even though Dominica has demonstrated good resilience in the past. The GSPS measures for dealing with environmental shocks center on disaster preparation and mitigation, planning that is 
facilitated by the GSPS implementation process, and the establishment of funding systems for environmental disasters. Unlike the environmental, economic shocks are more predictable. There are four areas that could exert economic shocks that would adversely affect the performance of the GSPS: 1) an energy crisis; 2) the loss of international donor support; 3 ) the inability of the economy to attract foreign investment; and 4) the failure to increase productivity and competitiveness. However, the main solution for shocks is to build resilience into the economy, and the GSPS measures can contribute significantly to this.

\section{B. The Energy Crisis}

The world oil situation with its rising and fluctuating prices has been felt in Dominica and threatens to affect the rate of inflation by its impact on the cost of living. The continuance of high fuel prices during the medium-term could adversely affect competitiveness and growth in the economy. The GSPS measures for dealing with this issue involve reducing the dependence on petrol by utilizing alternative sources of power. In Dominica, thermal energy development, the use of solar power in housing and commercial buildings and wind power in selected areas provide effective ways of reducing the dependence on petrol. The encouragement of the widespread use of solar power in housing in particular, as has been demonstrated in Barbados, is the most pragmatic way to reduce energy costs.

\section{Loss of International Donor Support}

The loss of international donor support is a threat to the implementation of the PSIP, particularly since a greater dependence on IFI's for loans can exacerbate the debt problem of the economy. The GSPS points out that the GOCD should do its utmost to attain the necessary international support for its PSIP and for meeting its social and poverty measures.

\section{Inability to Attract Private Foreign Investment}

The GSPS is dependent on expanding foreign private investment in the economy since a number of the measures for tourism and other sectors can benefit from this. With respect to attracting foreign investment, Dominica has to project an image in the international community that it is open for business, and the enabling environment is the most effective means of doing so. 


\section{E. $\quad$ Failure to Increase Productivity and Competitiveness}

Low productivity and its impact on competitiveness is the most serious economic risk to sustained growth that Dominica faces. Global forces and regional forces will require that Dominica compete internationally and regionally. The CARICOM Single Market and Economy (CSME) will have its winners and losers depending on the competitiveness of its members. The GSPS relies on increasing government efficiency, the enabling environment and other measures, such as improvements in the infrastructure, more relevant education etc, to improve productivity. However, the gains can be quickly eroded if wages increases keep pace with or exceed productivity increases. During the medium-term, irresponsible Trade Union demands for wage increases in the public or private sector could pose major obstacles to competitiveness and growth.

\section{F. $\quad$ Time Frame and Scheduling}

The period for implementation of the GSPS is from 2005/06 to 2009/10. This indicates that many of the measures of the GSPS will have to be incorporated in the Budget for 2005/06 to ensure that no time is lost in implementation. The scheduling strategy for the GSPS is based on taking some of the critical measures early in the period and involves the following:

1) Pursuing the administrative reform within a two-year implementation time frame;

2) Introducing fiscal measures early and establishing a stable fiscal situation;

3) Accelerating the PSIP implementation by improved planning, scheduling and removal of bottlenecks;

4) Creating the enabling environment by the removal of legislative and bureaucratic restrictions in 2005/06; and

5) Improving the social protection targeting coverage in $2005 / 06$. 


\section{IMPLICATIONS AND CONCLUSION}

The GSPS sets the course and direction for Dominica's economy over the next five years, 2005-2009. It is unique in that it incorporates a Poverty Reduction strategy within a macro-growth context that attempts to transform Dominica from a public-sector-led to a private-sector-led growth economy. The GSPS is opportune in that it comes at a time when there are signs of economic recovery after a period of economic stagnation with its attendant implications for unemployment and poverty; and when the government has been given a mandate at the polls for the period covered by the GSPS. Economic growth in Dominica was curtailed by a conjuncture of unfavourable circumstances, particularly with respect to trade, but there were underlying defects in the economy, such as a reliance on one or two sectors for growth, lack of diversity that affected its resilience to economic shocks, and poor fiscal management by the GOCD that led to unsustainable debt levels. The last aspect, which had adverse implications for future growth, has been tackled successfully by the ESAP. The other defects remain. Their most serious implications are that Dominica is not internationally competitive; and internally there is insufficient dynamism. The GSPS attempts to remedy this situation based on the following agendas: 1) a fiscal policy of restraint and improved administrative structure; 2 ) the creation of an enabling environment for private enterprise activity; 3) a strategy for sectoral growth; and 4) a strategy for poverty reduction and social protection. 


\section{REFERENCES:}

1. DFID/Oxford Policy Management, A Scoping Study for Strengthening the Enabling Environment in Dominica, (2001)

2. Commonwealth Secretariat (2000), A Commonwealth Vulnerability Index for Developing Countries, United Kingdom

3. Dominica Government Broadband Infrastructure Project, Connecting People, October (2002)

4. $\quad$ The Investor Roadmap and Sectoral Analysis of Dominica, USAID (2004)

5. Barton, Clifton, Micro-enterprise Business Development Services: Defining Institutional Options and Indicators of Performance, USAID (1997)

6. World Bank, (2005), OECS: Towards a New Agenda for Growth

7. The Productivity Enhancement Programme, Report, May (2005)

8. GOPA Consulting Services, (2002), Final Report and Strategic Plan, OECS

9. GOCD, (2005), Productivity Enhancement Programme Report

10. GOCD, (2003), Integrated Development Plan, Vols. I-III

11. World Bank Report, (2001), Natural Disasters

12. GOCD/CDB, (2003), Country Poverty Assessment, CPA

13. UNDP, (2004), MDG Progress Report, Barbados and the Eastern Caribbean

14. World Bank, (2003), Social Protection Review

15. GOCD, (2003), Interim Poverty Reduction Strategy Paper

16. GOCD, (2004), Dominica 2010 Tourism Policy Action Plan

17. World Bank, (2005), Dominica OECS Fiscal Issues - Policies to Achieve Fiscal Sustainability and Improve Efficiency and Equity of Public Expenditure

18. World Bank, (2005), A Time to Choose - Caribbean Development in the $\underline{21^{\text {st }} \text { Century }}$ 
19. GOCD, (2005), Development Plan for Roseau

20. GOCD, (2003), Education Development Plan 2000 - 2005 and Beyond

21. GOCD, (2004), Budget Address 2004/2005

22. OECS, (2000), Towards an OECS Development Strategy

23. GOCD, (2003), Carib People Development Plan

24. GOCD, (2002), National HIV/AIDS Strategic Plan 2003 to 2007

25. GOCD, (2001), Good Health and Sound Investment - The Action Plan for Health Care in Dominica for years $2002-2006$

26. World Bank, (2002), A Source Book for Poverty Reduction Strategies

27. GOCD, (1996), Poverty Assessment

28. GOCD, (2001), Population and Housing Census Report 
Appendix 1

Dominica Policy Matrix, 2005-2010 MATRIX OF STRATEGIC OBJECTIVES AND ACTIONS

\begin{tabular}{|c|c|c|c|c|c|c|}
\hline $\begin{array}{l}\text { STRATEGIC } \\
\text { OBJECTIVES } \\
\end{array}$ & PRIORITY ACTIONS & $\underline{2005 / 2006}$ & $\underline{2006 / 2007}$ & $\underline{2007 / 2008}$ & $\underline{2008 / 2009}$ & $\underline{2009 / 2010}$ \\
\hline \multicolumn{7}{|l|}{ FISCAL POLICY } \\
\hline $\begin{array}{l}\text { Controlling the Public } \\
\text { Service Wage Bill and } \\
\text { Staff Complement }\end{array}$ & $\begin{array}{l}\text { i) Total Wage Bill increases not } \\
\text { more than } 2 \% \text { a year. } \\
\text { ii) Staff replacements limited } \\
\text { to not more than } 40 \% \text { of the } \\
\text { natural attrition from the } \\
\text { Service. }\end{array}$ & $\begin{array}{l}\text { i) and ii) } \\
\text { Implemented }\end{array}$ & $\begin{array}{l}\text { i) and ii) } \\
\text { Implemented }\end{array}$ & $\begin{array}{l}\text { i) and ii) } \\
\text { Implemented }\end{array}$ & $\begin{array}{l}\text { i) and ii) } \\
\text { Implemented }\end{array}$ & $\begin{array}{l}\text { i) and ii) } \\
\text { Implemented }\end{array}$ \\
\hline $\begin{array}{l}\text { Modernization of the } \\
\text { Tax System }\end{array}$ & $\begin{array}{l}\text { i) Introduction of a VAT } \\
\text { ii) Broadening the tax base }\end{array}$ & $\begin{array}{l}\text { i)and ii) } \\
\text { implemented }\end{array}$ & $\begin{array}{l}\text { i)and ii) } \\
\text { implemented }\end{array}$ & $\begin{array}{l}\text { i)and ii) } \\
\text { implemented }\end{array}$ & $\begin{array}{l}\text { i)and ii) } \\
\text { implemented }\end{array}$ & $\begin{array}{l}\text { i)and ii) } \\
\text { implemented }\end{array}$ \\
\hline \multicolumn{7}{|l|}{$\begin{array}{l}\text { PUBLIC SECTOR } \\
\text { INVESTMENT } \\
\text { PROGRAMME (PSIP) }\end{array}$} \\
\hline $\begin{array}{l}\text { Integration of PSIP } \\
\text { with GSPS }\end{array}$ & $\begin{array}{l}\text { Build capacity in the planning } \\
\text { unit for PSIP management. } \\
\text { Establishment of the PPIU. }\end{array}$ & $\begin{array}{l}\text { PPIU } \\
\text { established }\end{array}$ & $\begin{array}{l}\text { PPIU } \\
\text { operational }\end{array}$ & $\begin{array}{l}\text { PPIU } \\
\text { operational }\end{array}$ & $\begin{array}{l}\text { PPIU } \\
\text { operational }\end{array}$ & $\begin{array}{l}\text { PPIU } \\
\text { operational }\end{array}$ \\
\hline $\begin{array}{l}\text { More growth-focussed } \\
\text { PSIP. }\end{array}$ & $\begin{array}{l}\text { i) Develop and apply objective } \\
\text { selection criteria ii) } \\
\text { Strategically link projects to } \\
\text { growth and poverty reduction }\end{array}$ & $\begin{array}{l}\text { New approach } \\
\text { implemented }\end{array}$ & $\begin{array}{l}\text { New approach } \\
\text { implemented }\end{array}$ & $\begin{array}{l}\text { New approach } \\
\text { implemented }\end{array}$ & $\begin{array}{l}\text { New approach } \\
\text { implemented }\end{array}$ & $\begin{array}{l}\text { New approach } \\
\text { implemented }\end{array}$ \\
\hline $\begin{array}{l}\text { Adopt more } \\
\text { comprehensive and } \\
\text { systematic approach } \\
\text { to PSIP. }\end{array}$ & $\begin{array}{l}\text { Launch road maintenance } \\
\text { project (EURO) }\end{array}$ & $\begin{array}{l}\text { Funding } \\
\text { acquired }\end{array}$ & implemented & implemented & implemented & Implemented \\
\hline \multicolumn{7}{|l|}{$\begin{array}{l}\text { MEDIUM TERM } \\
\text { PUBLIC SECTOR } \\
\text { REFORM }\end{array}$} \\
\hline $\begin{array}{l}\text { Modernization of key } \\
\text { ministries }\end{array}$ & $\begin{array}{l}\text { i) Restructure and modernize } \\
\text { growth and social services } \\
\text { ministries }\end{array}$ & $\begin{array}{l}\text { Consultancy } \\
\text { done }\end{array}$ & $\begin{array}{l}\text { Recommendat } \\
\text { ions } \\
\text { implemented }\end{array}$ & & & \\
\hline $\begin{array}{l}\text { Strengthening middle } \\
\text { management in the } \\
\text { public sector }\end{array}$ & $\begin{array}{l}\text { ii) Train middle managers in } \\
\text { key growth and poverty } \\
\text { reduction concepts }\end{array}$ & $\begin{array}{l}1 \text { workshop } \\
\text { held }\end{array}$ & $\begin{array}{l}2 \text { workshops } \\
\text { held }\end{array}$ & $\begin{array}{l}2 \text { workshops } \\
\text { held }\end{array}$ & $\begin{array}{l}2 \text { workshops } \\
\text { held }\end{array}$ & $\begin{array}{l}2 \text { workshops } \\
\text { held }\end{array}$ \\
\hline $\begin{array}{l}\text { Legislative/ } \\
\text { administrative reform }\end{array}$ & $\begin{array}{l}\text { Undertake growth inducing and } \\
\text { productivity enhancing } \\
\text { legislative reforms. } \\
\text { Review policies procedures and } \\
\text { practices for more effective } \\
\text { performance. }\end{array}$ & $\begin{array}{l}\text { Review } \\
\text { completed }\end{array}$ & $\begin{array}{l}\text { Legislative } \\
\text { changes } \\
\text { implemented }\end{array}$ & $\begin{array}{l}\text { Legislative } \\
\text { changes } \\
\text { implemented }\end{array}$ & $\begin{array}{l}\text { Legislative } \\
\text { changes } \\
\text { implemented }\end{array}$ & $\begin{array}{l}\text { Legislative } \\
\text { changes } \\
\text { implemented }\end{array}$ \\
\hline $\begin{array}{l}\text { Devolution of human } \\
\text { resource } \\
\text { management }\end{array}$ & $\begin{array}{l}\text { Provide permanent secretaries } \\
\text { with responsibility for } \\
\text { recruitment, discipline and } \\
\text { dismissal of lower level staff. }\end{array}$ & $\begin{array}{l}\text { Amending } \\
\text { Public Service } \\
\text { Regulations }\end{array}$ & $\begin{array}{l}\text { New } \\
\text { regulations } \\
\text { implemented }\end{array}$ & & & \\
\hline $\begin{array}{l}\text { Building of } \\
\text { meritocracy }\end{array}$ & $\begin{array}{l}\text { Introduce a transparent merit } \\
\text { pay system in the Public } \\
\text { Service }\end{array}$ & $\begin{array}{l}\text { Proposals } \\
\text { made for the } \\
\text { pay system }\end{array}$ & $\begin{array}{l}\text { The new } \\
\text { system } \\
\text { implemented }\end{array}$ & & & \\
\hline $\begin{array}{l}\text { Building public } \\
\text { awareness }\end{array}$ & $\begin{array}{l}\text { Continue public education } \\
\text { campaign regarding changes in } \\
\text { the Public Service }\end{array}$ & $\begin{array}{l}\text { Strategy for } \\
\text { the campaign } \\
\text { developed }\end{array}$ & $\begin{array}{l}\text { Measures } \\
\text { implemented }\end{array}$ & & & \\
\hline
\end{tabular}




\begin{tabular}{|c|c|c|c|c|c|c|}
\hline $\begin{array}{l}\text { ENABLING } \\
\text { ENVIRONMENT }\end{array}$ & & $\underline{2005 / 2006}$ & $\underline{2006 / 2007}$ & $\underline{2007 / 2008}$ & $\underline{2008 / 2009}$ & $\underline{2009 / 2010}$ \\
\hline $\begin{array}{l}\text { Attracting foreign } \\
\text { and domestic } \\
\text { investment }\end{array}$ & $\begin{array}{l}\text { i) Establishment of a one-stop } \\
\text { shop for foreign investment } \\
\text { approval. } \\
\text { ii) Reducing the cost of doing } \\
\text { business. } \\
\text { iii) Encouraging partnership } \\
\text { arrangements. } \\
\text { iv) Strengthening } \\
\text { competitiveness. } \\
\text { v) Outsourcing and } \\
\text { privatization of Government } \\
\text { enterprises }\end{array}$ & $\begin{array}{l}\text { i)-v) } \\
\text { Implemented }\end{array}$ & $\begin{array}{l}\text { i)-v) } \\
\text { Implemented }\end{array}$ & $\begin{array}{l}\text { i)-v) } \\
\text { Implemented }\end{array}$ & $\begin{array}{l}\text { i)-v) } \\
\text { Implemented }\end{array}$ & $\begin{array}{l}\text { i)-v) } \\
\text { Implemented }\end{array}$ \\
\hline \multicolumn{7}{|l|}{$\begin{array}{l}\text { IMPROVING THE } \\
\text { FINANCIAL SECTOR }\end{array}$} \\
\hline $\begin{array}{l}\text { Improving supervisory } \\
\text { mechanism for } \\
\text { financial sector }\end{array}$ & $\begin{array}{l}\text { Review legislative/regulatory } \\
\text { framework }\end{array}$ & $\begin{array}{l}\text { Review } \\
\text { undertaken }\end{array}$ & Legislation & & & \\
\hline $\begin{array}{l}\text { Improving } \\
\text { institutional capacity }\end{array}$ & $\begin{array}{l}\text { Train staff of Financial Services } \\
\text { Unit }\end{array}$ & & & & & \\
\hline $\begin{array}{l}\text { Building strategic } \\
\text { position of indigenous } \\
\text { banks }\end{array}$ & $\begin{array}{l}\text { Review the institutional } \\
\text { capabilities of indigenous banks }\end{array}$ & $\begin{array}{l}\text { Review } \\
\text { undertaken }\end{array}$ & & & & \\
\hline $\begin{array}{l}\text { Improving the } \\
\text { competitiveness of } \\
\text { credit unions }\end{array}$ & $\begin{array}{l}\text { Improve the banking } \\
\text { environment }\end{array}$ & $\begin{array}{l}\text { Review } \\
\text { undertaken }\end{array}$ & & & & \\
\hline $\begin{array}{l}\text { Improving access to } \\
\text { capital }\end{array}$ & $\begin{array}{l}\text { Encourage local companies to } \\
\text { participate in ECCB Stock } \\
\text { Exchange }\end{array}$ & & Implemented & Implemented & Implemented & Implemented \\
\hline \multicolumn{7}{|l|}{$\begin{array}{l}\text { OVERCOMING } \\
\text { VULNERABILITY }\end{array}$} \\
\hline $\begin{array}{l}\text { Improve } \\
\text { environmental } \\
\text { management }\end{array}$ & $\begin{array}{l}\text { Implement National } \\
\text { Environmental Management } \\
\text { Strategy and Action Plan } \\
\text { (NEMP) }\end{array}$ & $\begin{array}{l}\text { Meetings } \\
\text { conducted }\end{array}$ & implemented & implemented & implemented & implemented \\
\hline $\begin{array}{l}\text { Develop alternative } \\
\text { sources of fossil } \\
\text { fuels. }\end{array}$ & $\begin{array}{l}\text { Pursue geothermal energy } \\
\text { project } \\
\text { Participate in regional oil } \\
\text { procurement programme. }\end{array}$ & $\begin{array}{l}\text { Work continue } \\
\text { Discussions } \\
\text { continue }\end{array}$ & $\begin{array}{l}\text { Viability } \\
\text { determine } \\
\text { Agreement } \\
\text { reached }\end{array}$ & $\begin{array}{l}\text { Project } \\
\text { launched } \\
\text { Oil procured }\end{array}$ & $\begin{array}{l}\text { Construction } \\
\text { Oil procured }\end{array}$ & $\begin{array}{l}\text { Geothermal } \\
\text { energy } \\
\text { produced }\end{array}$ \\
\hline $\begin{array}{l}\text { Establish an } \\
\text { Environmental } \\
\text { Mitigation Fund under } \\
\text { the PSIP }\end{array}$ & $\begin{array}{l}\text { Make budgetary provisions in } \\
2005 / 2006 \text { capital budget }\end{array}$ & $\begin{array}{l}\text { Agreement } \\
\text { reached }\end{array}$ & $\begin{array}{l}\text { Funds } \\
\text { allocated }\end{array}$ & $\begin{array}{l}\text { Funds } \\
\text { allocated }\end{array}$ & $\begin{array}{l}\text { Funds } \\
\text { allocated }\end{array}$ & $\begin{array}{l}\text { Funds } \\
\text { allocated }\end{array}$ \\
\hline $\begin{array}{l}\text { Establish } \\
\text { vulnerability fund for } \\
\text { SIDS }\end{array}$ & Allocate $10 \%$ to SDR to fund & & $\begin{array}{l}\text { Project } \\
\text { submission to } \\
\text { SIDS Group }\end{array}$ & $\begin{array}{l}\text { Agreement } \\
\text { reached and } \\
\text { submitted to } \\
\text { World Bank }\end{array}$ & $\begin{array}{l}\text { World bank } \\
\text { Programme } \\
\text { developed }\end{array}$ & $\begin{array}{l}\text { Fund } \\
\text { established }\end{array}$ \\
\hline \multicolumn{7}{|l|}{ TOURISM } \\
\hline $\begin{array}{l}\text { Institutional } \\
\text { Strengthening }\end{array}$ & $\begin{array}{l}\text { Restructure and strengthen the } \\
\text { Ministry of Tourism } \\
\text { ii) Increased funding for } \\
\text { promotion }\end{array}$ & $\begin{array}{l}\text { Provision in } \\
\text { budget }\end{array}$ & $\begin{array}{l}\text { Implemented } \\
\text { Implemented }\end{array}$ & Implemented & Implemented & Implemented \\
\hline $\begin{array}{l}\text { Improvement in } \\
\text { tourism } \\
\text { infrastructure }\end{array}$ & $\begin{array}{l}\text { (i) Improve Melville Hall Airport } \\
\text { ii) Construct Melville } \\
\text { Hall/Roseau Road }\end{array}$ & $\begin{array}{l}\text { Work } \\
\text { Commence } \\
\text { Airport } \\
\text { Road }\end{array}$ & $\begin{array}{l}30 \% \\
\text { complete } \\
\text { Road }\end{array}$ & $\begin{array}{l}60 \% \\
\text { complete } \\
80 \%\end{array}$ & $\begin{array}{l}100 \% \\
\text { complete } \\
100 \%\end{array}$ & \\
\hline $\begin{array}{l}\text { Establishment of } \\
\text { yachting facilities }\end{array}$ & $\begin{array}{l}\text { i) Negotiate with private } \\
\text { enterprise operator } \\
\text { ii) Construct yacht of marina }\end{array}$ & & $\begin{array}{l}\text { Concept } \\
\text { finalized }\end{array}$ & $\begin{array}{l}\text { Negotiations } \\
\text { with Private } \\
\text { Investors }\end{array}$ & Construction & $\begin{array}{l}\text { Construction } \\
100 \% \\
\text { complete }\end{array}$ \\
\hline Hotel improvement & $\begin{array}{l}\text { i) Negotiate with hotel chain } \\
\text { company } \\
\text { ii) Construct large hotel }\end{array}$ & & $\begin{array}{l}\text { Concept } \\
\text { finalized }\end{array}$ & $\begin{array}{l}\text { Negotiations } \\
\text { with a Hotel } \\
\text { Chain }\end{array}$ & $\begin{array}{l}\text { Planning for } \\
\text { Implementati } \\
\text { on }\end{array}$ & $\begin{array}{l}\text { Construction } \\
\text { commences }\end{array}$ \\
\hline $\begin{array}{l}\text { Tourism marketing in } \\
\text { French West Indies }\end{array}$ & $\begin{array}{l}\text { Marketing and accommodation } \\
\text { arrangements with French West } \\
\text { Indies hotels }\end{array}$ & & $\begin{array}{l}\text { Plan } \\
\text { Negotiated }\end{array}$ & $\begin{array}{l}20 \% \text { increase } \\
\text { in Excursion } \\
\text { Tourists }\end{array}$ & $20 \%$ increase & $20 \%$ increase \\
\hline
\end{tabular}




\begin{tabular}{|c|c|c|c|c|c|c|}
\hline $\begin{array}{l}\text { Establish Air/Sea } \\
\text { combination link }\end{array}$ & $\begin{array}{l}\text { i) Establish Partnership with } \\
\text { large French hotels } \\
\text { ii) Utilize ferry services }\end{array}$ & $\begin{array}{l}\text { Concept } \\
\text { finalized }\end{array}$ & 2 hotels & 2 hotels & 2 hotels & 6 hotels total \\
\hline Development of sites & $\begin{array}{l}\text { Identify, develop and market } \\
\text { community tourism sites }\end{array}$ & $\begin{array}{l}\text { EU Tourism } \\
\text { Project }\end{array}$ & $\begin{array}{l}2 \text { new sites } \\
\text { added }\end{array}$ & $\begin{array}{l}2 \text { new sites } \\
\text { added }\end{array}$ & $\begin{array}{l}2 \text { new sites } \\
\text { added }\end{array}$ & $\begin{array}{l}2 \text { new sites } \\
\text { added }\end{array}$ \\
\hline $\begin{array}{l}\text { Achieving linkage } \\
\text { with agriculture }\end{array}$ & $\begin{array}{l}\text { Establish organic agriculture } \\
\text { /tourism linkage }\end{array}$ & $\begin{array}{l}\text { Concept } \\
\text { finalized }\end{array}$ & $\begin{array}{l}3 \text { sites } \\
\text { established }\end{array}$ & $\begin{array}{l}3 \text { sites } \\
\text { established }\end{array}$ & $\begin{array}{l}3 \text { sites } \\
\text { established }\end{array}$ & $\begin{array}{l}3 \text { sites } \\
\text { established }\end{array}$ \\
\hline $\begin{array}{l}\text { Public Education on } \\
\text { Tourism and } \\
\text { Improving security }\end{array}$ & $\begin{array}{l}\text { Launch public education } \\
\text { programme }\end{array}$ & & $\begin{array}{l}\text { Plan } \\
\text { developed } \\
\text { Funding } \\
\text { secured } \\
\end{array}$ & Implemented & $\begin{array}{l}\text { Better } \\
\text { awareness } \\
\text { and reception }\end{array}$ & $\begin{array}{l}\text { Better } \\
\text { awareness } \\
\text { and reception }\end{array}$ \\
\hline Product development & $\begin{array}{l}\text { Improve crafts, cuisine, display } \\
\text { etc. }\end{array}$ & & $\begin{array}{l}\text { Project } \\
\text { developed }\end{array}$ & 2 workshops & 2 workshops & 2 workshops \\
\hline $\begin{array}{l}\text { Local community } \\
\text { capacity building }\end{array}$ & $\begin{array}{l}\text { Establish broad based } \\
\text { Community Tourism } \\
\text { Management Committee }\end{array}$ & & $\begin{array}{l}\text { Concept } \\
\text { finalized }\end{array}$ & 3 committees & 3 committees & 3 committees \\
\hline \multicolumn{7}{|l|}{ AGRICULTURE } \\
\hline $\begin{array}{l}\text { Refining the role of } \\
\text { the Ministry of } \\
\text { Agriculture/strengthe } \\
\text { ning its capacity }\end{array}$ & $\begin{array}{l}\text { i) comprehensive review of } \\
\text { role of Ministry of Agriculture } \\
\text { ii) Launch organic farming } \\
\text { incentive programme } \\
\text { Teach Agricultural science in } \\
\text { schools }\end{array}$ & $\begin{array}{l}\text { RMU engaged } \\
\text { Working group }\end{array}$ & $\begin{array}{l}\text { Re } \\
\text { organization } \\
\text { of the Ministry }\end{array}$ & & & \\
\hline $\begin{array}{l}\text { Strengthening science } \\
\text { technology in } \\
\text { Agriculture } \\
\text { (production, } \\
\text { productivity, } \\
\text { seasonality) }\end{array}$ & $\begin{array}{l}\text { i) Improve farmer education } \\
\text { ii) Explore hydro phonics, } \\
\text { irrigation etc. } \\
\text { iii) Expand and better manage } \\
\text { of green house technology }\end{array}$ & & $\begin{array}{l}\text { Programme } \\
\text { formulated }\end{array}$ & $\begin{array}{l}\text { Programme } \\
\text { implemented }\end{array}$ & $\begin{array}{l}\text { Programme } \\
\text { implemented }\end{array}$ & $\begin{array}{l}\text { Programme } \\
\text { implemented }\end{array}$ \\
\hline $\begin{array}{l}\text { Promote agricultural } \\
\text { marketing and } \\
\text { market penetration }\end{array}$ & $\begin{array}{l}\text { Enhance sector's capacity for } \\
\text { market penetration }\end{array}$ & $\begin{array}{l}\text { Meetings } \\
\text { conducted }\end{array}$ & $\begin{array}{l}\text { Task force } \\
\text { formed }\end{array}$ & $\begin{array}{l}\text { Recommendat } \\
\text { ions } \\
\text { implemented }\end{array}$ & Implemented & Implemented \\
\hline $\begin{array}{l}\text { Provision of } \\
\text { transportation for } \\
\text { marketing of } \\
\text { agricultural produce. }\end{array}$ & $\begin{array}{l}\text { Facilitate private sector in } \\
\text { provision of transportation } \\
\text { facilities. }\end{array}$ & & $\begin{array}{l}\text { Increased } \\
\text { transportation } \\
\text { available. }\end{array}$ & $\begin{array}{l}\text { Increased } \\
\text { transportation } \\
\text { available }\end{array}$ & $\begin{array}{l}\text { Increased } \\
\text { transportation } \\
\text { available }\end{array}$ & $\begin{array}{l}\text { Increased } \\
\text { transportation } \\
\text { available }\end{array}$ \\
\hline $\begin{array}{l}\text { Improve and establish } \\
\text { micro credit scheme } \\
\text { for agriculture }\end{array}$ & $\begin{array}{l}\text { i) Review micro credit facilities } \\
\text { available to farmers } \\
\text { (accessibility) }\end{array}$ & & Review & Implemented & Implemented & Implemented \\
\hline $\begin{array}{l}\text { Improvement of } \\
\text { systems of } \\
\text { cooperation/farmer } \\
\text { organizations } \\
\end{array}$ & $\begin{array}{l}\text { i) Initiate farmers cooperatives } \\
\text { ii) Encourage cooperation in } \\
\text { marketing }\end{array}$ & & & & & \\
\hline $\begin{array}{l}\text { Increase farmer } \\
\text { productivity and } \\
\text { competitiveness }\end{array}$ & $\begin{array}{l}\text { i) Launch competitive farmer } \\
\text { award scheme } \\
\text { ii) Launch young farmers } \\
\text { incentive Programme } \\
\text { iii) Change the wage system }\end{array}$ & & $\begin{array}{l}\text { Develop Prog. } \\
\text { Amend Wage } \\
\text { legislation }\end{array}$ & Implemented & Implemented & Implemented \\
\hline \multicolumn{7}{|l|}{ FISHERIES } \\
\hline $\begin{array}{l}\text { Improving fisheries } \\
\text { Management }\end{array}$ & $\begin{array}{l}\text { i) Co- Management of Artisanal } \\
\text { fisheries } \\
\text { ii) Improved offshore fisheries } \\
\text { surveillance }\end{array}$ & $\begin{array}{l}\text { i) Co-mgt } \\
\text { areas } \\
\text { Identified } \\
\text { ii) } \\
\text { Surveillance } \\
\text { increased } \\
\end{array}$ & $\begin{array}{l}\text { i) Mgt. } \\
\text { implemented } \\
\text { ii) } \\
\text { Implemented }\end{array}$ & $\begin{array}{l}\text { i) Mgt. } \\
\text { implemented } \\
\text { ii) } \\
\text { Implemented }\end{array}$ & $\begin{array}{l}\text { i) Mgt. } \\
\text { implemented } \\
\text { ii) } \\
\text { Implemented }\end{array}$ & $\begin{array}{l}\text { i) Mgt. } \\
\text { Implemented } \\
\text { ii) } \\
\text { implemented }\end{array}$ \\
\hline $\begin{array}{l}\text { Conclude } \\
\text { arrangements for } \\
\text { management of } \\
\text { fisheries complexes. }\end{array}$ & $\begin{array}{l}\text { Examine options (e.g. statutory } \\
\text { or cooperative corporation, full } \\
\text { privatization,) for management } \\
\text { of fisheries operations. }\end{array}$ & & $\begin{array}{l}\text { Organization } \\
\text { formed }\end{array}$ & $\begin{array}{l}\text { manage } \\
\text { complex }\end{array}$ & $\begin{array}{l}\text { Complex self } \\
\text { financing }\end{array}$ & $\begin{array}{l}\text { Complex } \\
\text { privatized }\end{array}$ \\
\hline $\begin{array}{l}\text { Enhance offshore } \\
\text { fisheries capabilities. }\end{array}$ & $\begin{array}{l}\text { Facilitate procurement of } \\
\text { fishing vessels by private. }\end{array}$ & & $\begin{array}{l}\text { Project } \\
\text { developed \& } \\
\text { submitted }\end{array}$ & $\begin{array}{l}6 \text { vessels } \\
\text { obtained }\end{array}$ & $\begin{array}{l}\text { Vessels } \\
\text { operational }\end{array}$ & $\begin{array}{l}\text { Vessels } \\
\text { operational }\end{array}$ \\
\hline
\end{tabular}




\begin{tabular}{|c|c|c|c|c|c|c|}
\hline \multicolumn{7}{|l|}{$\begin{array}{l}\text { MANUFACTURING/ } \\
\text { AGRO INDUSTRIES }\end{array}$} \\
\hline $\begin{array}{l}\text { Link agro-processing } \\
\text { to agricultural } \\
\text { production. }\end{array}$ & $\begin{array}{l}\text { i) Determine agro-processing } \\
\text { demands for agricultural } \\
\text { products. } \\
\text { ii) Strengthening marketing ties } \\
\text { between agricultural producers } \\
\text { and agro-industries }\end{array}$ & & $\begin{array}{l}\text { DEXIA, agro- } \\
\text { processors } \\
\text { and agri } \\
\text { associations } \\
\text { meeting }\end{array}$ & $\begin{array}{l}\text { Improving } \\
\text { marketing ties }\end{array}$ & $\begin{array}{l}\text { Improving } \\
\text { marketing ties }\end{array}$ & $\begin{array}{l}\text { Regular } \\
\text { supply of raw } \\
\text { materials }\end{array}$ \\
\hline $\begin{array}{l}\text { Increase exports of } \\
\text { agro-products. }\end{array}$ & $\begin{array}{l}\text { Promoting joint venture } \\
\text { relationships with foreign } \\
\text { companies for the export } \\
\text { marketing of Dominican agro- } \\
\text { products. }\end{array}$ & & $\begin{array}{l}\text { Partners } \\
\text { identified } \\
\text { Campaign } \\
\text { launched }\end{array}$ & $\begin{array}{l}2 \text { joint } \\
\text { ventures } \\
\text { formed }\end{array}$ & $\begin{array}{l}2 \text { joint } \\
\text { ventures } \\
\text { formed }\end{array}$ & $\begin{array}{l}\text { Joint ventures } \\
\text { functioning }\end{array}$ \\
\hline $\begin{array}{l}\text { Improve micro credit } \\
\text { for agro-processing }\end{array}$ & $\begin{array}{l}\text { Promote greater coverage of } \\
\text { micro-credit to small agro- } \\
\text { producers, including cottage } \\
\text { industries by Financial } \\
\text { Institutions }\end{array}$ & & $\begin{array}{l}\text { Funding } \\
\text { conditions } \\
\text { improved }\end{array}$ & Implemented & & \\
\hline $\begin{array}{l}\text { Provide } \\
\text { infrastructure for } \\
\text { start up cottage } \\
\text { industries }\end{array}$ & $\begin{array}{l}\text { Construct and establish } \\
\text { incubator facilities }\end{array}$ & & $\begin{array}{l}\text { Proposals } \\
\text { prepared }\end{array}$ & $\begin{array}{l}\text { Funding } \\
\text { secured }\end{array}$ & $\begin{array}{l}2 \text { incubators } \\
\text { built }\end{array}$ & $\begin{array}{l}\text { Incubator } \\
\text { operating. }\end{array}$ \\
\hline $\begin{array}{l}\text { Build capacity for } \\
\text { testing and quality } \\
\text { control }\end{array}$ & $\begin{array}{l}\text { i) Establish a National Testing } \\
\text { Laboratory } \\
\text { ii) Establish a quality control } \\
\text { handbook }\end{array}$ & & $\begin{array}{l}\text { Planning for } \\
\text { the National } \\
\text { Testing } \\
\text { Laboratory }\end{array}$ & $\begin{array}{l}\text { Building } \\
\text { constructed. }\end{array}$ & $\begin{array}{l}\text { Operation of } \\
\text { facility } \\
\text { Handbook } \\
\text { published }\end{array}$ & \\
\hline \multicolumn{7}{|l|}{$\begin{array}{l}\text { INFORMATION AND } \\
\text { COMMUNICATION } \\
\text { TECHNOLOGY (ICT) } \\
\end{array}$} \\
\hline $\begin{array}{l}\text { ICT policy } \\
\text { formulation and } \\
\text { implementation. }\end{array}$ & $\begin{array}{l}\text { i) Endorse ICT policy } \\
\text { ii) Create the enabling } \\
\text { environment for E-Business. }\end{array}$ & $\begin{array}{l}\text { Policy } \\
\text { adopted }\end{array}$ & $\begin{array}{l}\text { Policy } \\
\text { implemented }\end{array}$ & $\begin{array}{l}\text { Policy } \\
\text { implemented }\end{array}$ & $\begin{array}{l}\text { Policy } \\
\text { implemented }\end{array}$ & $\begin{array}{l}\text { Policy } \\
\text { implemented }\end{array}$ \\
\hline $\begin{array}{l}\text { Establish of } \\
\text { Government } \\
\text { administrative } \\
\text { network }\end{array}$ & $\begin{array}{l}\text { Finalise project proposal on D- } \\
\text { GEN. }\end{array}$ & & $\begin{array}{l}\text { Proposal } \\
\text { submitted to } \\
\text { donor agency }\end{array}$ & $\begin{array}{l}\text { Implement } \\
\text { project }\end{array}$ & $\begin{array}{l}\text { Implement } \\
\text { project }\end{array}$ & $\begin{array}{l}\text { Implement } \\
\text { project }\end{array}$ \\
\hline $\begin{array}{l}\text { Improve of regulatory } \\
\text { framework. }\end{array}$ & $\begin{array}{l}\text { i) Improve and reduce the cost } \\
\text { of communication services. } \\
\text { ii) Improve training in } \\
\text { telecommunication services. } \\
\text { iii) Review regulatory } \\
\text { framework to make it more } \\
\text { conducive to growth and } \\
\text { efficiency. }\end{array}$ & $\begin{array}{l}\text { Actions } \\
\text { implemented }\end{array}$ & $\begin{array}{l}\text { Actions } \\
\text { implemented }\end{array}$ & $\begin{array}{l}\text { Actions } \\
\text { implemented }\end{array}$ & $\begin{array}{l}\text { Actions } \\
\text { implemented }\end{array}$ & $\begin{array}{l}\text { i) and ii) } \\
\text { Implemented }\end{array}$ \\
\hline \multicolumn{7}{|l|}{ CONSTRUCTION } \\
\hline $\begin{array}{l}\text { Construction of } \\
\text { affordable housing }\end{array}$ & $\begin{array}{l}\text { i) Launch private enterprise } \\
\text { affordable housing programme. } \\
\text { ii) Utilising government owned } \\
\text { lands for sale for housing. }\end{array}$ & & $\begin{array}{l}\text { Scheme } \\
\text { established }\end{array}$ & $\begin{array}{l}\text { Scheme } \\
\text { implemented. }\end{array}$ & $\begin{array}{l}\text { Scheme } \\
\text { implemented }\end{array}$ & $\begin{array}{l}\text { Scheme } \\
\text { implemented }\end{array}$ \\
\hline $\begin{array}{l}\text { Land allocation and } \\
\text { site development. }\end{array}$ & $\begin{array}{l}\text { i) Implement the shelter } \\
\text { development programme. }\end{array}$ & & $\begin{array}{l}\text { Funding } \\
\text { negotiated. }\end{array}$ & $\begin{array}{l}2 \text { Sites } \\
\text { established. }\end{array}$ & Houses built. & $\begin{array}{l}\text { Houses } \\
\text { occupied. }\end{array}$ \\
\hline $\begin{array}{l}\text { Encourage DIASPORA } \\
\text { investment in } \\
\text { housing. }\end{array}$ & Formulate a DIASPORA policy. & & $\begin{array}{l}\text { Policy } \\
\text { adopted. }\end{array}$ & $\begin{array}{l}\text { Policy } \\
\text { implemented }\end{array}$ & $\begin{array}{l}\text { Policy } \\
\text { implemented. }\end{array}$ & $\begin{array}{l}\text { Policy } \\
\text { implemented. }\end{array}$ \\
\hline $\begin{array}{l}\text { Improve credit for } \\
\text { housing. }\end{array}$ & $\begin{array}{l}\text { Dialogue with financial } \\
\text { institutions. }\end{array}$ & $\begin{array}{l}\text { Rates } \\
\text { reduced. }\end{array}$ & $\begin{array}{l}\text { Rates } \\
\text { reduced. }\end{array}$ & $\begin{array}{l}\text { More houses } \\
\text { built. }\end{array}$ & $\begin{array}{l}\text { More houses } \\
\text { built }\end{array}$ & $\begin{array}{l}\text { More houses } \\
\text { built }\end{array}$ \\
\hline \multicolumn{7}{|l|}{ ENERGY } \\
\hline $\begin{array}{l}\text { Development of } \\
\text { geothermal energy. }\end{array}$ & Conduct feasibility study. & & $\begin{array}{l}\text { Demonstra- } \\
\text { tion plant } \\
\text { established }\end{array}$ & $\begin{array}{l}\text { Demonstra- } \\
\text { tion plant } \\
\text { established }\end{array}$ & Plant built. & $\begin{array}{l}\text { Plant } \\
\text { operational. }\end{array}$ \\
\hline
\end{tabular}




\begin{tabular}{|c|c|c|c|c|c|c|}
\hline $\begin{array}{l}\text { Policy in favor of } \\
\text { energy efficiency } \\
\text { measures. }\end{array}$ & $\begin{array}{l}\text { i) Develop an energy } \\
\text { conservation policy. } \\
\text { ii) Encourage solar power in } \\
\text { housing and commercial } \\
\text { buildings. } \\
\text { iii) Introduce a new Energy } \\
\text { Supplies Act. }\end{array}$ & & $\begin{array}{l}\text { Policy } \\
\text { formulated. } \\
\text { Act drafted. }\end{array}$ & $\begin{array}{l}\text { Policy } \\
\text { implemented } \\
\text { Act passed }\end{array}$ & $\begin{array}{l}\text { Policy } \\
\text { implemented }\end{array}$ & $\begin{array}{l}\text { Policy } \\
\text { implemented }\end{array}$ \\
\hline \multicolumn{7}{|l|}{ TRANSPORTATION } \\
\hline $\begin{array}{l}\text { Road rehabilitation } \\
\text { and improvement. } \\
\text { Port improvement. }\end{array}$ & $\begin{array}{l}\text { Formulate comprehensive plan } \\
\text { for road maintenance and } \\
\text { improvement. } \\
\text { Formulate / implement plan for } \\
\text { port modernization. }\end{array}$ & & $\begin{array}{l}\text { Project } \\
\text { approved \& } \\
\text { implemented }\end{array}$ & $\begin{array}{l}50 \mathrm{~km} \text { of } \\
\text { roads } \\
\text { rehabilitated }\end{array}$ & $\begin{array}{l}50 \mathrm{~km} \text { of } \\
\text { roads } \\
\text { rehabilitated }\end{array}$ & $\begin{array}{l}50 \mathrm{~km} \text { of } \\
\text { roads } \\
\text { rehabilitated }\end{array}$ \\
\hline \multicolumn{7}{|l|}{ WATER } \\
\hline $\begin{array}{l}\text { Large increase in } \\
\text { export of bulk and } \\
\text { bottled water. }\end{array}$ & $\begin{array}{l}\text { Facilitate expansion of private } \\
\text { sector production and export of } \\
\text { water. }\end{array}$ & $\begin{array}{l}\text { Markets } \\
\text { found. } \\
\text { Financing } \\
\text { secured. Plant } \\
\text { constructed. }\end{array}$ & $\begin{array}{l}\text { Water } \\
\text { exported to } \\
\text { key markets. }\end{array}$ & $\begin{array}{l}\text { Water } \\
\text { exported to } \\
\text { key markets. }\end{array}$ & $\begin{array}{l}\text { Water } \\
\text { exported to } \\
\text { key markets. }\end{array}$ & $\begin{array}{l}\text { Water } \\
\text { exported to } \\
\text { key markets. }\end{array}$ \\
\hline $\begin{array}{l}\text { Maintain good quality } \\
\text { water }\end{array}$ & $\begin{array}{l}\text { Protect water catchments and } \\
\text { regular and transparent water } \\
\text { testing }\end{array}$ & Meetings held & $\begin{array}{l}\text { Testing } \\
\text { increase }\end{array}$ & $\begin{array}{l}\text { Testing } \\
\text { maintained }\end{array}$ & $\begin{array}{l}\text { Testing } \\
\text { maintained }\end{array}$ & $\begin{array}{l}\text { Water quality } \\
\text { improved by } \\
50 \%\end{array}$ \\
\hline \multicolumn{7}{|l|}{$\begin{array}{l}\text { DEVELOPMENT OF } \\
\text { MICRO AND SMALL } \\
\text { ENTERPRISES }\end{array}$} \\
\hline $\begin{array}{l}\text { Improve the policy } \\
\text { framework }\end{array}$ & $\begin{array}{l}\text { Formulate and implement a } \\
\text { national policy }\end{array}$ & & $\begin{array}{l}\text { Working group } \\
\text { established }\end{array}$ & $\begin{array}{l}\text { Policy } \\
\text { adopted }\end{array}$ & $\begin{array}{l}\text { Policy } \\
\text { prompted }\end{array}$ & $\begin{array}{l}\text { Policy fully } \\
\text { utilized }\end{array}$ \\
\hline Provide micro credit & $\begin{array}{l}\text { Review credit schemes and } \\
\text { make them more client } \\
\text { friendly. }\end{array}$ & & $\begin{array}{l}\text { Schemes } \\
\text { restructured. }\end{array}$ & $\begin{array}{l}\text { Greater } \\
\text { access } \\
\text { achieved. }\end{array}$ & $\begin{array}{l}\text { Greater } \\
\text { access } \\
\text { achieved. }\end{array}$ & $\begin{array}{l}\text { Greater } \\
\text { access } \\
\text { achieved. }\end{array}$ \\
\hline $\begin{array}{l}\text { Improve the } \\
\text { regulatory } \\
\text { framework. }\end{array}$ & $\begin{array}{l}\text { Review legislation for } \\
\text { continued viability of micro and } \\
\text { small enterprises. }\end{array}$ & & $\begin{array}{l}\text { Working group } \\
\text { established }\end{array}$ & $\begin{array}{l}\text { Legislation } \\
\text { adopted }\end{array}$ & $\begin{array}{l}\text { Legislation } \\
\text { adopted }\end{array}$ & $\begin{array}{l}\text { Legislation } \\
\text { fully used }\end{array}$ \\
\hline $\begin{array}{l}\text { Institutional capacity } \\
\text { enhancement }\end{array}$ & $\begin{array}{l}\text { Obtain micro-business } \\
\text { development expert to prepare } \\
\text { plan for micro-business } \\
\text { development. }\end{array}$ & $\begin{array}{l}\text { Expert } \\
\text { recruited. }\end{array}$ & $\begin{array}{l}\text { Plan } \\
\text { completed. }\end{array}$ & $\begin{array}{l}\text { Plan } \\
\text { implemented. } \\
\text { Sector } \\
\text { expands. }\end{array}$ & $\begin{array}{l}\text { Plan } \\
\text { implemented. } \\
\text { Sector } \\
\text { expands }\end{array}$ & $\begin{array}{l}\text { Plan } \\
\text { implemented. } \\
\text { Sector } \\
\text { expands }\end{array}$ \\
\hline \multicolumn{7}{|l|}{$\begin{array}{l}\text { PROMOTION OF } \\
\text { GOOD GOVERNANCE }\end{array}$} \\
\hline $\begin{array}{l}\text { Public participation } \\
\text { in national policy } \\
\text { formulation. }\end{array}$ & $\begin{array}{l}\text { Organise and institutionalize } \\
\text { consultations on policy and } \\
\text { plan formulation and } \\
\text { implementation. }\end{array}$ & $\begin{array}{l}\text { Pre-budget } \\
\text { consultations. }\end{array}$ & $\begin{array}{l}\text { Consultations } \\
\text { for GSPS } \\
\text { review. }\end{array}$ & $\begin{array}{l}\text { Consultations } \\
\text { for GSPS } \\
\text { review. }\end{array}$ & $\begin{array}{l}\text { Consultations } \\
\text { for GSPS } \\
\text { review. }\end{array}$ & $\begin{array}{l}\text { Consultations } \\
\text { for GSPS } \\
\text { review. }\end{array}$ \\
\hline $\begin{array}{l}\text { Strengthen the local } \\
\text { Government system }\end{array}$ & $\begin{array}{l}\text { Implement recommendations of } \\
\text { the Local Government study } \\
\text { report of } 1999\end{array}$ & & $\begin{array}{l}\text { Recommen- } \\
\text { dations } \\
\text { implemented. }\end{array}$ & $\begin{array}{l}\text { New } \\
\text { legislation } \\
\text { adopted. }\end{array}$ & $\begin{array}{l}\text { New } \\
\text { arrangements } \\
\text { implemented. }\end{array}$ & $\begin{array}{l}\text { New } \\
\text { arrangements } \\
\text { implemented. }\end{array}$ \\
\hline \multicolumn{7}{|l|}{ HEALTH } \\
\hline $\begin{array}{l}\text { Strengthen Primary } \\
\text { Health Care (PHC) } \\
\text { system to deliver } \\
\text { more equitable } \\
\text { preventative } \\
\text { services. }\end{array}$ & $\begin{array}{l}\text { 1. Repair and renovate health } \\
\text { centers. } \\
\text { 2. Construct Roseau and Clifton } \\
\text { Health Centres }\end{array}$ & $\begin{array}{l}\text { Conduct } \\
\text { evaluation of } \\
\text { current } \\
\text { structure }\end{array}$ & $\begin{array}{l}\text { 1. Relevance } \\
\text { of current } \\
\text { structure of } \\
\text { PHC Service } \\
\text { assessed by } \\
\text { Jan } 2007 \\
\text { 2. Construct } \\
\text { Roseau Health } \\
\text { Centre }\end{array}$ & $\begin{array}{l}\text { Elaboration of } \\
\text { action plan }\end{array}$ & $\begin{array}{l}\text { Implementati } \\
\text { on of action } \\
\text { plan }\end{array}$ & $\begin{array}{l}\text { Action plan on } \\
\text { going - } 40 \% \\
\text { reduction in } \\
\text { incidence of } \\
\text { chronic and } \\
\text { non - } \\
\text { communicable } \\
\text { diseases. }\end{array}$ \\
\hline $\begin{array}{l}\text { Reduced incidence of } \\
\text { HIV AIDS in the } \\
\text { populace }\end{array}$ & $\begin{array}{l}\text { Implement the AIDS/HIV } \\
\text { strategic plan }\end{array}$ & $\begin{array}{l}\text { AIDS/HIV } \\
\text { strategic plan } \\
\text { implemented }\end{array}$ & $50 \%$ complete & $75 \%$ complete & $\begin{array}{l}100 \% \\
\text { complete }\end{array}$ & $50 \%$ reduction \\
\hline $\begin{array}{l}\text { Build public } \\
\text { awareness of lifestyle } \\
\text { diseases. }\end{array}$ & $\begin{array}{l}\text { Strengthen alliances with } \\
\text { media, educational institutions } \\
\text { and Private Sector for Public } \\
\text { Education. }\end{array}$ & & $\begin{array}{l}\text { Action plan } \\
\text { prepared }\end{array}$ & $\begin{array}{l}\text { Implementati } \\
\text { on ongoing }\end{array}$ & $\begin{array}{l}\text { Implementati } \\
\text { on ongoing }\end{array}$ & $\begin{array}{l}\text { Implementati } \\
\text { on ongoing }\end{array}$ \\
\hline
\end{tabular}




\begin{tabular}{|c|c|c|c|c|c|c|}
\hline $\begin{array}{l}\text { Strengthen Secondary } \\
\text { Care Delivery System }\end{array}$ & $\begin{array}{l}\text { 1. Strengthen } \mathrm{PMH} \\
\text { management structure. } \\
\text { 2. Upgrade of services provided } \\
\text { at PMH. }\end{array}$ & $\begin{array}{l}\text { 1. Review } \\
\text { current } \\
\text { management } \\
\text { structure at } \\
\text { PMH. } \\
\text { 2.Introduction } \\
\text { of Intensive } \\
\text { Care Unit }\end{array}$ & $\begin{array}{l}\text { Proposal } \\
\text { submitted to } \\
\text { Cabinet to } \\
\text { revamp } \\
\text { management } \\
\text { structure }\end{array}$ & $\begin{array}{l}\text { Implementati } \\
\text { on of proposal }\end{array}$ & $\begin{array}{l}\text { Implementati } \\
\text { on ongoing }\end{array}$ & $\begin{array}{l}\text { Implementati } \\
\text { on }\end{array}$ \\
\hline $\begin{array}{l}\text { Develop National } \\
\text { Health Care Financing } \\
\text { Mechanism }\end{array}$ & $\begin{array}{l}\text { Evaluate User Fee Programme } \\
\text { and Introduce National Health } \\
\text { Coverage. }\end{array}$ & $\begin{array}{l}\text { 1. Current } \\
\text { regime } \\
\text { reviewed } \\
\text { 2. Consensus } \\
\text { building on } \\
\text { the } \\
\text { introduction } \\
\text { of Universal } \\
\text { Health } \\
\text { Coverage } \\
\text { (UHC) }\end{array}$ & $\begin{array}{l}\text { Proposal } \\
\text { made, } \\
\text { Cabinet } \\
\text { decision }\end{array}$ & $\begin{array}{l}\text { Consensus } \\
\text { building and } \\
\text { public } \\
\text { education on } \\
\text { UHC ongoing }\end{array}$ & $\begin{array}{l}\text { Introduction } \\
\text { of UHC }\end{array}$ & $\begin{array}{l}\text { Implementati } \\
\text { on }\end{array}$ \\
\hline $\begin{array}{l}\text { Strengthening } \\
\text { Private/Public } \\
\text { partnership in Health } \\
\text { and Social } \\
\text { Development }\end{array}$ & $\begin{array}{l}\text { Conduct a study and establish } \\
\text { mechanism for necessary } \\
\text { Private sector participation in } \\
\text { health and social development. }\end{array}$ & & $\begin{array}{l}\text { Draft paper } \\
\text { prepared }\end{array}$ & $\begin{array}{l}1 \text { partnership } \\
\text { established }\end{array}$ & $\begin{array}{l}2 \text { partner- } \\
\text { ships } \\
\text { established }\end{array}$ & $\begin{array}{l}\text { Partnerships } \\
\text { evaluated }\end{array}$ \\
\hline $\begin{array}{l}\text { Availability of } \\
\text { appropriate medical } \\
\text { supplies }\end{array}$ & $\begin{array}{l}\text { Ensure continued participation } \\
\text { in OECS drug procurement } \\
\text { programme. }\end{array}$ & $\begin{array}{l}\text { Timely } \\
\text { payment } \\
\text { made }\end{array}$ & $\begin{array}{l}\text { Timely } \\
\text { payment } \\
\text { made }\end{array}$ & $\begin{array}{l}\text { Timely } \\
\text { payment } \\
\text { made }\end{array}$ & $\begin{array}{l}\text { Timely } \\
\text { payment } \\
\text { made }\end{array}$ & $\begin{array}{l}\text { Timely } \\
\text { payment } \\
\text { made }\end{array}$ \\
\hline \multicolumn{7}{|l|}{ EDUCATION } \\
\hline $\begin{array}{l}\text { Achieve universal } \\
\text { secondary education }\end{array}$ & $\begin{array}{l}\text { Continued expansion of } \\
\text { universal secondary education } \\
\text { programme. }\end{array}$ & $\begin{array}{l}\text { Universal } \\
\text { secondary } \\
\text { education } \\
\text { achieved. }\end{array}$ & $\begin{array}{l}\text { USE } \\
\text { maintained }\end{array}$ & $\begin{array}{l}\text { USE } \\
\text { maintained }\end{array}$ & $\begin{array}{l}\text { USE } \\
\text { maintained }\end{array}$ & $\begin{array}{l}\text { USE } \\
\text { maintained }\end{array}$ \\
\hline $\begin{array}{l}\text { Increase efficiency of } \\
\text { school system. }\end{array}$ & $\begin{array}{l}\text { Keep under review the issue of } \\
\text { number of small schools. }\end{array}$ & $\begin{array}{l}\text { Further } \\
\text { review } \\
\text { conducted. }\end{array}$ & $\begin{array}{l}\text { Action taken } \\
\text { pursuant to } \\
\text { review. }\end{array}$ & $\begin{array}{l}\text { Action taken } \\
\text { pursuant to } \\
\text { review. }\end{array}$ & $\begin{array}{l}\text { Action taken } \\
\text { pursuant to } \\
\text { review. }\end{array}$ & $\begin{array}{l}\text { Action taken } \\
\text { pursuant to } \\
\text { review. }\end{array}$ \\
\hline $\begin{array}{l}\text { Improve quality of } \\
\text { teaching staff. }\end{array}$ & $\begin{array}{l}\text { Train and hire qualified } \\
\text { teachers. }\end{array}$ & & $\begin{array}{l}25 \% \\
\text { improvement } \\
\text { in quality of } \\
\text { teaching } \\
\text { staff. } \\
\end{array}$ & $\begin{array}{l}50 \% \\
\text { improvement } \\
\text { in quality of } \\
\text { teaching } \\
\text { staff. } \\
\end{array}$ & $\begin{array}{l}75 \% \\
\text { improvement } \\
\text { in quality of } \\
\text { teaching } \\
\text { staff. } \\
\end{array}$ & $\begin{array}{l}100 \% \\
\text { improvement } \\
\text { in quality of } \\
\text { teaching } \\
\text { staff. }\end{array}$ \\
\hline $\begin{array}{l}\text { Improved tertiary } \\
\text { education }\end{array}$ & $\begin{array}{l}\text { i) Continued improvement in } \\
\text { state college. } \\
\text { ii) Establishing distance- } \\
\text { learning linkages. }\end{array}$ & & $\begin{array}{l}\text { Distant- } \\
\text { learning } \\
\text { Agreement } \\
\text { with regional } \\
\text { community } \\
\text { colleges }\end{array}$ & $\begin{array}{l}\text { Library } \\
\text { facilities } \\
\text { improved } \\
\text { Implementati } \\
\text { on of } \\
\text { distance- } \\
\text { learning } \\
\text { programme } \\
\end{array}$ & $\begin{array}{l}\text { Standards } \\
\text { increase } \\
\text { Implementati } \\
\text { on of } \\
\text { distance- } \\
\text { learning } \\
\text { programme }\end{array}$ & $\begin{array}{l}\text { Pass rate } \\
\text { improved by } \\
25 \% \\
\text { Implementati } \\
\text { on of } \\
\text { distance- } \\
\text { learning } \\
\text { programme } \\
\end{array}$ \\
\hline $\begin{array}{l}\text { Improved cost } \\
\text { recovery programme } \\
\text { in secondary and } \\
\text { tertiary education } \\
\end{array}$ & $\begin{array}{l}\text { Revise secondary and tertiary } \\
\text { education fees }\end{array}$ & & $\begin{array}{l}\text { Recommendat } \\
\text { ions approved }\end{array}$ & $\begin{array}{l}\text { Recommendat } \\
\text { ions } \\
\text { implemented }\end{array}$ & $\begin{array}{l}\text { Recommendat } \\
\text { ions } \\
\text { implemented }\end{array}$ & $\begin{array}{l}\text { Recommendat } \\
\text { ions } \\
\text { implemented }\end{array}$ \\
\hline $\begin{array}{l}\text { Promote sports and } \\
\text { fitness in schools and } \\
\text { communities. }\end{array}$ & $\begin{array}{l}\text { i) Improve and expand sports } \\
\text { and fitness facilities in schools } \\
\text { or regions. } \\
\text { ii) Construct national sports } \\
\text { stadium in Roseau. }\end{array}$ & $\begin{array}{l}\text { i) Develop } \\
\text { concept } \\
\text { ii) Start } \\
\text { construction }\end{array}$ & $\begin{array}{l}\text { i) Develop } \\
\text { Strategy/Acti } \\
\text { on plan } \\
\text { ii) } \\
\text { Construction } \\
\text { in progress }\end{array}$ & $\begin{array}{l}\text { i) Implement } \\
\text { Strategy/Acti } \\
\text { on plan } \\
\text { ii) Facility } \\
\text { completed }\end{array}$ & $\begin{array}{l}\text { i) Facilities } \\
\text { fully } \\
\text { functional } \\
\text { ii) Facility in } \\
\text { full use }\end{array}$ & $\begin{array}{l}\text { i) Facilities } \\
\text { fully } \\
\text { operational } \\
\text { ii) Facility in } \\
\text { full use }\end{array}$ \\
\hline $\begin{array}{l}\text { Increased access of } \\
\text { the poor to } \\
\text { secondary education }\end{array}$ & $\begin{array}{l}\text { i) Strengthen and expand } \\
\text { education Trust Fund and other } \\
\text { support programme. } \\
\text { ii) Work with the Christian } \\
\text { Children Fund (CCF) }\end{array}$ & $\begin{array}{l}\text { Meetings } \\
\text { conducted } \\
\text { Meetings } \\
\text { conducted }\end{array}$ & $\begin{array}{l}\text { Funding } \\
\text { negotiated } \\
\text { Partnership } \\
\text { established }\end{array}$ & $\begin{array}{l}\text { Budget } \\
\text { doubled } \\
\text { Information } \\
\text { exchange/ } \\
\text { Sharing } \\
\end{array}$ & $\begin{array}{l}\text { Budget } \\
\text { doubled } \\
\text { Joint project } \\
\text { established }\end{array}$ & $\begin{array}{l}100 \% \text { increase } \\
\text { in } \\
\text { beneficiaries } \\
\text { Joint project } \\
\text { fully } \\
\text { implemented }\end{array}$ \\
\hline
\end{tabular}




\begin{tabular}{|c|c|c|c|c|c|c|}
\hline $\begin{array}{l}\text { Achieve greater } \\
\text { match between the } \\
\text { education system and } \\
\text { the labor market. }\end{array}$ & $\begin{array}{l}\text { i) Review technical education } \\
\text { at secondary level and remove } \\
\text { stigma } \\
\text { ii) Maintain student guidance } \\
\text { counseling programme. }\end{array}$ & $\begin{array}{l}\text { Meetings } \\
\text { conducted } \\
\text { Meetings } \\
\text { conducted }\end{array}$ & $\begin{array}{l}\text { Programme } \\
\text { implemented } \\
\text { Counseling in } \\
\text { all Sec. } \\
\text { schools }\end{array}$ & $\begin{array}{l}\text { Programme } \\
\text { ongoing } \\
\text { Done in all } \\
\text { Sec. schools }\end{array}$ & $\begin{array}{l}\text { Programme } \\
\text { ongoing } \\
\text { Done in all } \\
\text { Sec. schools }\end{array}$ & $\begin{array}{l}\text { Programme } \\
\text { ongoing } \\
\text { Done in all } \\
\text { Sec. Schools }\end{array}$ \\
\hline $\begin{array}{l}\text { Improved school } \\
\text { curricula and } \\
\text { literacy. }\end{array}$ & $\begin{array}{l}\text { i) Implement BERP2 } \\
\text { ii) Build strong parent } \\
\text { involvement in education } \\
\text { through PTA etc. }\end{array}$ & $\begin{array}{l}\text { Ongoing } \\
\text { Meetings } \\
\text { Conducted }\end{array}$ & $\begin{array}{l}\text { Ongoing } \\
25 \% \\
\text { functioning }\end{array}$ & $\begin{array}{l}\text { Ongoing } \\
40 \% \\
\text { functioning }\end{array}$ & $\begin{array}{l}\text { Completed } \\
75 \% \\
\text { functioning }\end{array}$ & $\begin{array}{l}\text { Universal Sec. } \\
\text { Ed. Achieved } \\
\text { All } \\
\text { functioning }\end{array}$ \\
\hline $\begin{array}{l}\text { Promotion of skills } \\
\text { training. }\end{array}$ & $\begin{array}{l}\text { Provide support to operation } \\
\text { youth quake, calls, youth skills } \\
\text { training programme, adult } \\
\text { education. }\end{array}$ & $\begin{array}{l}\text { Conduct } \\
\text { meetings }\end{array}$ & $\begin{array}{l}\text { Develop } \\
\text { proposal }\end{array}$ & $\begin{array}{l}25 \% \text { increase } \\
\text { in grants and } \\
\text { contributions }\end{array}$ & $\begin{array}{l}\text { Contribution } \\
\text { maintained }\end{array}$ & $\begin{array}{l}25 \% \text { increase } \\
\text { in grant } \\
\text { /contributions }\end{array}$ \\
\hline \multicolumn{7}{|l|}{$\begin{array}{l}\text { COMMUNITY } \\
\text { DEVELOPMENT } \\
\end{array}$} \\
\hline $\begin{array}{l}\text { Improvement in } \\
\text { welfare programme. }\end{array}$ & $\begin{array}{l}\text { Expand and better target } \\
\text { welfare programme. }\end{array}$ & & $\begin{array}{l}\text { Recommend- } \\
\text { ations } \\
\text { adopted }\end{array}$ & $\begin{array}{l}\text { Implementati } \\
\text { on of } \\
\text { recommendati } \\
\text { ons } \\
\end{array}$ & $\begin{array}{l}\text { Implementati } \\
\text { on of } \\
\text { recommendati } \\
\text { ons } \\
\end{array}$ & $\begin{array}{l}\text { Implementati } \\
\text { on of } \\
\text { recommendati } \\
\text { ons }\end{array}$ \\
\hline $\begin{array}{l}\text { Improvement in local } \\
\text { community } \\
\text { governance. }\end{array}$ & $\begin{array}{l}\text { i) Initiate, work with and build } \\
\text { the capacity of Community } \\
\text { Based Organizations (CBO's). } \\
\text { ii) Build partnership with local } \\
\text { communities through local level } \\
\text { structures for participation in } \\
\text { national development, policy } \\
\text { formulation and planning }\end{array}$ & & $\begin{array}{l}\text { District } \\
\text { planning } \\
\text { sessions held }\end{array}$ & $\begin{array}{l}\text { District } \\
\text { sessions held }\end{array}$ & $\begin{array}{l}\text { District } \\
\text { sessions held }\end{array}$ & $\begin{array}{l}\text { District } \\
\text { sessions held }\end{array}$ \\
\hline $\begin{array}{l}\text { Expansion of systems } \\
\text { of cooperation and } \\
\text { community } \\
\text { cooperatives }\end{array}$ & $\begin{array}{l}\text { i) Community education, } \\
\text { mobilization and organization } \\
\text { programme. }\end{array}$ & & $\begin{array}{l}15 \\
\text { programmes } \\
\text { launched }\end{array}$ & $\begin{array}{l}40 \\
\text { programmes } \\
\text { launched }\end{array}$ & $\begin{array}{l}60 \\
\text { programmes } \\
\text { launched }\end{array}$ & $\begin{array}{l}90 \\
\text { programmes } \\
\text { launched }\end{array}$ \\
\hline \multicolumn{7}{|l|}{ CARIB COMMUNITY } \\
\hline $\begin{array}{l}\text { Pursue integrated } \\
\text { development for the } \\
\text { Carib people }\end{array}$ & $\begin{array}{l}\text { i) Implement the } \\
\text { recommendations of the Carib } \\
\text { Integrated Development Plan. } \\
\text { ii) Implement the Integrated } \\
\text { Community Development } \\
\text { Programme for the Carib } \\
\text { Territory. }\end{array}$ & & $\begin{array}{l}20 \% \\
\text { implemented } \\
20 \% \text { complete }\end{array}$ & $\begin{array}{l}40 \% \\
\text { implemented } \\
50 \% \text { complete }\end{array}$ & $\begin{array}{l}60 \% \\
\text { implemented } \\
75 \% \text { complete }\end{array}$ & $\begin{array}{l}80 \% \\
\text { implemented } \\
100 \% \\
\text { complete }\end{array}$ \\
\hline $\begin{array}{l}\text { Improvement in Carib } \\
\text { peoples' access to } \\
\text { financial services. }\end{array}$ & $\begin{array}{l}\text { Explore possibility of a } \\
\text { guarantee fund for Carib } \\
\text { people. }\end{array}$ & & $\begin{array}{l}\text { Study } \\
\text { conducted }\end{array}$ & $\begin{array}{l}\text { Recom. } \\
\text { implemented }\end{array}$ & $\begin{array}{l}\text { Recom. } \\
\text { implemented }\end{array}$ & $\begin{array}{l}\text { Facility in } \\
\text { place }\end{array}$ \\
\hline $\begin{array}{l}\text { Promotion of Carib } \\
\text { Model Village }\end{array}$ & $\begin{array}{l}\text { Ensure efficient and effective } \\
\text { operation of model Carib } \\
\text { Village. }\end{array}$ & & Full operation & $\begin{array}{l}30 \% \text { tourist } \\
\text { increase }\end{array}$ & $50 \%$ increase & $100 \%$ increase \\
\hline $\begin{array}{l}\text { Developing Carib } \\
\text { traditional herbal } \\
\text { medicine. }\end{array}$ & $\begin{array}{l}\text { Research, documentation and } \\
\text { protection of Carib medicinal } \\
\text { herbs. }\end{array}$ & & $\begin{array}{l}\text { Funding } \\
\text { negotiated. }\end{array}$ & $\begin{array}{l}\text { Funding } \\
\text { negotiated }\end{array}$ & $\begin{array}{l}\text { Research } \\
\text { conducted. }\end{array}$ & $\begin{array}{l}\text { Documentatio } \\
\text { n done. }\end{array}$ \\
\hline \multicolumn{7}{|l|}{$\begin{array}{l}\text { FISHING } \\
\text { COMMUNITIES }\end{array}$} \\
\hline $\begin{array}{l}\text { Increased fishermen's } \\
\text { catch. }\end{array}$ & $\begin{array}{l}\text { Organize training programmes } \\
\text { for fishermen. } \\
\text { Introduce adaptive and } \\
\text { sustainable technology. } \\
\text { Improve the marketing and } \\
\text { distribution of fish. } \\
\text { Improve fisheries } \\
\text { infrastructure- landing sites } \\
\text { etc. }\end{array}$ & $\begin{array}{l}\text { Meetings } \\
\text { conducted }\end{array}$ & $\begin{array}{l}\text { Working group } \\
\text { in place } \\
1 \text { established }\end{array}$ & $\begin{array}{l}\text { Cabinet } \\
\text { approval rec. } \\
2 \text { established }\end{array}$ & $\begin{array}{l}\text { System in } \\
\text { place } \\
3 \text { established }\end{array}$ & $\begin{array}{l}\text { Systems } \\
\text { operating } \\
\text { effectively } \\
5 \text { operating }\end{array}$ \\
\hline
\end{tabular}




\begin{tabular}{|c|c|c|c|c|c|c|}
\hline $\begin{array}{l}\text { Integration of } \\
\text { fisheries with other } \\
\text { sectors }\end{array}$ & $\begin{array}{l}\text { Introduce co-management } \\
\text { arrangement with fisheries, } \\
\text { marine tourism and Community } \\
\text { Development } \\
\text { Launch Integrated Community } \\
\text { Fisheries Programme in } \\
\text { selected communities }\end{array}$ & $\begin{array}{l}\text { Meetings } \\
\text { conducted }\end{array}$ & $\begin{array}{l}\text { Funding } \\
\text { negotiated }\end{array}$ & $\begin{array}{l}\text { Programmes } \\
\text { implemented }\end{array}$ & $\begin{array}{l}50 \% \text { increase } \\
\text { catch }\end{array}$ & $\begin{array}{l}100 \% \text { increase } \\
\text { in catch }\end{array}$ \\
\hline \multicolumn{7}{|l|}{$\begin{array}{l}\text { ROSS UNIVERSITY } \\
\text { MEDICINE SCHOOL }\end{array}$} \\
\hline $\begin{array}{l}\text { Enhancement of } \\
\text { contribution to } \\
\text { Dominica's } \\
\text { development of Ross } \\
\text { Medical School. }\end{array}$ & $\begin{array}{l}\text { i) Establish a concordat with } \\
\text { DeVry Inc. } \\
\text { ii) Link Ross University to } \\
\text { Portsmouth Hospital and } \\
\text { medical services. } \\
\text { iii) Link Ross University with } \\
\text { tertiary education. } \\
\text { iv) Review annual fee } \\
\text { structure. }\end{array}$ & & $\begin{array}{l}\text { Working group } \\
\text { est. } \\
\text { Concordat } \\
\text { negotiated }\end{array}$ & $\begin{array}{l}\text { Proposal } \\
\text { prepared }\end{array}$ & $\begin{array}{l}\text { Proposal } \\
\text { implemented }\end{array}$ & $\begin{array}{l}\text { Greater } \\
\text { contribution } \\
\text { achieved }\end{array}$ \\
\hline \multicolumn{7}{|l|}{ HIV/AIDS } \\
\hline $\begin{array}{l}\text { Confronting the } \\
\text { AIDS/HIV epidemic }\end{array}$ & $\begin{array}{l}\text { Implement HIV/AIDS strategic } \\
\text { plan (NHSP) }\end{array}$ & $10 \%$ impl. & $30 \%$ impl. & $50 \%$ impl. & 75\% impl. & $100 \%$ impl. \\
\hline
\end{tabular}


Appendix 2

\section{Government and NGO-Administered Social Programmes}

\section{Government Administered and Supported Programmes}

- Dominica Social Security (DSS) -- the Social Insurance Programme established in 1970 as the National Provident fund and transformed into Dominica Social Security in 1976.

- The Dominica Social Investment Fund (DSIF) -- This Fund should have become operational since May 2004 but for the considerable lay in concluding arrangements previously agreed with the European Union. The DSIF targets the following vulnerable groups: groups adversely affected by macro-economic adjustment; the Carib community; children at risk; youth at risk; and older persons.

- Public Assistance -- Administered by the Ministry of Community Development, Gender Affairs and Information. This programme provides income support to the poor. Eligibility is subject to a means test, a home visit and an annual review; however, criteria for eligibility are not documented.

- Legal aid Clinic -- Established in April 28, 2003, with assistance from CIDA.

- School Feeding Programme -- Administered by the Ministry of Education, Sports and Youth Affairs. Founded in 1991 under the World Food Programme (WFP).

- Education Trust Fund -- administered by a Board of Trustees appointed by the Ministry of Education. Provides assistance to secondary school and some tertiary students for transportation, uniforms, books and external examination fees.

- Basic Needs Trust Fund -- Established in 1979, this CDB-funded programme has been making an important contribution to meeting the basic needs of the population and to community empowerment in the rural communities

- Textbook Scheme -- Programme established in 1996, to assist primary and secondary school students who are unable to purchase the required textbooks.

- School for the Hearing Impaired -- Provides special education for persons with disabilities.

- Home for the Aged -- There are three (3) homes for the aged that provide daily care for the elderly not able to receive care at home or in the local community. 
Programmes Administered by NGOs

- Dominica Association of Disabled Persons ${ }^{17 *}$ (DADP) -- Empowerment of the mentally and physically challenged. Founded in 1983 with funds received from the British and Canadian Governments for premises and equipment.

- The Social Center -- Founded in 1950. Designed to benefit the disadvantaged. Pioneered the preschool education programme and the Adolescent Skills Training Programme.

- The Dominica Council of Women (DNCW) -- Established with funds from Canada IICA, which assists with providing seed money for projects implemented by the rural poor. This organization serves as an umbrella organization of women's groups; provides skills training for selfemployment; a family hot line for access to a counselor; and assists women to access training from other organizations.

- Dominica Council for Ageing -- Established as an umbrella organization for men and women over 60.

- Reaching Elderly Abandoned Citizens Housebound*(REACH) -Commenced operations in 1978 to assist the elderly who have been abandoned by their families.

- Operation Youth Quake* (OYQ) -- Established in 1978 to provide a rehabilitative service for deprived, abused and neglected children.

- Christian Children Fund (CCF) -- Headquartered in the USA. Local operations began in 1983 to assist poor families to provide for their children.

- Alpha Centre*(AC) -- Established in 1974. Caters for children with mental disabilities.

- Small Project Assistance Team (SPAT) -- Established in 1981 to provide/develop community development activities in targeted communities where need is identified. Funding provided by external donor agencies.

- National Development Foundation of Dominica (NDFD) -- Founded in 1981 to provide venture capital for entrepreneurs who do not qualify for funding from commercial banks. Eligibility is determined based on economic viability, utilization of local raw materials, and potential for generating exports or import substitution.

- Dominica's Hucksters Association -- Established in 1982 to support smallscale intra island trade in agricultural commodities. Produce obtained from farmers, often on consignment, with payment made once the goods are sold overseas.

- Society of St. Vincent de Paul -- A Catholic Charity established in 1973. Helps provide basic needs assistance in a variety of areas.

\footnotetext{
17 * Denotes programmes receiving direct funding support as well as in kind or duty free concessions from
} the GOCD 
Appendix 3

Medium-Term Strategic Reform Agenda

\begin{tabular}{|c|c|c|c|c|}
\hline Policy Area & \multicolumn{4}{|c|}{ Implementation Period } \\
\hline & March 2006 & $\begin{array}{l}\text { Year } 1 \text { (FY } \\
\text { 06/07) }\end{array}$ & $\begin{array}{l}\text { Year } 2 \text { (FY } \\
07 / 08)\end{array}$ & $\begin{array}{l}\text { Year } 3(\mathrm{FY} \\
08 / 09)\end{array}$ \\
\hline $\begin{array}{l}\text { Investment } \\
\text { climate }\end{array}$ & $\begin{array}{l}\text { Diagnostic of } \\
\text { current } \\
\text { situation } \\
\text { based on } \\
\text { investment } \\
\text { roadmaps } \\
\text { Prioritize } \\
\text { actions }\end{array}$ & $\begin{array}{l}\text { Specific actions } \\
\text { for reform of } \\
\text { DEXIA, NDC and } \\
\text { AID-Bank } \\
\text { Define and } \\
\text { start } \\
\text { implementation } \\
\text { of regulations } \\
\text { affecting entry } \\
\text { and exit of } \\
\text { businesses }\end{array}$ & $\begin{array}{l}\text { Develop } \\
\text { investment } \\
\text { promotion } \\
\text { strategy based } \\
\text { on investment } \\
\text { roadmap }\end{array}$ & \\
\hline $\begin{array}{l}\text { Regulatory } \\
\text { framework } \\
\text { (Energy } \\
\text { sector) }\end{array}$ & $\begin{array}{l}\text { Enactment of } \\
\text { electricity } \\
\text { supply Act and } \\
\text { related } \\
\text { legislation }\end{array}$ & $\begin{array}{l}\text { Establishment } \\
\text { of regulatory } \\
\text { commission } \\
\text { Assess large } \\
\text { scale energy } \\
\text { options }\end{array}$ & $\begin{array}{l}\text { Enactment of } \\
\text { alternative } \\
\text { energy Act }\end{array}$ & $\begin{array}{l}\text { Consolidate } \\
\text { national } \\
\text { regulatory } \\
\text { framework and } \\
\text { transition to } \\
\text { regional } \\
\text { regulatory } \\
\text { regime }\end{array}$ \\
\hline $\begin{array}{l}\text { Regulatory } \\
\text { framework } \\
\text { (Agricultural } \\
\text { exports) }\end{array}$ & & & $\begin{array}{l}\text { Support the } \\
\text { establishment } \\
\text { and application } \\
\text { of standards to } \\
\text { enhance } \\
\text { agricultural } \\
\text { exports }\end{array}$ & \\
\hline
\end{tabular}




\section{Medium-Term Strategic Reform Agenda}

\begin{tabular}{|c|c|c|c|c|}
\hline Policy Area & \multicolumn{4}{|c|}{ Implementation Period } \\
\hline & March 2006 & $\begin{array}{l}\text { Year } 1 \text { (FY } \\
06 / 07)\end{array}$ & $\begin{array}{l}\text { Year } 2 \text { (FY } \\
07 / 08)\end{array}$ & $\begin{array}{l}\text { Year } 3(\mathrm{FY} \\
08 / 09)\end{array}$ \\
\hline $\begin{array}{l}\text { Public sector } \\
\text { reform }\end{array}$ & & $\begin{array}{l}\text { Customs reform } \\
\text { Land market } \\
\text { regulation }\end{array}$ & $\begin{array}{l}\text { Improve } \\
\text { functioning of } \\
\text { magistracy to } \\
\text { strengthen the } \\
\text { commercial } \\
\text { justice system } \\
\text { Public sector } \\
\text { streamlining (to } \\
\text { be elaborated) }\end{array}$ & \\
\hline $\begin{array}{l}\text { Budgetary } \\
\text { and fiscal } \\
\text { management }\end{array}$ & $\begin{array}{l}\text { Prepare an } \\
\text { Action Plan for } \\
\text { the } \\
\text { improvement of } \\
\text { the } \\
\text { procurement } \\
\text { framework }\end{array}$ & $\begin{array}{l}\text { New FAA } \\
\text { submitted to } \\
\text { Parliament } \\
\text { Continue } \\
\text { strengthening } \\
\text { Financial } \\
\text { Management }\end{array}$ & $\begin{array}{l}\text { Regional } \\
\text { Procurement } \\
\text { initiatives } \\
\text { Begin } \\
\text { implementation } \\
\text { of procurement } \\
\text { Action Plan }\end{array}$ & $\begin{array}{l}\text { Continue } \\
\text { implementation } \\
\text { of procurement } \\
\text { Action Plan }\end{array}$ \\
\hline $\begin{array}{l}\text { Labor market } \\
\text { reforms }\end{array}$ & & & $\begin{array}{l}\text { Review labor } \\
\text { market laws and } \\
\text { regulation }\end{array}$ & \\
\hline $\begin{array}{l}\text { Social } \\
\text { protection } \\
\text { reform }\end{array}$ & $\begin{array}{l}\text { Cabinet } \\
\text { approval of } \\
\text { Growth and } \\
\text { Social } \\
\text { Protection } \\
\text { Strategy }\end{array}$ & $\begin{array}{l}\text { Improve } \\
\text { targeting of } \\
\text { social } \\
\text { assistance } \\
\text { programs }\end{array}$ & & \\
\hline
\end{tabular}


Appendix 4

\section{Investor Roadmap Process Recommendations}

\section{A. Employing}

1. Update labour related legislation;

2. Improve transparency of work permit process;

3. Lengthen work permit timeframes;

4. Streamline and speed up work permit application process; and

5. Review operation of regime of professional licensing.

\section{B. $\quad$ Reporting}

1. Improve incentives policy;

2. Create a more automatic incentives allocation process;

3. Redefine NDC's role as an Investment Promotion Agency - NDC needs to focus on promoting, targeting and facilitating investment.

4. Improve information accessibility about company registration procedures;

5. Improve coordination among company registration agencies; and

6. Implement new intellectual property rights regulations as soon as possible.

\section{Locating}

1. Improve the purchase / lease process for land acquisition;

2. Develop a land information database, and in particular establish priorities for the phased implementation of a land cadastral system;

3. Prepare a national physical development plan; and

4. Improve the capacity of the Physical Planning Division to manage land use policy in Dominica.

D. $\quad$ Operating

1. Consider the creation of a single Independent Revenue Authority;

2. $\quad$ Reduce length of the tax assessment process;

3. Reduce the time it takes for goods to be cleared by Customs;

4. Develop a system of risk management to reduce the number of inspections;

5. Provide customs broker and imported training and develop disincentives for repeated errors;

6. Improve administration of the master list system;

8. Assist the process of establish domestic accounting standards based on international best practices; and

9. Evaluate framework and application of bankruptcy law. 
Appendix 5

\section{Indicative Financial Implications of Priority Poverty Reduction Actions}

\begin{tabular}{|c|c|c|}
\hline ACTION & Financial Implications & Cost estimate \\
\hline $\begin{array}{l}\text { Maintain immunisation } \\
\text { programme and distribution of } \\
\text { primary health care facilities. }\end{array}$ & Existing programmes & Not applicable \\
\hline $\begin{array}{l}\text { Investigate feasibility of health } \\
\text { charges with protection for the } \\
\text { poor }\end{array}$ & None unless done by outsider & $\begin{array}{l}\text { US\$16,000 (if done by } \\
\text { outsider) ( } 2 \text { months at } \\
\text { US\$8,000 per month) }\end{array}$ \\
\hline $\begin{array}{l}\text { Secure participation in OECS } \\
\text { Drug Procurement Programme }\end{array}$ & Would produce net savings & Not applicable \\
\hline $\begin{array}{l}\text { Maintain government pro-poor } \\
\text { education assistance } \\
\text { programmes }\end{array}$ & \multicolumn{2}{|c|}{$\begin{array}{l}\text { Existing programmes. Current annual costs of TBS, ETF, } \\
\text { and SFP are } \$ 180,000, \$ 45,000 \text {, and } \$ 50,000 \text { (for } \\
\text { administration only) respectively but these may be } \\
\text { inadequate to maintain these programmes and provide } \\
\text { negligible scope for their expansion. }\end{array}$} \\
\hline $\begin{array}{l}\text { Review distribution of primary } \\
\text { schools }\end{array}$ & $\begin{array}{l}\text { None - would be done } \\
\text { internally. Likely to result in } \\
\text { savings }\end{array}$ & None \\
\hline $\begin{array}{l}\text { Establish committee on } \\
\text { educational assistance } \\
\text { programmes }\end{array}$ & None & None \\
\hline $\begin{array}{l}\text { Prioritise maintenance of water } \\
\text { supply and road networks }\end{array}$ & From existing budgets & None \\
\hline $\begin{array}{l}\text { Establish committee on } \\
\text { assistance programmes for } \\
\text { vulnerable groups }\end{array}$ & None & None \\
\hline $\begin{array}{l}\text { HIV/ AIDS/ Teenage Pregnancy } \\
\text { Awareness Programme }\end{array}$ & $\begin{array}{l}\text { Would need preparation, } \\
\text { printing of materials and staff } \\
\text { time }\end{array}$ & Not assessed \\
\hline $\begin{array}{l}\text { Introduce curricula } \\
\text { improvements and extend TVET }\end{array}$ & $\begin{array}{l}\text { Some re-training of teaching } \\
\text { staff may be required as well as } \\
\text { equipment }\end{array}$ & Not assessed \\
\hline $\begin{array}{l}\text { Introduce courses in life skills } \\
\text { education }\end{array}$ & $\begin{array}{l}\text { None unless overseas staff re- } \\
\text { training required }\end{array}$ & $\begin{array}{l}\text { Not assessed but } \\
\text { unlikely to be } \\
\text { significant }\end{array}$ \\
\hline $\begin{array}{l}\text { Review operation of welfare } \\
\text { system }\end{array}$ & \multicolumn{2}{|c|}{$\begin{array}{l}\text { Initial review would cost little but outside expertise would } \\
\text { be required to draft new legislation and annual costs of } \\
\text { raising PA and increasing eligibility could exceed } \$ 10 \\
\text { million annually }\end{array}$} \\
\hline $\begin{array}{l}\text { Initiate research into adolescent } \\
\text { and young adult males }\end{array}$ & $\begin{array}{l}\text { Say } 50 \text { case studies / focus } \\
\text { groups @ } \$ 50 \text { each }+\$ 2,500 \text { for } \\
\text { analysis and reporting }\end{array}$ & $\begin{array}{l}\$ 5,000 \text { (over and above } \\
\text { staff -time) }\end{array}$ \\
\hline
\end{tabular}




\begin{tabular}{|l|l|l|}
\hline \multicolumn{1}{|c|}{ ACTION } & \multicolumn{1}{|c|}{ Financial Implications } & \multicolumn{1}{c|}{ Cost estimate } \\
\hline $\begin{array}{l}\text { Prepare funding proposal for a } \\
\text { facility for young offenders }\end{array}$ & $\begin{array}{l}\text { None for study and proposal but } \\
\text { eventual cost would be } \\
\text { significant }\end{array}$ & Not assessed \\
\hline $\begin{array}{l}\text { Improve operation of child } \\
\text { maintenance system }\end{array}$ & $\begin{array}{l}\text { None unless additional staff can } \\
\text { be hired. Should eventually be } \\
\text { self-financing and reduce } \\
\text { pressure on PA. }\end{array}$ & None \\
\hline Reform magistracy operations & $\begin{array}{l}\text { None unless additional staff can } \\
\text { be hired. }\end{array}$ & $\begin{array}{l}\text { None (no additional } \\
\text { staff assumed) }\end{array}$ \\
\hline $\begin{array}{l}\text { Establish task force to review } \\
\text { legal framework for families and } \\
\text { children }\end{array}$ & $\begin{array}{l}\text { None unless outside expertise } \\
\text { required for legal drafting. }\end{array}$ & $\begin{array}{l}\text { US\$24,000 (if outsider } \\
\text { hired) (3 months at } \\
\$ 8,000 \text { per month) }\end{array}$ \\
\hline Examine housing land delivery & $\begin{array}{l}\text { None for study. Eventual costs } \\
\text { would depend on preferred } \\
\text { approach and degree of } \\
\text { subsidy. }\end{array}$ & None \\
\hline
\end{tabular}

